Nevada

Environmental

Restoration

Project

\title{
Corrective Action Investigation Plan for Corrective Action Unit 309: Area 12 Muckpiles, \\ Nevada Test Site, Nevada
}

Controlled Copy No::

Revision No.: 0

December 2004

Approved for public release; further dissemination unlimited.

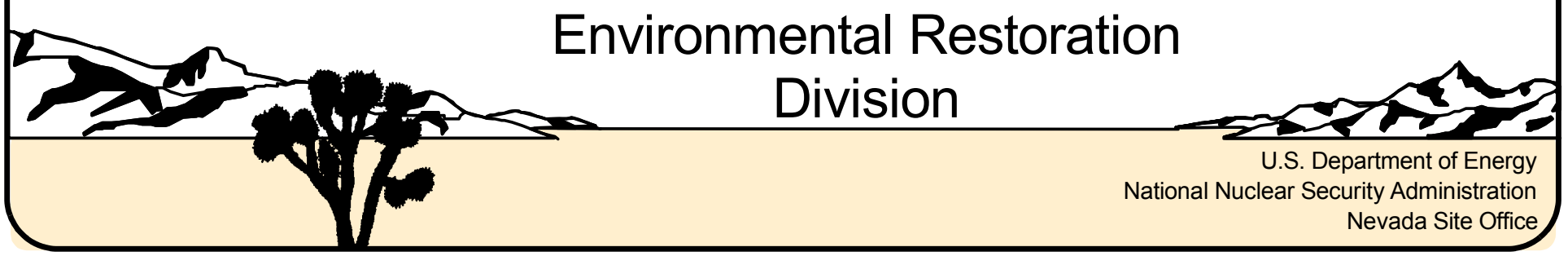


Available for sale to the public from:

U.S. Department of Commerce

National Technical Information Service

5285 Port Royal Road

Springfield, VA 22161

Phone: 800.553.6847

Fax: 703.605.6900

Email: orders@ntis.gov

Online ordering: http://www.ntis.gov/ordering.htm

Available electronically at $h t t p: / / w w w . o s t i . g o v / b r i d g e$

Available for a processing fee to U.S. Department of Energy and its contractors, in paper, from:

U.S. Department of Energy

Office of Scientific and Technical Information

P.O. Box 62

Oak Ridge, TN 37831-0062

Phone: 865.576 .8401

Fax: 865.576.5728

Email: reports@adonis.osti.gov

Reference herein to any specific commercial product, process, or service by trade name, trademark, manufacturer, or otherwise, does not necessarily constitute or imply its endorsement, recommendation, or favoring by the United States Government or any agency thereof or its contractors or subcontractors. 


\title{
CORRECTIVE ACTION INVESTIGATION PLAN FOR CORRECTIVE ACTION UNIT 309: AREA 12 MUCKPILES, NEVADA TEST SITE, NEVADA
}

\author{
U.S. Department of Energy \\ National Nuclear Security Administration \\ Nevada Site Office \\ Las Vegas, Nevada
}

Controlled Copy No.:

Revision No.: 0

December 2004

Approved for public release; further dissemination unlimited. 
CORRECTIVE ACTION INVESTIGATION PLAN

FOR CORRECTIVE ACTION UNIT 309:

AREA 12 MUCKPILES, NEVADA TEST SITE, NEVADA

Approved by: Signature Approved

Date: $12 / 21 / 04$

Janet Appenzeller-Wing, Project Manager

Industrial Sites Project

Approved by: $\frac{\text { Signature Approved }}{\begin{array}{l}\text { Robert M. Bangerter, Jr., Acting Division Director } \\ \text { Environmental Restoration Division }\end{array}}$

Date: $12 / 21 / 04$ 


\section{Table of Contents}

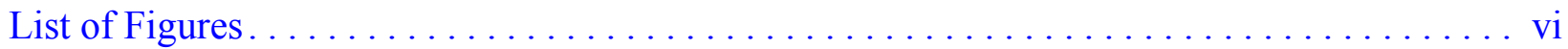

List of Tables. . . . . . . . . . . . . . . . . . . . . . . . . . . . . . .

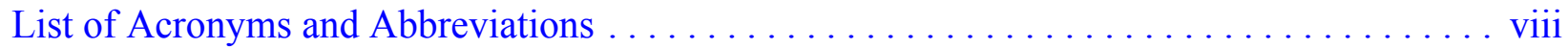

Executive Summary . . . . . . . . . . . . . . . . . . . . . . . ES-1

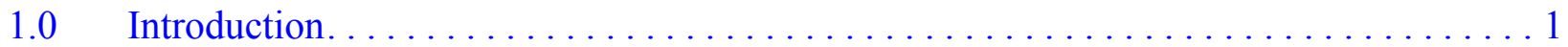

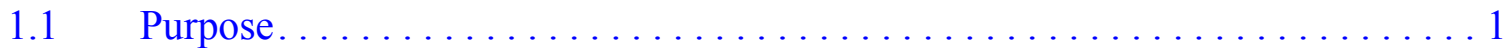

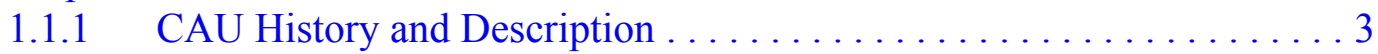

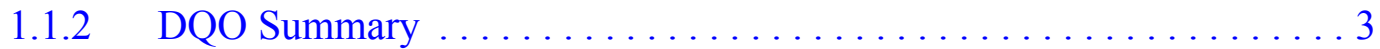

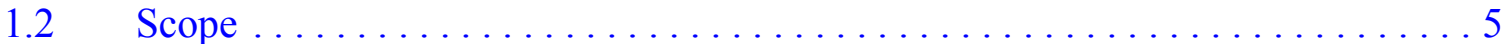

$1.3 \quad$ CAIP Contents . . . . . . . . . . . . . . . . . . . . . . 6

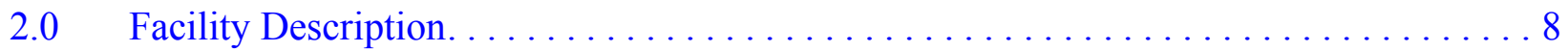

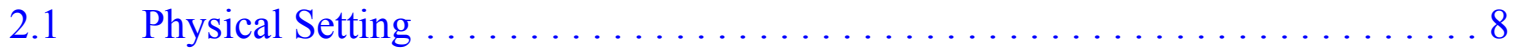

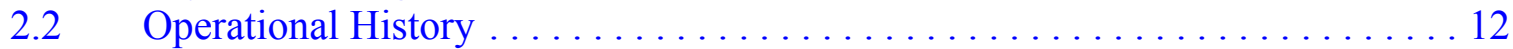

2.2.1 CAS 12-06-09, Muckpile. . . . . . . . . . . . . . . . 12

2.2.2 CAS 12-08-02, Contaminated Waste Dump ............... 13

2.2.3 CAS 12-28-01, I-, J-, and K- Tunnel Debris . . . . . . . . . . . . 13

$2.3 \quad$ Waste Inventory . . . . . . . . . . . . . . . . . . . . . . 14

2.3.1 CAS 12-28-01, I-, J-, and K-Tunnel Debris . . . . . . . . . . . 14

2.3.2 CASs 12-06-09 and 12-08-02, Muckpiles . . . . . . . . . . . . . 14

$2.4 \quad$ Release Information . . . . . . . . . . . . . . . . . . . . . . . . . 15

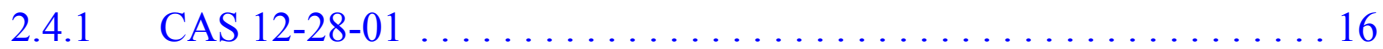

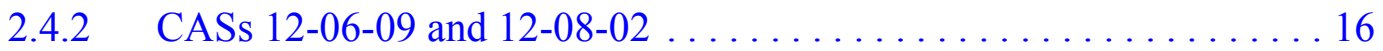

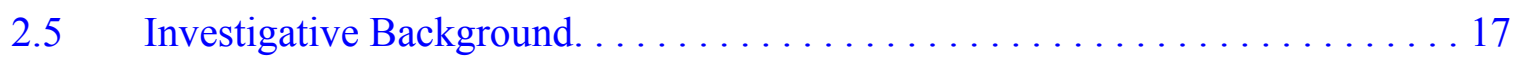

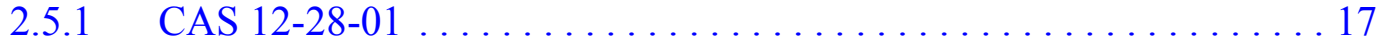

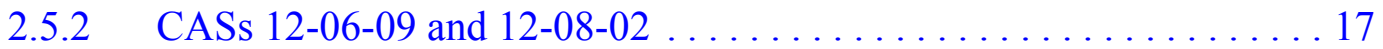

$2.6 \quad$ National Environmental Policy Act . . . . . . . . . . . . . . 18

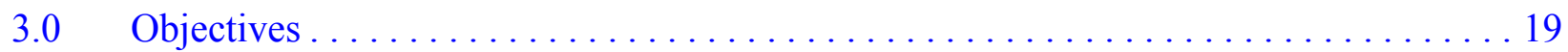

$3.1 \quad$ Conceptual Site Models . . . . . . . . . . . . . . . . . . . . . . . . . . . 19

$3.1 .1 \quad$ Future Land Use. . . . . . . . . . . . . . . . . . . . . . . . 22

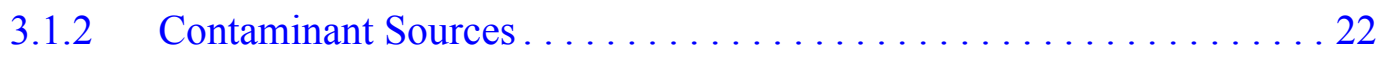

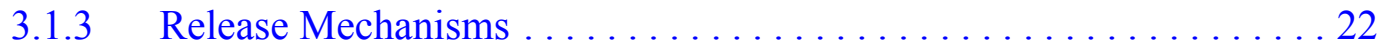

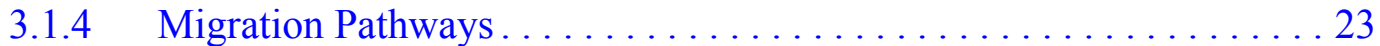

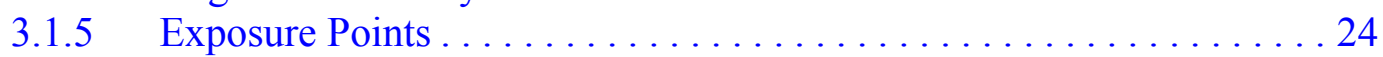

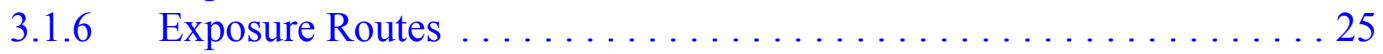

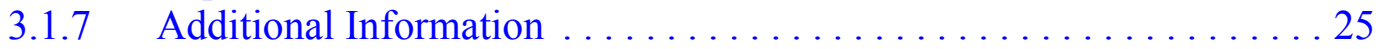

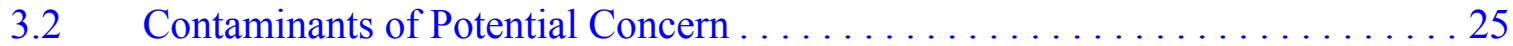

3.3 Preliminary Action Levels . . . . . . . . . . . . . . . . . . . 27

3.3.1 Chemical PALs . . . . . . . . . . . . . . . . . . . . 28 


\section{Table of Contents (Continued)}

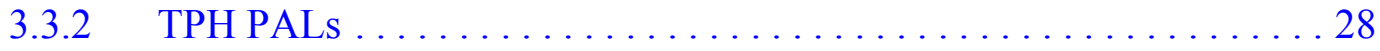

$3.3 .3 \quad$ Radiological PALs............................. 28

$3.4 \quad$ DQO Process Discussion . . . . . . . . . . . . . . . . . . . . . . . . . . . . 29

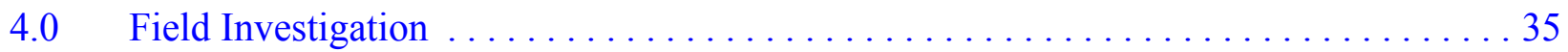

$4.1 \quad$ Technical Approach ...................................... 35

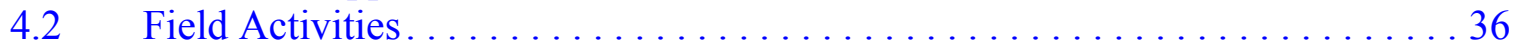

4.2.1 Site Preparation Activities . . . . . . . . . . . . . . . . 36

4.2.2 Sample Location Selection ........................ 37

$4.2 .3 \quad$ Sample Collection ............................... 37

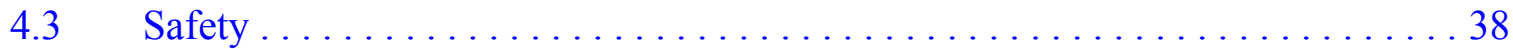

$5.0 \quad$ Waste Management. .................................... 41

$5.1 \quad$ Waste Minimization. ................................ 41

$5.2 \quad$ Potential Waste Streams. . . . . . . . . . . . . . . . . . . . . . . . . . . . . . 41

$5.3 \quad$ Investigation-Derived Waste Management . . . . . . . . . . . . . . 42

$5.3 .1 \quad$ Sanitary Waste . . . . . . . . . . . . . . . . . . . . . 42

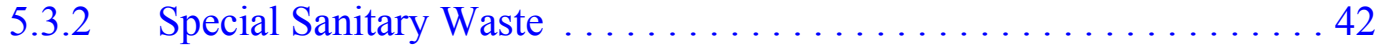

5.3 .3 Hazardous Waste . . . . . . . . . . . . . . . . . . . . . . 44

5.3.4 Management of Personal Protective Equipment ............ 44

5.3.5 Management of Decontamination Rinsate................ 45

5.3.6 Management of Muck and Soil ....................... 46

5.3 .7 Management of Debris. . . . . . . . . . . . . . . . . . . . . . 46

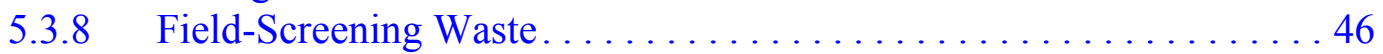

5.3 .9 Polychlorinated Biphenyls. . . . . . . . . . . . . . . . . . . 47

5.3 .10 Low-Level Waste. . . . . . . . . . . . . . . . . . . . . . . 47

5.3 .11 Mixed Waste .............................. 48

6.0 Quality Assurance/Quality Control $\ldots \ldots \ldots \ldots \ldots \ldots \ldots \ldots \ldots \ldots \ldots$

$6.1 \quad$ Quality Control Field Sampling Activities ..................... 49

6.2 Laboratory/Analytical Quality Assurance $\ldots \ldots \ldots \ldots \ldots \ldots \ldots \ldots \ldots$

$6.2 .1 \quad$ Data Validation ............................. 50

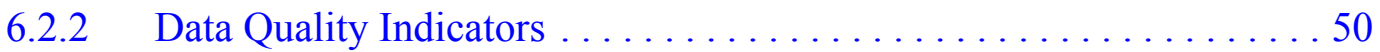

$6.2 .3 \quad$ Precision. . . . . . . . . . . . . . . . . . . . . . . . 51

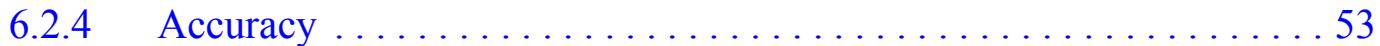

$6.2 .5 \quad$ Representativeness.......................... 54

6.2 .6 Completeness............................. 54

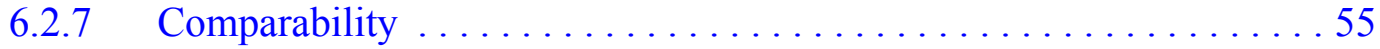

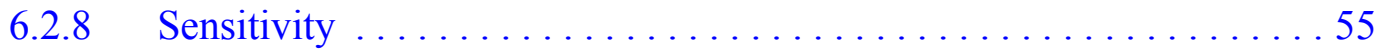

$7.0 \quad$ Duration and Records Availability . . . . . . . . . . . . . . . . . . . . . 56 


\section{Table of Contents (Continued)}

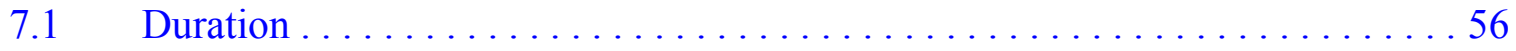

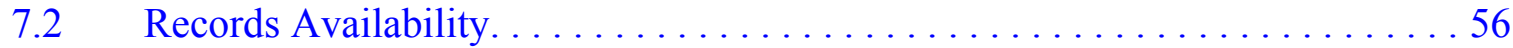

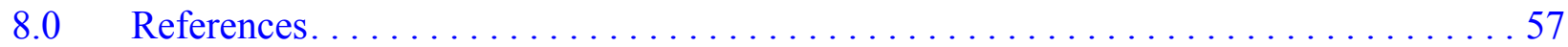

\section{Appendix A - Data Quality Objectives Process for CAU 309}

A.1.0 Introduction. . . . . . . . . . . .

A.2.0 Background Information. . . . . . . . . . . . . . . . . A-2

A.2.1 CAS 12-06-09, Muckpile and CAS 12-08-02,

Contaminated Waste Dump . . . . . . . . . . . . . . . . . . . A-2

A.2.2 CAS 12-28-01, I-, J-, and K- Tunnel Debris . . . . . . . . . . . . A-11

A.3.0 Step $1-$ State the Problem. . . . . . . . . . . . . . . . . . . . .

A.3.1 Planning Team Members . . . . . . . . . . . . . . . . . . . A

A.3.2 Conceptual Site Model. . . . . . . . . . . . . . . . . . . . . . A-16

A.3.2.1 Contaminant Release ..................... A-21

A.3.2.2 Potential Contaminants . . . . . . . . . . . . . . . A-22

A.3.2.3 Contaminant Characteristics . . . . . . . . . . . . . A-24

A.3.2.4 Site Characteristics . . . . . . . . . . . . . . . A 25

A.3.2.5 Migration Pathways and Transport Mechanisms............ A-25

A.3.2.6 Exposure Scenarios . . . . . . . . . . . . . . . . . A-27

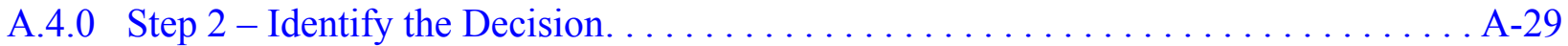

A.4.1 Decision Statements . . . . . . . . . . . . . . . . . . . . . . . . A A-29

A.4.1.1 Decision Statements for CAS 12-28-01, I-, J-, and K-Tunnel Debris . . . . . . . . . . . . . . . . . . . . . A-29

A.4.1.2 Decision Statements for CASs 12-06-09,

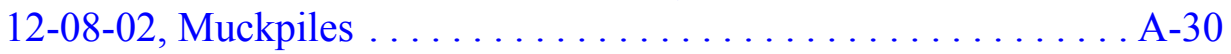

A.4.2 Alternative Actions to the Decision.................. A-34

A.4.2.1 Alternative Actions to Decision I for CAS 12-28-01 (Fallout Plume) . . . . . . . . . . . . . . . A-34

A.4.2.2 Alternative Actions to Decision I for CASs 12-06-09 and 12-08-02 (Muckpiles) . . . . . . . . . . . . . A-34

A.4.2.3 Alternative Actions to Decision II for CAU 309 CASs. . . . . . . . . . A-35

A.5.0 Step 3 - Identify the Inputs to the Decisions $\ldots \ldots \ldots \ldots \ldots \ldots \ldots \ldots \ldots$. . . . . . . . .

A.5.1 Information Needs for Decision I . . . . . . . . . . . . . A-36

A.5.2 Information Needs for Decision II . . . . . . . . . . . . . A-36

A.5.3 Sources of Information. . . . . . . . . . . . . . . . . A-37 


\section{Table of Contents (Continued)}

A.5.3.1 Sample Locations.......................... A-38

A.5.3.2 Analytical Methods ......................... A-39

A.6.0 Step 4 - Define the Boundaries of the Study $\ldots \ldots \ldots \ldots \ldots \ldots \ldots \ldots$ A-41

A.6.1 Populations of Interest . . . . . . . . . . . . . . . . . . . . . A 41

A.6.2 Spatial Boundaries ................................. A-42

A.6.3 Practical Constraints. ............................ A-43

A.6.4 Define the Scale of Decision Making ........................ A-44

A.7.0 Step 5 - Develop a Decision Rule . . . . . . . . . . . . . . . . . . . . . . A-45

A.7.1 Population Parameter ............................... A-45

A.7.2 Decision Rule................................ A-45

A.7.3 Preliminary Action Levels $\ldots \ldots \ldots \ldots \ldots \ldots \ldots \ldots \ldots \ldots \ldots \ldots$ A-46

A.7.3.1 Chemical PALs ............................. A-46

A.7.3.2 Total Petroleum Hydrocarbon PALs . . . . . . . . . . . . A A-47

A.7.3.3 Radionuclide PALs . . . . . . . . . . . . . . . . . . . . A-47

A.7.4 Measurement and Analysis Sensitivity ................... A-47

A.8.0 Step 6 - Tolerable Limits on Decision Errors $\ldots \ldots \ldots \ldots \ldots \ldots \ldots \ldots \ldots \ldots$. A-48

A.8.1 False Negative Decision Error . . . . . . . . . . . . . . . . . . A-49

A.8.2 False Positive Decision Error. . . . . . . . . . . . . . . . . A 51

A.9.0 Step 7 - Optimize the Design for Obtaining Data $\ldots \ldots \ldots \ldots \ldots \ldots \ldots \ldots$ A-53

A.9.1 CAS 12-28-01, I-, J-, and K-Tunnel Debris. . . . . . . . . . . . . A-55

A.9.2 CAS 12-06-09, Muckpile, and CAS 12-08-02, CWD . ............ A-57

A.10.0 References. . . . . . . . . . . . . . . . . . . . . . . . . . . . . . . . A 60

Appendix B - Documentation to Support the Assumption that the CAU 309 Muckpiles are Similar to Previously Investigated NTS Muckpiles

B.1.0 Documentation to Support the Assumption that the CAU 309

Muckpiles are Similar to Previously Investigated NTS Muckpiles $\ldots \ldots \ldots \ldots$. B-1

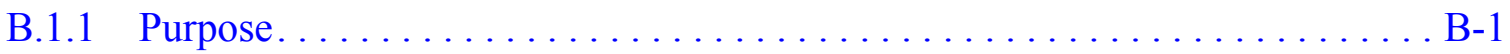

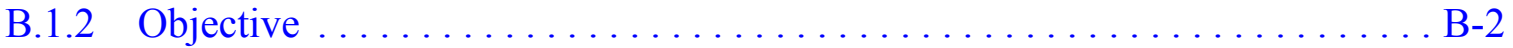

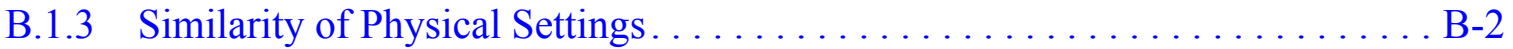

B.1.3.1 Geology ...............................

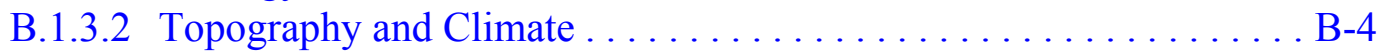

B.1.3.3 Summary of Physical Setting Considerations ............. B-4

B.1.4 Similarity of Waste-Generating Operations. . . . . . . . . . . . . . B-5

B.1.4.1 Nuclear Testing Time Lines $\ldots \ldots \ldots \ldots \ldots \ldots \ldots \ldots \ldots \ldots \ldots$ 


\section{Table of Contents (Continued)}

B.1.4.2 Standard Early Tunnel Operations. . . . . . . . . . . . . . . . . . B-6

B.1.4.3 Significant Changes in Tunnel Operations and Policies . . . . . . . . . B-6

B.1.4.4 Summary of Waste-Generating Operations Considerations . . . . . . B-10

B.1.5 Data From Comparable Muckpiles . . . . . . . . . . . . . . . B-11

B.1.6 Conclusion . . . . . . . . . . . . . . . . . . . . . . . . . B-19

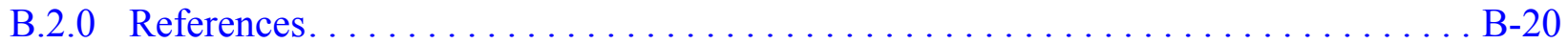

\section{Appendix C - Project Organization}

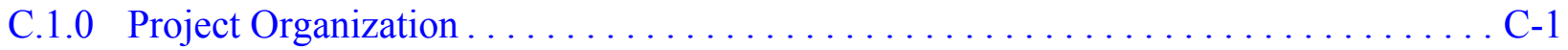

\section{Appendix D - NDEP Responses}




\section{List of Figures}

Number

Title

Page

1-1 Nevada Test Site Map with CAU 309, Area 12 Muckpiles CAS Locations . . . . . . 2

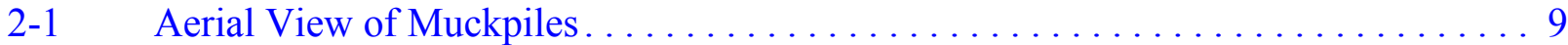

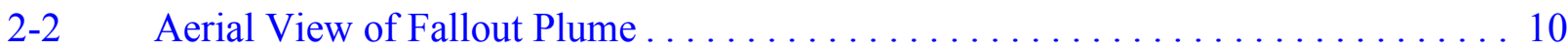

3-1 CAU 309 Conceptual Site Model (Profile Model) . . . . . . . . . . . . . . 20

3-2 CAU 309 Conceptual Site Model (Drainage Model) . . . . . . . . . . . . . . 21

A.2-1 CAU 309, CAS Location Map . . . . . . . . . . . . . . . . . . A-3

A.2-2 Site Sketch of CAS 12-06-09, Muckpile. ..................... A-5

A.2-3 Site Sketch of CAS 12-08-02, CWD . . . . . . . . . . . . . . . . A-6

A.2-4 CAU 309 Surface Radiological Survey $\ldots \ldots \ldots \ldots \ldots \ldots \ldots \ldots \ldots \ldots$

A.2-5 Approximate Footprint of CAS 12-28-01, I-, J-, K-Tunnel Debris . . . . . . . . A-12

A.3-1 CAU 309 Conceptual Site Model (Profile Model) . . . . . . . . . . . . . . A-18

A.3-2 CAU 309 Conceptual Site Model (Drainage Model) . . . . . . . . . . . . . . . A-19

A.4-1 CAU 309 Decision Flow Diagram ....................... A-31

A.9-1 Estimated Sampling Areas for Fallout Plume . . . . . . . . . . . . A-56

A.9-2 Estimated Sampling Areas for Muckpiles. . . . . . . . . . . . . A-58

B.1-1 Time Lines for Testing in Tunnels I, J, K, N, P, T, 15a and e, and 16a ........ B-7 


\section{List of Tables}

Number

3-1 Analytes Reported from VOC Analysis........................ 26

3-2 Analytes Reported from SVOC Analysis..................... 26

3-3 Analytes Reported from Radionuclides, PCB, and Metals Analyses . . . . . . . 27

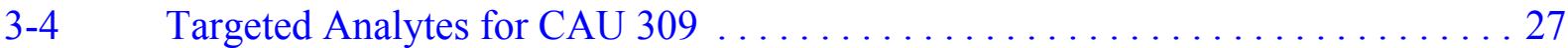

3-5 Analytical Requirements for Radionuclides for CAU $309 \ldots \ldots \ldots \ldots$

3-6 Analytical Requirements for Chemical COPCs for CAU 309 . . . . . . . . . . . . 33

4-1 Analytical Program ........................................ 39

5-1 Waste Management Regulations and Requirements ............... 43

6-1 Laboratory and Analytical Performance Criteria for CAU 309

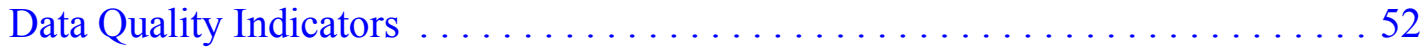

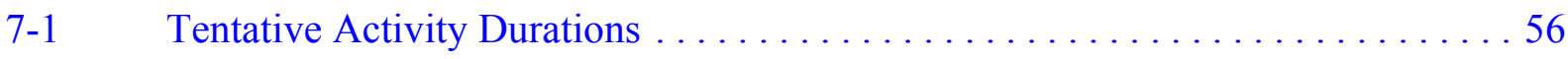

A.3-1 Final DQO Meeting Participants for CAU 309

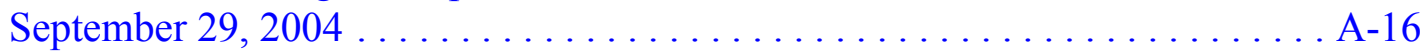

A.3-2 Conceptual Site Model Description of Elements for

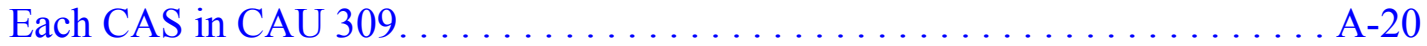

A.3-3 Analytes Reported from VOC Analysis..................... A-23

A.3-4 Analytes Reported from SVOC Analysis. . . . . . . . . . . . . . A-23

A.3-5 Analytes Reported from Radionuclides, PCB, and Metals Analyses . . . . . . . A-24

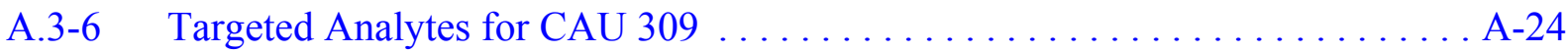

A.3-7 Future Land-Use Scenarios for CAU $309 \ldots \ldots \ldots \ldots \ldots \ldots \ldots \ldots$ A-28

A.4-1 Expected COCs for CAU 309 Muckpile Investigation .............. A-33

A.6-1 Spatial Boundaries of CAU 309 CASs $\ldots \ldots \ldots \ldots \ldots \ldots \ldots \ldots . . \ldots$ A 43

B.1-1 Analytical Detects above MRLs in Muck Samples Collected

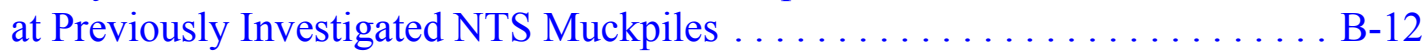

B.1-2 Analytical Detects above MRLs in Native Soil Samples Collected at Previously Investigated NTS Muckpiles . . 


\section{List of Acronyms and Abbreviations}

ACM Asbestos-containing material

Am Americium

amsl Above mean sea level

AST Above ground storage tank

ASTM American Society for Testing and Materials

bgs Below ground surface

BN Bechtel Nevada

CADD Corrective Action Decision Document

CAI Corrective Action Investigation

CAIP Corrective Action Investigation Plan

CAS Corrective Action Site

CAU Corrective Action Unit

CFR Code of Federal Regulations

CLP Contract Laboratory Program

$\mathrm{cm} \quad$ Centimeter

Co Cobalt

COC Contaminant of concern

COPC Contaminant of potential concern

cpm Counts per minute

cps Counts per second

Cs Cesium

CSM Conceptual site model

CWD Contaminated Waste Dump

DoD U.S. Department of Defense 


\section{List of Acronyms and Abbreviations (Continued)}

\begin{tabular}{|c|c|}
\hline DOE & U.S. Department of Energy \\
\hline DOT & U.S. Department of Transportation \\
\hline DQI & Data quality indicator \\
\hline DQO & Data quality objective \\
\hline DRO & Diesel-range organics \\
\hline DTRA & Defense Threat Reduction Agency \\
\hline EPA & U.S. Environmental Protection Agency \\
\hline EQL & Estimated quantitation limit \\
\hline $\exp -\mathrm{COC}$ & Expected contaminant of concern \\
\hline FAL & Final action level \\
\hline FFACO & Federal Facility Agreement and Consent Order \\
\hline FSL & Field-screening level \\
\hline FSR & Field-screening result \\
\hline $\mathrm{ft}$ & Foot \\
\hline $\mathrm{ft}^{2}$ & Square feet \\
\hline $\mathrm{ft} / \mathrm{yr}$ & Feet per year \\
\hline FWP & Field work plan \\
\hline gal & Gallon \\
\hline GPS & Global Positioning System \\
\hline GRO & Gasoline-range organics \\
\hline HASP & Health and Safety Plan \\
\hline HWAA & Hazardous Waste Accumulation Areas \\
\hline IDW & Investigation-derived waste \\
\hline in. & Inch \\
\hline
\end{tabular}




\title{
List of Acronyms and Abbreviations (Continued)
}

\author{
IRIS Integrated Risk Information System \\ IS HASP Industrial Sites Health and Safety Plan \\ ISMS Integrated Safety Management System \\ K-40 Potassium-40 \\ LCS Laboratory control sample \\ m Meter \\ $\mathrm{m}^{2} \quad$ Square meters \\ M\&O Management and Operating \\ MDC Minimum detection concentration \\ $\mathrm{mg} / \mathrm{kg} \quad$ Milligram per kilogram \\ $\mathrm{mg} / \mathrm{L} \quad$ Milligrams per liter \\ mi Mile \\ mrem/yr Millirem per year \\ MRL Minimum reporting limit \\ MS Matrix spike \\ MSD Matrix spike duplicate \\ NAC Nevada Administrative Code \\ $\mathrm{nCi} / \mathrm{m}^{2} \quad$ Nanocuries per square meter \\ NCRP National Council on Radiation Protection and Measurements \\ ND Normalized difference \\ NDEP Nevada Division of Environmental Protection \\ NEPA National Environmental Policy Act \\ NFA No Further Action \\ NNSA/NSO U.S. Department of Energy, National Nuclear Security Administration \\ Nevada Site Office
}




\section{List of Acronyms and Abbreviations (Continued)}

\begin{tabular}{|c|c|}
\hline NRS & Nevada Revised Statutes \\
\hline NTS & Nevada Test Site \\
\hline NTSWAC & Nevada Test Site Waste Acceptance Criteria \\
\hline PA & Preliminary assessment \\
\hline PAL & Preliminary action level \\
\hline PCB & Polychlorinated biphenyl \\
\hline $\mathrm{pCi} / \mathrm{g}$ & Picocurries per gram \\
\hline $\mathrm{pCi} / \mathrm{L}$ & Picocurries per liter \\
\hline PID & Photoionization detector \\
\hline POC & Performance Objective for the Certification of Nonradioactive Hazardous Waste \\
\hline PPE & Personal protective equipment \\
\hline ppm & Part(s) per million \\
\hline PRG & Preliminary remediation goal \\
\hline $\mathrm{Pu}$ & Plutonium \\
\hline QA & Quality assurance \\
\hline QAPP & Quality Assurance Project Plan \\
\hline QC & Quality control \\
\hline $\mathrm{R} / \mathrm{hr}$ & Roentgen per hour \\
\hline RadCon & Radiological Control \\
\hline RCRA & Resource Conservation and Recovery Act \\
\hline RMA & Radioactive materials area \\
\hline ROTC & Record of Technical Change \\
\hline RPD & Relative percent difference \\
\hline RWMS & Radioactive Waste Management Site \\
\hline
\end{tabular}




\section{List of Acronyms and Abbreviations (Continued)}

SAA Satellite accumulation area

SDWS $\quad$ Safe Drinking Water Standards

SNJV Stoller-Navarro Joint Venture

$\mathrm{Sr} \quad$ Strontium

SVOC Semivolatile organic compound

TPH Total petroleum hydrocarbon

TSCA Toxic Substance Control Act

VOC Volatile organic compound

$\mu \mathrm{m} \quad$ Micrometers

$\% \mathrm{R} \quad$ Percent recovery 


\section{Executive Summary}

This Corrective Action Investigation Plan (CAIP) for Corrective Action Unit (CAU) 309, Area 12 Muckpiles, Nevada Test Site (NTS), Nevada, has been developed in accordance with the Federal Facility Agreement and Consent Order (FFACO) that was agreed to by the State of Nevada, the U.S. Department of Energy, and the U.S. Department of Defense. The general purpose of the investigation is to ensure that adequate data are collected to provide sufficient and reliable information to identify, evaluate, and select technically viable corrective actions.

Corrective Action Unit 309 is comprised of the following three corrective action sites (CASs) in Area 12 of the NTS:

- CAS 12-06-09, Muckpile

- CAS 12-08-02, Contaminated Waste Dump (CWD)

- CAS 12-28-01, I-, J-, and K-Tunnel Debris

Corrective Action Site 12-06-09 consists of a muckpile and debris located on the hillside in front of the I-, J-, and K-Tunnels on the eastern slopes of Rainier Mesa in Area 12. The muckpile includes mining debris (muck) and debris generated during the excavation and construction of the I-, J-, and K-Tunnels. Corrective Action Site 12-08-02, CWD, consists of a muckpile and debris and is located on the hillside in front of the re-entry tunnel for K-Tunnel.

For the purpose of this investigation CAS 12-28-01 is defined as debris ejected by containment failures during the Des Moines and Platte Tests and the associated contamination that is not covered in the two muckpile CASs. This site consists of debris scattered south of the I-, J-, and K-Tunnel muckpiles and extends down the hillside, across the valley, and onto the adjacent hillside to the south. In addition, the site will cover the potential contamination associated with "ventings" along the fault, fractures, and various boreholes on the mesa top and face.

One conceptual site model was developed for all three CASs to address possible contamination migration pathways associated with CAU 309. The data quality objective (DQO) process was used to identify and define the type, quantity, and quality of data needed to complete the investigation phase of the corrective action process. The DQO process addresses the primary problem that sufficient information is not available to determine the appropriate corrective action for the CAU. Due to the 
practical constraints posed by steep slopes on and around the CAU 309 muckpiles, a conservative, simplifying strategy was developed to resolve the presence and nature of contaminants. This strategy includes the use of historical data from similar sites (i.e., previously investigated NTS muckpiles) and the collection of samples from accessible areas of the muckpiles.

Based on site history, process knowledge, and previous investigations of similar sites, contaminants of potential concern for CAU 309 collectively include radionuclides, total petroleum hydrocarbons (diesel range only), polychlorinated biphenyls, Resource Conservation and Recovery Act metals, volatile organic compounds, and semivolatile organic compounds.

The general technical approach for investigation of CAU 309 includes the following activities:

- Perform radiological land area surveys at CAU 309 to document the radiological condition of land within the site boundary.

- Collect and submit environmental samples for laboratory analysis from accessible, biased locations to aid in determining the nature and extent of potential contamination.

- Collect required quality control samples.

- Collect additional samples, as necessary, to estimate volumes and determine disposal options for potential corrective action waste streams.

- Record sample location coordinates using Global Positioning System technology.

This CAIP provides investigative details for CAU 309, whereas programmatic aspects of this project are discussed in the Project Management Plan (DOE/NV, 1994). General field and laboratory quality assurance and quality control issues are presented in the Industrial Sites Quality Assurance Project Plan (NNSA/NV, 2002). Health and safety aspects of the project are documented in the current version of the Environmental Engineering Services Contractor's Health and Safety Plan, and will be supplemented with a site-specific health and safety plan.

Under the FFACO, the CAIP will be submitted to the Nevada Division of Environmental Protection for approval. Field work will be conducted following approval of the plan. The results of the field investigation will support a defensible evaluation of corrective action alternatives that will be presented in the investigation report. 


\subsection{Introduction}

This Corrective Action Investigation Plan (CAIP) contains project-specific information including facility descriptions, environmental sample collection objectives, and criteria for conducting site investigation activities at Corrective Action Unit (CAU) 309, Area 12 Muckpiles, Nevada Test Site (NTS), Nevada.

This CAIP has been developed in accordance with the Federal Facility Agreement and Consent Order (FFACO) (1996) that was agreed to by the State of Nevada, the U.S. Department of Energy (DOE), and the U.S. Department of Defense (DoD).

Corrective Action Unit 309 is located in Area 12 of the NTS, which is approximately 65 miles (mi) northwest of Las Vegas, Nevada (Figure 1-1). Area 12 is approximately $40 \mathrm{mi}$ beyond the main gate to the NTS. Corrective Action Unit 309 is comprised of the three Corrective Action Sites (CASs) shown on Figure 1-1 and listed below:

- CAS 12-06-09, Muckpile

- CAS 12-08-02, Contaminated Waste Dump (CWD)

- CAS 12-28-01, I, J, and K-Tunnel Debris

Corrective Action Sites 12-06-09 and 12-08-02 will be collectively referred to as muckpiles in this document. Corrective Action Site 12-28-01 will be referred to as the fallout plume because of the extensive lateral area of debris and fallout contamination resulting from the containment failures of the J-and K-Tunnels.

The corrective action investigation (CAI) will include field inspections, radiological surveys, and media sampling, where appropriate. Data will also be obtained to support waste management decisions.

\subsection{Purpose}

The CASs in CAU 309 are being investigated because hazardous and/or radioactive constituents may be present in concentrations that could potentially pose a threat to human health and/or the environment. Existing information on the nature and extent of potential contamination at these sites 


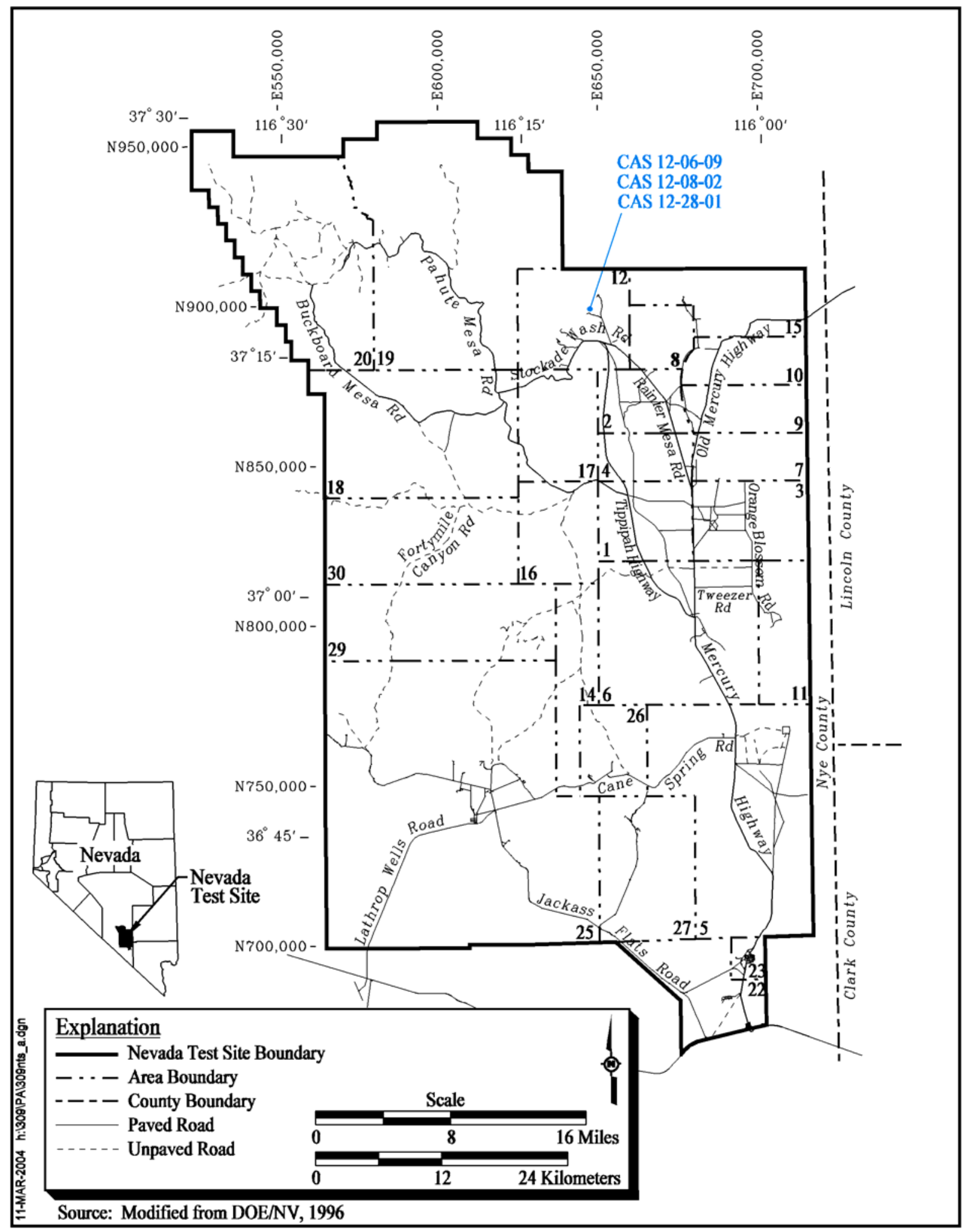

Figure 1-1

Nevada Test Site Map with CAU 309, Area 12 Muckpiles CAS Locations 
are insufficient to evaluate and recommend corrective action alternatives for the CASs. Therefore, additional information will be obtained by conducting a CAI prior to evaluating corrective action alternatives and selecting the appropriate corrective action for each CAS.

\subsubsection{CAU History and Description}

Corrective Action Unit 309, Area 12 Muckpiles, lies on the eastern slopes of Rainier Mesa at approximately 5,600 feet (ft) above mean sea level (amsl). The terrain is very steep, and consists of rock outcroppings and thin patches of soil and alluvium.

Corrective Action Site 12-06-09 consists of a muckpile and debris located on the hillside in front of the I-, J-, and K-Tunnels on the eastern slopes of Rainier Mesa in Area 12. The muckpile includes mining debris (i.e., muck) and debris generated during the excavation and construction of the I-, J-, and K-Tunnels. Corrective Action Site 12-08-02 (CWD) consists of a muckpile and debris and is located on the hillside in front of the re-entry tunnel for K-Tunnel.

For the purpose of this investigation CAS 12-28-01 is defined as debris ejected by containment failures during the Des Moines and Platte Tests and the associated contamination not covered in the two muckpile CASs. This site consists of debris scattered south of the I-, J-, and K-Tunnel muckpiles and extends down the hillside, across the valley and onto the adjacent hillside to the south. In addition, the site will cover the potential contamination associated with "ventings" along the fault, fractures, and various boreholes on the mesa top and face. Operational histories for each CAU 309 CAS are detailed in Section 2.2.

\subsubsection{DQO Summary}

The sites will be investigated based on data quality objectives (DQOs) developed by representatives of the Nevada Division of Environmental Protection (NDEP); DOE, National Nuclear Security Administration Nevada Site Office (NNSA/NSO); Stoller-Navarro Joint Venture (SNJV); and Bechtel Nevada (BN). The DQOs are used to identify and define the type, amount, and quality of data needed to develop and evaluate appropriate corrective actions for CAU 309. This CAIP describes the investigative approach developed to collect the data needs identified in the DQO 
process. While a detailed discussion of the DQO methodology and the DQOs specific to each CAS are presented in Appendix A of this document, a summary of the DQO process is provided below.

The DQO problem statement for CAU 309 is: "Existing information on the nature and extent of potential contamination is insufficient to evaluate and recommend corrective action alternatives for the CASs in CAU 309." To address this problem statement, the resolution of two decision statements is required:

- Decision I: "Is any contaminant of potential concern (COPC) present in environmental media within the CAS at a concentration exceeding its corresponding action level?" Any contaminant associated with a CAS activity that is present at concentrations exceeding its corresponding action level will be defined as a contaminant of concern (COC). If a COC is detected, then Decision II must be resolved. Otherwise, the investigation for that CAS is complete.

- Decision II: "If a COC is present, is sufficient information available to evaluate potential corrective action alternatives?" Sufficient information is defined to include:

- Identification of the lateral and vertical extent of COC contamination in media.

- Collection of the information needed to characterize investigation-derived waste (IDW) for disposal and for potential remediation waste.

The informational inputs and data needs to resolve the problem statement and the decision statements were generated as part of the DQO process for this CAU and are documented in Appendix A. The information necessary to resolve the DQO decisions will be generated for each CAU 309 CAS by collecting and analyzing samples generated during a field investigation. The presence and nature of contamination at each CAS will be determined by sampling locations that are identified as being the most probable to contain COCs if they are present anywhere within the CAS. If while defining the nature of contamination it is determined that COCs are present at a CAS, that CAS will be further addressed by determining the extent of contamination before evaluating corrective action alternatives.

Because the investigation of the fallout plume (CAS 12-28-01) follows a more typical CAI, Decisions I and II are precise as presented and no further development is needed. The information necessary to resolve the decision statements for CAS 12-28-01 will be generated by collecting and analyzing samples gathered during a field investigation. The presence and nature of contamination at CAS 12-28-01 will be determined by sampling locations that are identified as the most probable to 
contain COCs. If while defining the nature of contamination it is determined that COCs are present at CAS 12-28-01, that CAS will be further addressed by determining the extent of contamination before evaluating corrective action alternatives.

For CASs 12-06-09 and 12-08-02, muckpiles, it is impractical to resolve the decision statements based solely on collecting and analyzing samples gathered at CAU 309. Slopes on and around the muckpiles present a climbing hazard to samplers and surveyors, and limit accessibility to mechanical sampling equipment. Therefore, necessary information will be obtained from two sources: (1) data generated from previous NTS muckpile investigations, and (2) samples collected from accessible areas on the muckpiles. This approach is based on the assumption that the conceptual site model (CSM) for the CAU 309 muckpiles is sufficiently similar to those of previously investigated NTS muckpiles, and the explicit assumption that the operational histories and environmental settings are similar enough that COPCs and their fates can be expected to be similar. Validated data generated from previous NTS muckpile investigations at CAUs 475, 476, 477, 482, and 504 has been used to generate a list of expected COCs for CAU 309. Expected COCs are defined as contaminants identified in muck sample(s) from any one of the five previously investigated NTS muckpile CAUs. The data used to generate the list of expected COCs is published in the Corrective Action Decision Documents (CADDs) for CAUs 475, 476, 477, 482, and 504 (DTRA, 2000, 2001, 2002, and 2003). Data was obtained from the SNJV Analytical Services Database. Uncertainty about the presence and nature of other contamination at the CAU 309 muckpiles will be reduced through the collection and laboratory analysis of samples from locations on CAU 309 muckpiles that are determined to be the most probable to contain COCs and that are safely accessible.

\subsection{Scope}

To generate information needed to resolve the decision statements identified in the DQO processes, the scope of the CAI for CAU 309 includes the following activities:

- Review historical data from similar NTS muckpile sites.

- Determine survey and sample locations that can be safely accessed.

- Perform field screening to aid in selection of soil sample locations. 
- Perform radiological land area surveys at CAU 309 to document the radiological condition of land within the site boundary.

- Collect and submit environmental samples for laboratory analysis from accessible, biased locations to determine the nature of potential contamination.

- Collect and submit a sample of source material (if present) from the corrugated metal tank at CAS 12-06-09 and the outhouse at CAS 12-08-02.

- Collect and submit environmental samples for laboratory analysis to determine the nature and extent of potential contamination.

- Remove and properly dispose of any accessible lead bricks on the surface of the muckpiles and collect verification samples beneath.

- Collect required quality control samples.

- Collect additional samples, as necessary, to estimate volumes and determine disposal options for potential corrective action waste streams.

- Record sample locations using Global Positioning System (GPS) technology.

Soil contamination originating from activities not identified in the conceptual site model of any CAS or identified as originating from outside of CAU 309 (e.g., venting or breaches from other tunnels) will not be considered as part of this CAU unless the CSM and DQOs are modified to include the associated release. As such, contamination that can be identified as originating from these sources will not be considered for sample location selection, and/or will not be considered COCs for Decision II. If such contamination is present, the contamination will be identified as part of a new or other existing CAS, as necessary.

\subsection{CAIP Contents}

Section 1.0 presents the purpose and scope of this CAIP, while Section 2.0 provides background information about CAU 309. Objectives of the investigation, including conceptual site models, are presented in Section 3.0. Field investigation and sampling activities are discussed in Section 4.0, and waste management issues for this project are discussed in Section 5.0. General field and laboratory quality assurance (QA) and quality control (QC) requirements (including collection of QC samples) are presented in Section 6.0 and in the Industrial Sites Quality Assurance Project Plan (QAPP) 
(NNSA/NV, 2002). The project schedule and records availability are discussed in Section 7.0, and Section 8.0 provides a list of references.

Appendix A provides a detailed discussion of the DQO methodology and the DQOs specific to each CAS, while Appendix B contains information supporting the assumptions derived and presented in Appendix A. Appendix C contains information on the project organization. Appendix D contains NDEP responses.

The health and safety aspects of this project are documented in the Industrial Sites Health and Safety Plan (IS HASP) and will be supplemented with a site-specific field work plan (FWP) developed prior to the start of field work.

Public involvement activities are documented in the "Public Involvement Plan" contained in Appendix V of the FFACO (1996). The managerial aspects of this project are discussed in the Project Execution Plan (NNSA/NSO, 2004) and will be supplemented with a site-specific field management plan that will be developed prior to field activities. 


\subsection{Facility Description}

Corrective Action Unit 309 is comprised of three CASs, which were grouped together based on the geographical location of the sites, technical similarities (muckpiles), and the agency responsible for closure. The two muckpiles were derived from similar geological material, lie within $600 \mathrm{ft}$. of each other, were created from and managed through similar tunnel activities (e.g., drilling activities, weapons-related tests) during the same time period (1962 through 1963), and have been subjected to the same environmental conditions. The muckpiles are located in Area 12 of the NTS and include CASs 12-06-09 and 12-08-02. The third CAS, 12-28-01 (fallout plume), resulted from the containment failures of the J-and K-Tunnels, lies in the area of the other two CASs, affects the same geological material, and has also been subjected to the same environmental conditions.

\subsection{Physical Setting}

The CAU 309 CASs are located on the eastern slope of Rainier Mesa within Area 12 of the NTS. General background information pertaining to topography, geology, hydrogeology, and climatology are provided for these specific areas or the NTS region in the Geologic Map of the Nevada Test Site, Southern Nevada (USGS, 1990); CERCLA Preliminary Assessment for DOE's Nevada Operations Office Nuclear Weapons Testing Areas (DRI, 1988); the Final Environmental Impact Statement Nevada Test Site, Nye County, Nevada (ERDA, 1977); and the Final Environmental Impact Statement for the Nevada Test Site and Off-Site Locations in the State of Nevada (DOE/NV, 1996).

The CAU 309 CASs are located on a south facing slope along the eastern side of the Rainier Mesa within Area 12 of the NTS. The muckpile at CAS 12-08-02 lies approximately $600 \mathrm{ft}$. east of the muckpile at CAS 12-06-09. The fallout plume (CAS 12-28-01) ejected debris and the associated contamination is scattered south of the I-, J-, and K-Tunnel muckpiles and extends down the hillside, across the valley and onto the adjacent hillside to the south. In addition, CAS 12-28-01 includes potential contamination associated with "ventings" along fractures and various boreholes on the mesa top and face. The T-Tunnel muckpile and ponds (CAU 478) is not part of this CAU but is in close proximity (the ponds are located within the suspected area of the fallout plume). Overall views of the CAU and nearby features are shown in aerial photographs (Figure 2-1 and Figure 2-2). 


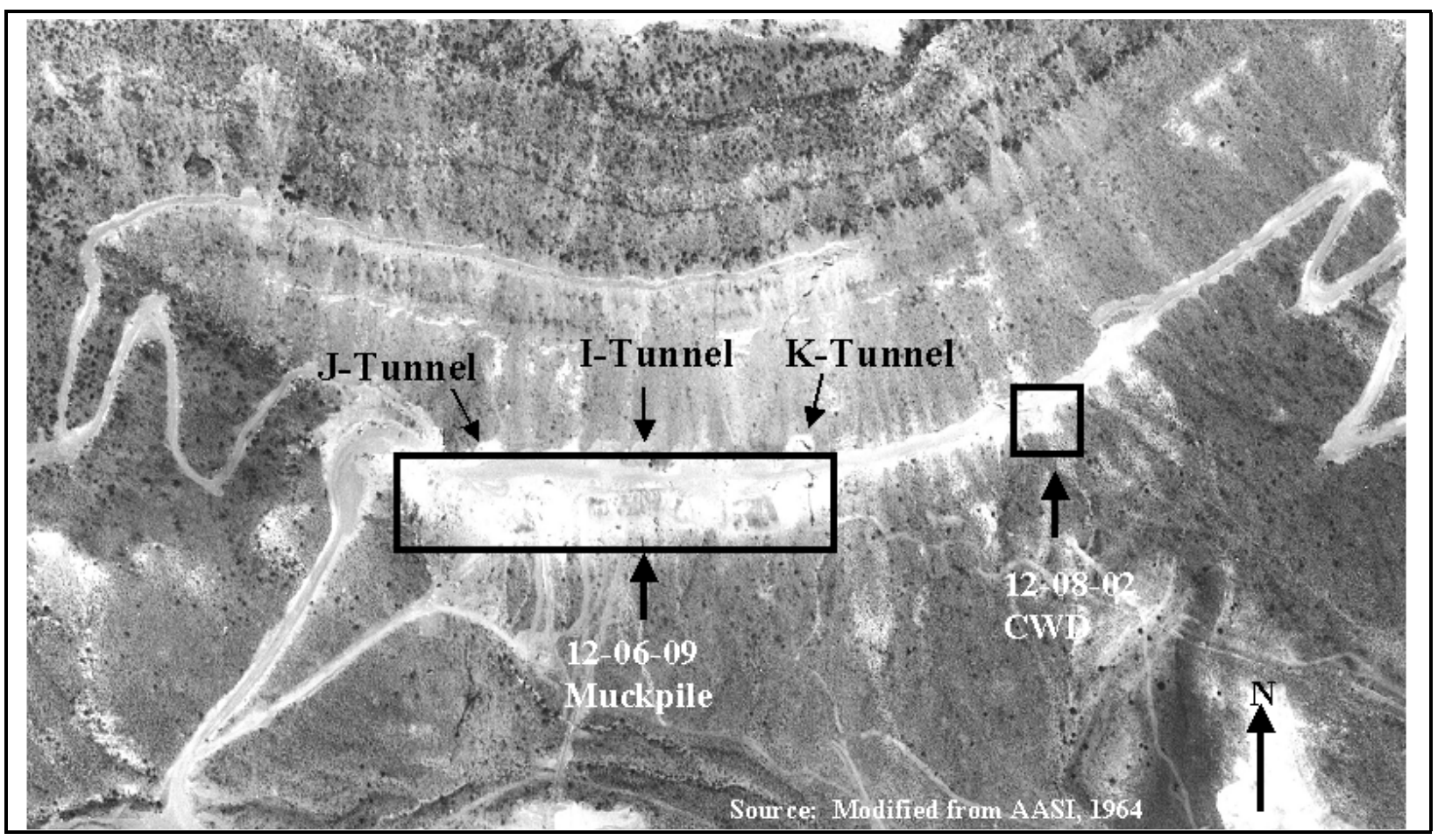

Figure 2-1 Aerial View of Muckpiles

The general topography consists of rock outcroppings of bedded tuff aquitard, welded tuff aquitard, and talus slopes, upon which thin patches of soil have developed. Several small gullies are present in the CAU. Drainage in the floor of the canyon is to the southeast through a series of braided intermittent washes. The talus slope angles are estimated to be from 20 to 30 degrees; some portions of the CAS muckpiles may be closer to, or slightly above, the angle of repose (i.e., the angle of slope that a pile of granular material forms under the force of gravity and when at rest, ranging from 35 degrees for fine sand to 45 degrees for angular gravel). Corrective Action Unit 309 is at an elevation of approximately $5,600 \mathrm{ft}$ amsl (DRI, 1988). 


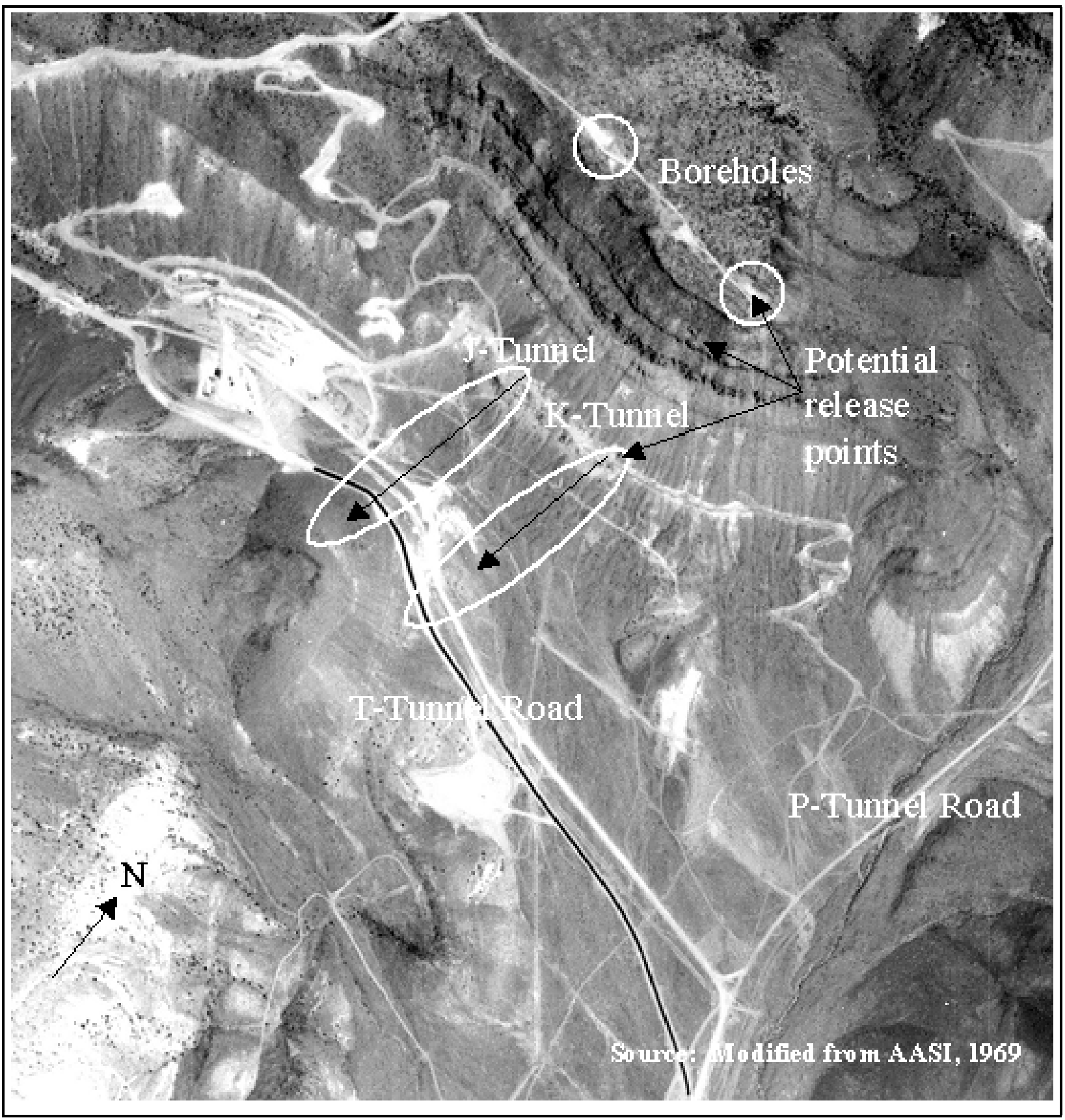

Figure 2-2

Aerial View of Fallout Plume 
Geologically, Rainier Mesa is comprised of a welded tuff overlying friable-bedded tuff and zeolitized-bedded tuffs of the Piapi Canyon Group and Indian Trail Formation of the Tertiary age (USGS, 1965; Winograd and Thordarson, 1975). Rainier Mesa is the highest of a group of mesas, ridges, and low mountains that compose the Belted Range, and is the remnant of a volcanic plateau uplifted during an episode of tectonic extension during the middle to late Cenozoic (DRI, 1987). The tuff is up to 5,000 ft thick, and soda rhyolitic in composition. The tuff includes the Grouse Canyon Member, the most densely welded tuff, many outcrops resemble a lava rather than a welded tuff (GSA, 1968). The tuff originated from a series of calderas.

Rainier Mesa serves as part of a drainage divide that separates westerly surface drainage to the Fortymile Canyon from the easterly surface drainage to Yucca Flat (DRI, 1987). Drainage from CAU 309 is to Yucca Flat. Within the subsurface, the regional zone of saturation occurs in the Paleozoic strata several thousand feet beneath the surface. At Rainier Mesa, perched water occurs only within the tuff aquitard, the top of which occurs at about $6,600 \mathrm{ft}$ amsl. The perched water table that exists in fractures within the aquitard occurs between 6,033 and 6,184 ft amsl in the east-central portion of Rainier Mesa. In some tunnels, perched water was found in poorly connected fractures. No water was found in the I-, J-, and K-Tunnels. The water table within the underlying lower carbonate aquifer exists at about 2,000 ft below the perched water table (Winograd and Thordarson, 1975). Groundwater beneath Rainier Mesa may flow westward or southward within the Alkali Flat-Furnace Creek Ranch subbasin, or some part may flow eastward (USGS, 1996).

Well ER-12-1 is located near the base of the eastern slope of Rainier Mesa, alongside the U-12e Tunnel access road at the base of Dolomite Hill in Area 12, approximately 2.5 mi west of CAU 309. Well ER-12-1 is at 5,817 ft amsl, and was drilled to a depth of 3,588 $\mathrm{ft}$ in 1991. The purpose of Well ER-12-1 was to determine the hydrogeology of Paleozoic carbonate rocks and the Eleana Formation (a regional aquitard in an area potentially down gradient from underground nuclear testing). Since 1997, Well ER-12-1 has been used as a monitoring well for the E-Tunnel evaporation ponds. Only the uppermost sleeve $(1,757 \mathrm{ft})$ within ER-12-1 is open and accessing formational groundwater for the purposes of sampling (DRI, 1996). Groundwater in Well ER-12-1 was measured in September 2003 at 1,526.41 ft below ground surface (bgs) (USGS and DOE, 2003). 
Precipitation rates for this region (i.e., Rainier Mesa to Yucca Flat) averages from 6 to 12 inches (in.) as indicated on isohyetal maps (USGS, 1965). Precipitation deposited on Rainier Mesa either infiltrates into soil and rock, runs off in gullies and washes, or is lost to evapotranspiration.

Precipitation that infiltrates into the overlying soil and exposed rock percolates through unsaturated rock material, locally recharging the groundwater system (USGS, 1996). Recharge on top of the Mesa is estimated at 140-acre feet per year ( $\mathrm{ft} / \mathrm{yr})$ based on a proportional percentage of precipitation. It should be noted that distribution, rate, and quantity of recharge are only estimates (USGS, 1996).

\subsection{Operational History}

The following subsections provide a description of the use and history of each CAS in CAU 309 . The CAS-specific summaries are designed to illustrate all significant, known activities that could pertain to the CAI or evaluation of CASs. A site visit was conducted on October 13, 2004, and included representatives from NDEP, NNSA/NSO, and NNSA/NSO contractors. Information gathered during this and other site visits has been added to the individual CAS operational histories.

\subsubsection{CAS 12-06-09, Muckpile}

Corrective Action Site 12-06-09 consists of a muckpile and debris located on the hillside in front of the I-, J-, and K-Tunnels on the eastern slopes of Rainier Mesa in Area 12. The muckpile includes mining debris (muck) and debris generated during the excavation and construction of the I-, J-, and K-Tunnels. The muckpile also includes reentry mining debris produced during nuclear tests which likely includes radioactively contaminated muck. Debris on the muckpile consists of scattered wood, twisted and rusted metal, cables, railroad tracks, and pipes. The top of the muckpile is surrounded by a two-strand yellow rope fence, which is posted with "Underground Radioactive Material" signs. The areas around the portals and additional structures are fenced with three-strand yellow-rope fences and posted with "Caution Contamination Area" signs. Debris within these posted areas is also included in the scope of CAS 12-06-09 and consists of wood, beams, twisted and rusted metal, cables, wooden pallets, wooden tunnel supports, and metal pipes. The location of CAS 12-06-09 is shown in Figure A.2-2.

Construction of the I-, J-, and K-Tunnels started in late 1961. The I-, J-, and K-Tunnels were used for weapons-related tests. Testing at both J-Tunnel and K-Tunnel was conducted under Operation 
Nougat. Only one test was conducted in each of these tunnels. The Platte Test was detonated in K-Tunnel on April 14, 1962, and the Des Moines Test was detonated in J-Tunnel on June 13, 1962 (DOE/NV, 2000b). The engineered containment structures for the tests failed and these tests were not contained. As a result, decontamination and re-entry problems were extensive. When the containment systems were breached, radioactive material and debris was ejected out of the portals onto the muckpile and across the canyon. No testing was conducted in I-Tunnel, due to the catastrophic failure of the J- and K-Tunnel containment systems. Fissures created in the mountainside from the testing at J-Tunnel caused the area to be unstable. The area containing the I-, J-, and K-Tunnels was abandoned following the Des Moines Test.

\subsubsection{CAS 12-08-02, Contaminated Waste Dump}

Corrective Action Site 12-08-02, CWD, consists of a muckpile and debris and is located on the hillside southeast of the front of the re-entry tunnel for K-Tunnel. During re-entry mining operations, potentially contaminated muck was removed from the tunnel and deposited on the muckpile. Debris on the CWD consists of rusted and twisted metal, wood, cables, a lighting fixture, and railroad tracks still attached to their wooden supports. It is likely that debris may be buried. The CWD is posted, "Caution Contamination Area." The signs are faded and some of them have fallen off the yellow-rope, three-strand fence surrounding the muckpile. Similar debris is also located off the muckpile, close to the mountainside and K-Tunnel re-entry tunnel. Included in this debris is a wooden outhouse that is tipped on its side. The collection reservoir consists of a 55-gallon (gal) drum. The drum appears empty and there is no staining visible beneath the drum. The scope of this investigation does not include the areas within the tunnel portals and/or support areas. The muckpiles of the CASs are delineated in Figure A.2-2. The operational history is similar to CAS 12-06-09.

\subsubsection{CAS 12-28-01, I-, J-, and K- Tunnel Debris}

Corrective Action Site 12-28-01 is defined as debris ejected during the Des Moines and Platte Tests and the associated contamination that is not covered in the two muckpiles CASs. This site consists of debris scattered south of the I-, J-, and K-Tunnel muckpiles and extends down the hillside, across the valley and onto the adjacent hillside to the south. In addition, the site covers the potential contamination associated with "ventings" along fractures and various boreholes on the mesa top and face. The operational history is also similar to the other two CASs except that T-Tunnel Ponds and 
other support facilities constructed in impacted areas after the release may have redistributed some contaminants. The T-Tunnel ponds are located in the posted area at the bottom of the canyon. These ponds are covered in CAU 478, CAS 12-23-01, and are excluded from further investigation in CAU 309.

\subsection{Waste Inventory}

Available documentation, interviews with former site employees, process knowledge, and general historical NTS practices were used to identify wastes that may be present. These sources did not indicate that this CAU was or was not used to dispose of material considered to be hazardous waste as defined by current standards. However, during a recent site visit, lead bricks were observed on the CWD at CAS 12-08-02. Other than the lead bricks, no known occurrences of hazardous waste disposal have been identified for CAU 309. Materials remaining from past activities conducted at, or near, this CAU could potentially be hazardous and/or radioactive waste by current standards.

\subsubsection{CAS 12-28-01, I-, J-, and K-Tunnel Debris}

Specific waste types have not been identified at this site, but likely include radionuclides based on the contamination postings on the fences within the fallout plume. Radioactive waste from tunnel containment failures may be present on the muckpiles or on the ground surface in the path of the fallout plume.

\subsubsection{CASs 12-06-09 and 12-08-02, Muckpiles}

The muckpiles contain material consisting primarily of mining debris (rock) generated during the excavation phase of shaft construction; therefore, the bulk of the muckpile is assumed to be uncontaminated material. The post-test portion, which includes disturbed geologic materials and construction/reentry debris, comprises a small fraction of the muckpile. Past surface activities of concern include equipment maintenance and storage of equipment and petroleum products. Releases to the muckpile from surface activities may be locally significant; however, vertical infiltration of contaminants into native material should not be a concern, based on findings at previous NTS muckpile investigations. 
Materials that could be hazardous and radioactive waste by today's standards from tunnel operations may be present in the muckpiles or on the ground surface in the area of the I-, J- and K-Tunnels. Specific waste types, other than lead bricks, have not been identified at this site, but likely include radionuclides based on the contamination postings on the muckpiles. Corrective Action Site 12-06-09 is posted with "Underground Radioactive Material." Corrective Action Site 12-08-02 is posted with "Caution Contamination Area," signs. Lead bricks have been identified at CAS 12-08-02 and, if removed, could be mixed waste.

\subsection{Release Information}

The CAS-specific release information, migration routes, exposure pathways, and affected media are discussed in this section. Based on historical information and process knowledge, the primary sources of potential environmental contaminants released to the soil within CAU 309 consist of potentially contaminated muck and debris from the muckpiles, release of contaminants on muckpiles from spills/leaks, and release of contaminants by forceful ejection from tunnels, vents, boreholes, and fractures.

In August 2004, SNJV personnel collected 26 surface soil samples for in-house analysis of gamma-emitting radionuclides. Eleven of these samples were sent to Paragon Analytical Laboratory for gamma-emitting radionuclides, isotopic plutonium, strontium (Sr)-90, beryllium, and lead analyses. Results were used to determine current site conditions and if beryllium was present at levels that would require additional personal protective equipment (PPE) for site workers. Results of the soil samples indicate lead and beryllium concentrations well below preliminary action levels (PALs) and safety concerns. Radiological results indicate Americium (Am)-241, cesium (Cs)-137, plutonium (Pu)-238, and Pu-239/240 were detected above PALs in samples collected within the fallout plumes from the J- and K-Tunnels. No other historical analytical data of CAU 309 was identified.

It is expected that vertical migration of contaminants would be very limited due to the low annual rate of precipitation and high annual potential evapotranspiration rate at the site. The limited recharge to groundwater from precipitation does not provide a significant mechanism for vertical migration of contaminants to groundwater (DOE/NV, 1992). Also, process knowledge from previous muckpile investigations shows the native material underlying these muckpiles has been largely uncontaminated 
(Appendix B). However, lateral migration of contaminants may be an important transport mechanism due to erosion and the steep slopes of the area.

Potentially affected media for all CASs include surface and shallow subsurface soil. Exposure routes to site workers include ingestion, inhalation, and/or dermal contact (absorption) from disturbance of contaminated soils, debris, and/or structures. Site workers may be exposed to radiation by performing activities in proximity to radiologically contaminated materials.

The following subsections contain CAS-specific descriptions of known or potential releases associated with CAU 309.

\subsubsection{CAS 12-28-01}

The Platte Test (K-Tunnel) was detonated on April 14, 1962. Immediately following the detonation, a fissure opened up in the face of the mesa, releasing large amounts of radioactive effluent into the atmosphere over a period of several minutes. Also, effluent escaped from the tunnel portal and from the instrumentation pipe on top of the mesa (AEC, 1966).

The Des Moines Test (J-Tunnel) was detonated on June 13, 1962. Following the detonation, a dense black cloud, apparently containing both gaseous and particulate material, emanated from the tunnel portal, the top of the mesa, and a monitoring hole about halfway up the side of the mesa (AEC, 1966).

This historical information verifies what was seen during SNJV site visits by the debris path emanating from the J-Tunnel fallout and the lack of debris observed in front of K-Tunnel.

\subsubsection{CASs 12-06-09 and 12-08-02}

The muckpiles consist of potentially contaminated muck and debris removed from nearby tunnels. Historical documentation identifies posted dumps (i.e., muckpiles) in the current locations of these muckpiles. The nature of this contamination was not defined. The current status of contamination at the dump is unknown. Potential release of contamination from these muckpiles into the surrounding environment is unknown, although the most likely means would be from overland transport in stormwater run-off to drainages down slope from the muckpiles. 


\section{$2.5 \quad$ Investigative Background}

The following subsections summarize the investigations conducted at the CAU 309 sites. More detailed discussions of these investigations and other investigations are found in Appendix A.

\subsubsection{CAS 12-28-01}

In August 2004, SNJV personnel collected 26 surface soil samples for in-house analysis of gamma-emitting radionuclides. The purpose of this analysis was to develop a correlation of on-site gamma spectroscopy with off-site laboratory analysis and to assess the general magnitude of the fallout plume. Eleven of these samples were sent to Paragon Analytical Laboratory for gamma-emitting radionuclides, isotopic plutonium, Sr-90, beryllium, and lead analyses. Results were used to determine current site conditions and if beryllium was present at levels that would require additional PPE for site workers.

Results of the soil samples indicate lead and beryllium concentrations well below PALs and safety concerns. Radiological results indicate Am-241, Cs-137, Pu-238, and Pu-239/240 were detected above PALs in samples collected within the fallout plumes from the J-and K-Tunnels.

\subsubsection{CASs 12-06-09 and 12-08-02}

The memorandum entitled Preliminary Assessments Radiological Survey 2004 (Alderson, 2004), identifies results of a radiological survey conducted at CAU 309 in January 2004. The objective of the radiological survey was to determine if radiological contamination is present in surface soil at concentrations statistically greater than surface soil from undisturbed background locations. A radiological walk-over survey was performed on January 21, 2004, at the muckpile and surrounding areas in front of the tunnels (Alderson, 2004). The area surveyed covered 20,781 square feet $\left(\mathrm{ft}^{2}\right)$. The maximum gamma radiation emission rate was 8,492 counts per second (cps), which is approximately 26.5 times greater than the mean undisturbed background gamma radiation emission rate. The most elevated gamma emission rates in the survey area were seen at the CWD in the northeast corner of the survey area in front of K-Tunnel re-entry, inside a posted contamination area (Figure A.2-4). No removable contamination was encountered. The surveyed area included the access road leading from K-Tunnel to the K-Tunnel re-entry, and the CWD outside K-Tunnel 
re-entry. More detailed discussions of these investigations and other CAU 309 related investigations can be found in Section A.2.1.

\subsection{National Environmental Policy Act}

The Final Environmental Impact Statement for the Nevada Test Site and Off-Site Locations in the State of Nevada (DOE/NV, 1996) includes site investigation activities such as those proposed for CAU 309.

In accordance with the NNSA/NSO National Environmental Policy Act (NEPA) Compliance Program, a NEPA checklist will be completed prior to commencement of site investigation activities at CAU 309. This checklist compels NNSA/NSO project personnel to evaluate their proposed project activities against a list of potential impacts that include, but are not limited to: air quality, chemical use, waste generation, noise level, and land use. Completion of the checklist results in a determination of the appropriate level of NEPA documentation required by the NNSA/NSO NEPA Compliance Officer. This will be accomplished prior to mobilization for the field investigation. 


\subsection{Objectives}

This section presents an overview of the DQOs for CAU 309 and formulation of the CSM. Also presented is a summary listing of the contaminants reasonably suspected to be present at each CAS, the COPCs, the action levels for the investigation, and the process used to move from PALs to final action levels (FALs). Additional details and figures depicting the CSM are located in Appendix A.

\subsection{Conceptual Site Models}

The CSM describes the most probable scenario for current conditions at each site and defines the assumptions that are the basis for identifying the future land use, contaminant sources, release mechanisms, migration pathways, exposure points, and exposure routes. The CSM is also used to support appropriate sampling strategies and data collection methods. One CSM has been developed for CAU 309 using information from the physical setting, potential contaminant sources, release information, historical background information, knowledge from similar sites, and physical and chemical properties of the potentially affected media and COPCs.

As discussed in Appendix A, the CSM for the muckpiles contains an assumption that the CAU 309 muckpiles are comparable to previously investigated NTS muckpiles and contain COCs identified during those investigations. Additional information to support this assumption and/or account for potential differences is provided in Appendix B.

The CSM represents contamination of soil and mine tailings due to the operational and tunnel containment discharges described in Section 2.4. The CSM is shown in profile view in Figure 3-1, and in drainage view in Figure 3-2. The scope of this investigation is limited to the CAU 309 muckpiles, fallout plume, and potential contamination of the environment contiguous to the CASs within CAU 309. This scope does not include potential contamination associated with overlapping CAUs, such as the muckpile outside of the P- or T-Tunnels.

If evidence of contamination that is not consistent with the presented CSM is identified during investigation activities, the situation will be reviewed, the CSM will be revised, the DQOs will be re-assessed, and a recommendation will be made as to how best to proceed. In such cases, decision 


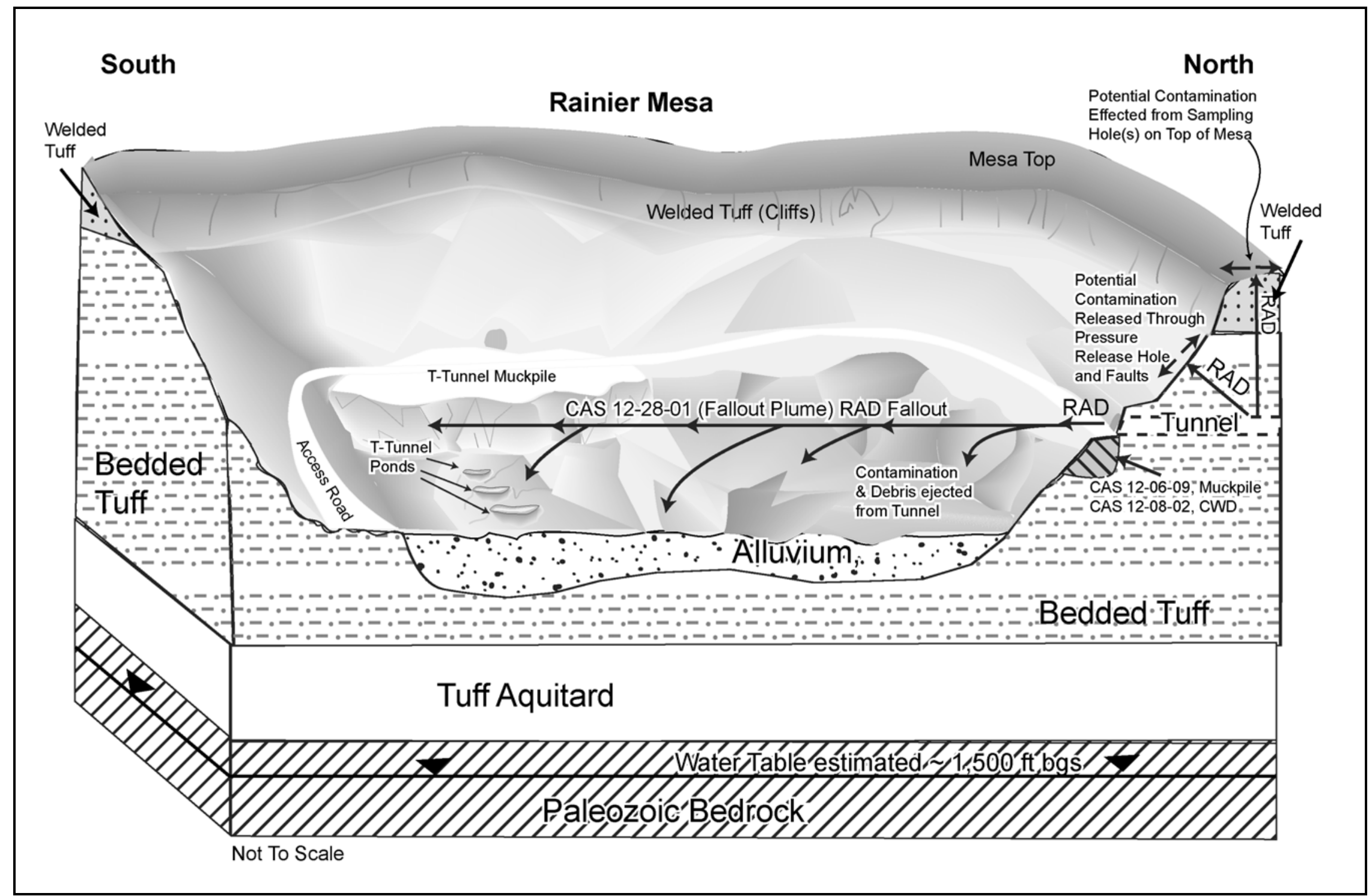

Figure 3-1

CAU 309 Conceptual Site Model (Profile Model) 


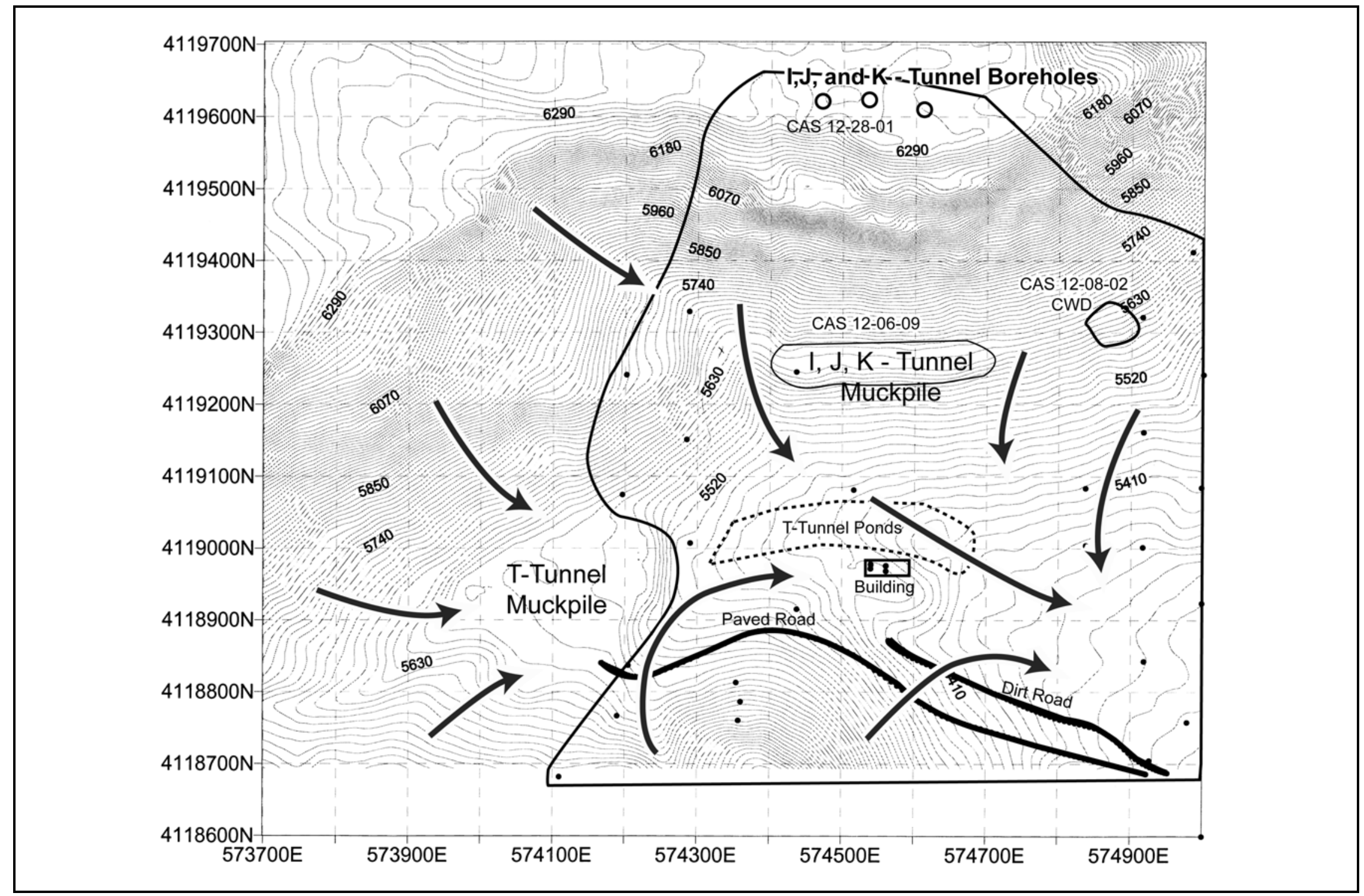

Figure 3-2

CAU 309 Conceptual Site Model (Drainage Model) 
makers listed in Section A.3.1 will be notified for comment on and/or concurrence with the recommendation.

The following sections discuss future land use and the identification of exposure pathways (i.e., combination of source, release, migration, exposure point, and receptor exposure route) for the CAU.

\subsubsection{Future Land Use}

The future land-use scenario, as a Nuclear and High Explosives Test Zone, limits uses of CAU 309 to various nonresidential uses (i.e., industrial uses) including defense and nondefense research, development, and testing activities. The Nuclear Test Zone is defined as “...reserved for dynamic experiments, hydrodynamic tests, and underground nuclear weapons and weapons effects tests..." (DOE/NV, 1998).

\subsubsection{Contaminant Sources}

The contaminant sources for the CSM are potential contamination present within each muckpile and the fallout plume from operations in and around the tunnels. Those operations include nuclear testing and tunnel containment failure, maintenance and decontamination procedures, and related tunnel activities.

\subsubsection{Release Mechanisms}

The CSM identifies three release mechanisms for CAU 309 and include:

- The release of potentially contaminated muck and debris onto the native surfaces resulting from re-entry tunneling following nuclear detonations.

- Potential releases of contaminants (e.g., oil, diesel) from accidental spills/leaks onto the muckpiles.

- Release of contaminants by forceful ejection from tunnels, vents, boreholes, and fractures. 


\subsubsection{Migration Pathways}

An important element of the CSM in developing a sampling strategy is the expected fate and transport of contaminants (how contaminants migrate through media and where they can be expected in the environment). Fate and transport of contaminants are presented in the CSM as the migration pathways and transport mechanisms that could potentially move the contaminants throughout the various media. Fate and transport are influenced by physical and chemical characteristics of the contaminants and media described in Section A.3.2.3 and Section A.3.2.4. Contaminant characteristics include, but are not limited to: solubility, density, and adsorption potential. Media characteristics include permeability, porosity, water saturation, sorting, chemical composition, and organic content. In general, contaminants with low solubility, high affinity for media, and high density can be expected to be found relatively close to release points. Contaminants with high solubility, low affinity for media, and low density can be expected to be found further from release points. These factors affect the migration pathways and potential exposure points for the contaminants in the various media under consideration.

Infiltration and percolation of precipitation can serve as a driving force for downward migration of contaminants. However, potential evapotranspiration (the evaporative capacity of the atmosphere at the soil surface) at the NTS is significantly greater than precipitation; thus, limiting vertical migration of contaminants. The annual average precipitation for this region (i.e., Rainier Mesa to Yucca Flat) is only 6 to 12 in. per year (USGS, 1965). The amount of precipitation falling on this unit, which is approximately $800 \mathrm{ft}$ below the mesa top, is greatly exceeded by the potential evapotranspiration rates of these areas, estimated to be from 24 to 70 in. of water per year (NBMG, 1996). Lower elevations generally receive less precipitation and are subjected to atmospheric conditions that are conducive to higher evaporation rates. Limited moisture would be available to carry dissolved contaminants through the muckpiles. Therefore, recharge to groundwater from precipitation is not considered to be significant at the NTS and does not provide a significant mechanism for migration of contaminants to groundwater.

The CAU 309 CASs have very steep surface gradients and are located in drainage channels; therefore, the predominant migration pathway shown in the CSM is expected to be lateral migration over soils and talus material. The drainage channels are confined within the same watershed, and flow to a common wash near the P-Tunnel access road. This wash is a few hundred feet down 
gradient from the T-Tunnel muckpile and ponds (CAU 478). This wash eventually joins other washes and flows out to Yucca Flat (DRI, 1987).

Because of the low volatility of the critical contaminants in the muckpiles and fallout plume, an airborne release subsequent to the initial contaminant release is not considered a significant release pathway. The main process of migration through the air would be through windblown dust.

The resuspension of particles is directly affected by particle size, weathering, and migration. The three mechanisms that result in movement of particles deposited onto surfaces are surface creep (particles rolling across the surface), saltation (bouncing particles that become airborne for short distances $[\sim 10$ meters $\{\mathrm{m}\}]$ ), and true suspension (particles that were once deposited on the ground become airborne and travel upward for great distances). True resuspension affects only particles that are less than 50 micrometers $(\mu \mathrm{m})$ in size. However, smaller particles can attach to larger soil particles and larger particles can be broken up so that long-term behavior cannot, in general, be predicted from the initial particle size of the deposited material. Various resuspension studies have been conducted on plutonium contaminated soils at the NTS and other locations. These studies have identified that for fresh deposition $\left(<1\right.$ year) the initial resuspension factors to be used are $10^{-4}$ to $10^{-6}$ $\mathrm{m}^{-1}$. These studies also have shown that as the deposition ages the resuspension factor drops exponentially and within 30 days of initial deposition the resuspension factor has dropped by 2 to 3 orders of magnitude even on asphalt surfaces. A conservative determination of the appropriate resuspension factor based on age of deposition is given by (NRC, 1983).

\subsubsection{Exposure Points}

Exposure points for the CSM are expected to be locations of surface contamination where visitors and site workers will come in contact with soil surface. Contamination, if present, is expected to be contiguous to the release site, with possible contaminated spots down gradient from the CASs in drainages. Concentrations of contaminants are generally expected to decrease with increasing horizontal and vertical distance from the locations of release. A possible exception would be an increase in concentration at down gradient sediment traps due to scouring and flushing of contaminants with stormwater run-off events. Another possible exception would be an increase in concentration at down gradient locations of the fallout plume due to shielding from the muckpile. 


\subsubsection{Exposure Routes}

The potential for contamination exposure is limited to industrial and construction workers, and military personnel conducting training. These human receptors may be exposed to COPCs through oral ingestion, inhalation, dermal contact (absorption) of soil and/or debris due to inadvertent disturbance of these materials or irradiation by radioactive materials.

\subsubsection{Additional Information}

Information concerning topography, climatic conditions, hydrogeology, floodplains, and infrastructure at the CAU 309 CASs are available and are presented in Section 2.1 as they pertain to the investigation. This information has been addressed in the CSM and will be considered during the evaluation of corrective action alternatives, as applicable. No additional information on these topics is required to complete the investigation and the evaluation of corrective action alternatives.

Climatic and site conditions (e.g., surface and subsurface soil descriptions) as well as specific structure descriptions will be observed and recorded during the CAI.

\subsection{Contaminants of Potential Concern}

The COPCs for CAU 309 are generally defined as the list of constituents reported from laboratory analyses. The list of COPCs is intended to encompass all of the contaminants that could potentially be present at each CAS. These COPCs were identified during the planning process through the review of site history, process knowledge, personnel interviews, past investigation efforts (where available), and inferred activities associated with the CASs. Common contaminants detected at other similar or other NTS sites were also included in the COPC list to reduce the uncertainty about potential contamination at the CASs because complete information regarding activities performed at the CAU 309 sites is not available.

Organic and inorganic COPCs are analytes listed in Table 3-1 and Table 3-2 for which the U.S. Environmental Protection Agency (EPA) Region 9 has established Preliminary Remediation Goals (PRGs) (EPA, 2002d) or for which toxicity and/or carcinogenicity data are listed in the EPA Integrated Risk Information System (IRIS) database (EPA, 2002e). The radionuclides, polychlorinated biphenyls (PCBs), and metals compounds are listed in Table 3-3. 
Table 3-1

Analytes Reported from VOC Analysis

\begin{tabular}{|c|c|c|}
\hline $\begin{array}{l}\text { 1,1,1-Trichloroethane } \\
\text { 1,1,1,2-Tetrachloroethane } \\
\text { 1,1,2,2-Tetrachloroethane } \\
\text { 1,1,2-Trichloroethane } \\
\text { 1,1-Dichloroethane } \\
\text { 1,1-Dichloroethene } \\
\text { cis-1,2-Dichloroethene } \\
\text { trans-1,2-Dichloroethene } \\
\text { 1,2-Dichloroethane } \\
\text { 1,2-Dichloropropane } \\
\text { 1,2,3-Trichloropropane } \\
\text { 1,2,4-Trimethylbenzene } \\
\text { 1,2-Dibromo-3-chloropropane } \\
\text { 1,2-Dibromoethane } \\
\text { 1,3,5-Trimethylbenzene } \\
\text { cis-1,3-Dichloropropene } \\
\text { trans-1,3-Dichloropropene } \\
\text { 2-Butanone } \\
\text { 2-Chlorotoluene }\end{array}$ & $\begin{array}{l}\text { 4-Methyl-2-pentanone } \\
\text { Acetone } \\
\text { Benzene } \\
\text { Bromobenzene } \\
\text { Bromochloromethane } \\
\text { Bromodichloromethane } \\
\text { Bromoform } \\
\text { Bromomethane } \\
\text { Carbon disulfide } \\
\text { Carbon tetrachloride } \\
\text { Chlorobenzene } \\
\text { Chloroethane } \\
\text { Chloroform }\end{array}$ & $\begin{array}{l}\text { Chloromethane } \\
\text { Dibromochloromethane } \\
\text { Dibromomethane } \\
\text { Dichlorodifluoromethane } \\
\text { Ethylbenzene } \\
\text { lodomethane } \\
\text { Isopropylbenzene } \\
\text { Methyl tertbutyl ether } \\
\text { Methylene chloride } \\
\text { N-Butylbenzene } \\
\text { N-Propylbenzene } \\
\text { sec-Butylbenzene } \\
\text { Styrene } \\
\text { tert-Butylbenzene } \\
\text { Tetrachloroethene } \\
\text { Toluene } \\
\text { Trichloroethene } \\
\text { Trichlorofluoromethane } \\
\text { Trichlorotrifluoroethane } \\
\text { Vinyl acetate } \\
\text { Vinyl chloride } \\
\text { Xylenes }\end{array}$ \\
\hline
\end{tabular}

Table 3-2

Analytes Reported from SVOC Analysis

\begin{tabular}{|l|l|l}
\hline 1,2,4-Trichlorobenzene (a) & Acenaphthylene & Di-n-butyl Phthalate \\
1,2-Dichlorobenzene (a) & Aniline & Di-n-octyl Phthalate \\
1,3-Dichlorobenzene (a) & Anthracene & Fluoranthene \\
1,4-Dichlorobenzene (a) & Benzo(a)anthracene & Fluorene \\
2,4,5-Trichlorophenol & Benzo(a)pyrene & Hexachlorobenzene \\
2,4,6-Trichlorophenol & Benzo(b)fluoranthene & Hexachlorocyclopentadiene \\
2,4-Dichlorophenol & Benzo(g,h,i)perylene & Hexachloroethane \\
2,4-Dimethylphenol & Benzo(k)fluoranthene & Hydroquinone \\
2,4-Dinitrophenol & Benzoic Acid & Indeno(1,2,3-cd)pyrene \\
2,4-Dinitrotoluene & Benzyl Alcohol & Isophorone \\
2,6-Dinitrotoluene & Bis(2-chloroethoxy) methane & Naphthalene (a) \\
2-Chloronaphthalene & Bis(2-chloroethyl)ether & Nitrobenzene \\
2-Chlorophenol & Bis(2-chloroisopropyl)ether & N-Nitroso-di-n-propylamine \\
2-Methylphenol & Bis(2-ethylhexyl) phthalate & N-Nitrosodimethylamine \\
2-Nitroaniline & Butyl benzyl phthalate & N-Nitrosodiphenylamine \\
3,3-Dichlorobenzidine & Carbazole & Pentachlorophenol \\
4-Bromophenyl phenyl ether & Chrysene & Phenanthrene \\
4-Chloroaniline & Dibenzo(a,h)anthracene & Phenol \\
4-Methylphenol & Dibenzofuran & Pyrene \\
4-Nitrophenol & Diethyl Phthalate & Pyridine \\
Acenaphthene & Dimethyl Phthalate & .
\end{tabular}

(a) May be reported with VOCs 
Table 3-3

Analytes Reported from Radionuclides, PCB, and Metals Analyses

\begin{tabular}{||l|ll|ll||}
\hline \multicolumn{1}{|c|}{ Radionuclides } & \multicolumn{1}{|c|}{ PCB } & & \multicolumn{1}{c|}{ Metals } \\
\hline \hline Gamma-emitting radionuclides & Aroclor-1016 & Aroclor-1248 & Arsenic & Lead \\
Strontium-90 & Aroclor-1221 & Aroclor-1254 & Barium & Mercury \\
Uranium-234, 235, 238 & Aroclor-1232 & Aroclor-1260 & Beryllium & Selenium \\
Plutonium-238, 239/240 & Aroclor-1242 & & Cadmium & Silver \\
Tritium & & & Chromium \\
\hline
\end{tabular}

During the review of site history documentation, process knowledge information, personnel interviews, past investigation efforts of other muckpiles, and inferred activities associated with the CASs, some of the COPCs were identified as targeted analytes at specific CASs. Targeted analytes are those COPCs for which evidence in the available site and process information suggests that they may be reasonably suspected to be present at a given CAS. The targeted analytes are required to meet a more stringent completeness criteria than other COPCs thus providing greater protection against a decision error (see Section A.3.2). Targeted analytes for each CAU 309 CAS are identified in Table 3-4.

Table 3-4

Targeted Analytes for CAU 309

\begin{tabular}{|c|c|c|}
\hline CAS & $\begin{array}{c}\text { Chemical } \\
\text { Targeted Analyte(s) }\end{array}$ & \multicolumn{1}{c|}{$\begin{array}{c}\text { Radiological } \\
\text { Targeted Analyte(s) }\end{array}$} \\
\hline \hline $\begin{array}{c}12-06-09 \\
12-08-02\end{array}$ & Arsenic, Lead, TPH (DRO) & Sr-90, Cs-137, Co-60, Pu-238, Pu239 \\
\hline $12-28-01$ & None & $\begin{array}{l}\text { Sb-125, Sr-90, Eu-152, Eu-154, Eu-155, Cs-137, } \\
\text { Co-60, Am-241, Pu-238, Pu-239/240 }\end{array}$ \\
\hline
\end{tabular}

The steepness of the slopes on and around the muckpiles creates unsafe conditions for survey and sampling personnel; therefore, "expected COCs" for the muckpiles were established based on data from previously investigated NTS muckpiles. A more thorough discussion of this approach is presented in the DQOs (Appendix A).

\subsection{Preliminary Action Levels}

The PALs presented in this section are to be used for site screening purposes. They are not necessarily intended to be used as cleanup action levels or FALs. However, they are useful in screening out analytes that are not present in sufficient concentrations to warrant further evaluation; 
therefore, streamline the consideration of remedial alternatives. The process that will be used to move from PALs to FALs is to:

- Establish FALs that are equal to the PALs or

- Establish FALs based on risk to human health and the environment and site-specific conditions.

If FALs are used that are not equal to the PALs, the derivation of the FALs will be presented in an appendix to the investigation report. The FALs (along with the basis for their selection) will be proposed in the investigation report where they will be compared to laboratory results in the evaluation of potential corrective actions.

\subsubsection{Chemical PALs}

Except as noted herein, the chemical PALs are defined as the EPA PRGs for chemical constituents in industrial soils (EPA, 2002d). Background concentrations for Resource Conservation and Recovery Act (RCRA) metals will be used instead of PRGs when natural background concentrations exceed the PRG, as is often the case with arsenic on the NTS. Background is considered the mean plus two standard deviations of the mean for sediment samples collected by the Nevada Bureau of Mines and Geology throughout the Nevada Test and Training Range (formerly the Nellis Air Force Range) (NBMG, 1998; Moore, 1999). For detected chemical COPCs without established PRGs that have toxicity and carcinogenicity data listed in the EPA IRIS database (EPA, 2002e), the protocol used by the EPA Region 9 in establishing PRGs (or similar) will be used to establish PALs. If used, this process will be documented in the investigation report.

\subsubsection{TPH PALs}

The PAL for total petroleum hydrocarbons (TPH) in soil is the TPH action limit of 100 parts per million (ppm) established by the Nevada Administrative Code (NAC) 445A.2272 (NAC, 2003).

\subsubsection{Radiological PALs}

The PALs for radiological contaminants (other than tritium) are based on the National Council on Radiation Protection and Measurements (NCRP) Report No. 129 recommended screening limits for 
construction, commercial, industrial land-use scenarios (NCRP, 1999) scaled from 25 to 15 millirems per year (mrem/yr) dose constraint and the generic guidelines for residual concentration of radionuclides in DOE Order 5400.5 (DOE, 1993). These PALs are based on the construction, commercial, industrial land-use scenario provided in the guidance and are appropriate for the NTS based on future land-use scenarios as presented in Section 3.1.1. The radiological PALs for CAU 309 are listed in Table 3-5.

Solid media such as concrete and/or structures may pose a potential radiological exposure risk to site workers if contaminated. The radiological PAL for solid media will be defined as the unrestricted-release criteria defined in the NV/YMP Radiological Control (RadCon) Manual (DOE/NV, 2000a).

\subsection{DQO Process Discussion}

This section contains a summary of the DQO process that is presented in Appendix A. The DQO process is a strategic planning approach based on the scientific method that is designed to ensure that the data collected will provide sufficient and reliable information to identify, evaluate, and technically defend the recommendation of viable corrective actions (e.g., no further action, clean closure, or closure in place).

The DQO strategy for CAU 309 was developed at a meeting on September 29, 2004. The DQOs were developed to identify data needs, clearly define the intended use of the environmental data, and to design a data collection program that will satisfy these purposes. During the DQO discussions for this CAU, the informational inputs or data needs to resolve problem statements and decision statements were documented.

The problem statement for CAU 309 is: "Existing information on the nature and extent of potential contamination is insufficient to evaluate and recommend corrective action alternatives for the CASs in CAU 309." To address this question, the resolution of two decisions statements is required:

- Decision I: "Is any COPC present in environmental media within the CAS at a concentration exceeding its corresponding action level?" Any contaminant associated with a CAS activity that is present at concentrations exceeding its corresponding action level will be defined as a COC. If a COC is detected, then Decision II must be resolved. Otherwise, the investigation for that CAS is complete. 
Table 3-5

Analytical Requirements for Radionuclides for CAU 309

\begin{tabular}{|c|c|c|c|c|c|c|}
\hline Parameter/Analyte & Matrix & $\begin{array}{l}\text { Analytical } \\
\text { Method }\end{array}$ & $\mathrm{MDC}^{\mathrm{a}}$ & PAL $^{b, c}$ & $\begin{array}{c}\text { Laboratory } \\
\text { Precision (RPD) }\end{array}$ & $\begin{array}{c}\text { Percent Recovery } \\
(\% \mathrm{R})\end{array}$ \\
\hline \multicolumn{7}{|c|}{ Gamma Spectrometry } \\
\hline Americium-241 & Soil & HASL- $300^{\dagger}$ & $2.0 \mathrm{pCi} / \mathrm{g}^{\mathrm{e}}$ & $7.62 \mathrm{pCi} / \mathrm{g}$ & \multirow{5}{*}{$\begin{array}{c}\text { Relative Percent } \\
\text { Difference (RPD) 35\% } \\
\text { Normalized } \\
\text { Difference } \\
-2<\mathrm{ND}<2^{9}\end{array}$} & \multirow{5}{*}{$\begin{array}{c}\text { Laboratory Control } \\
\text { Sample Recovery } \\
80-120 \text { Percent } \\
\text { Recovery }(\% \mathrm{R})\end{array}$} \\
\hline Cesium-137 & Soil & HASL-300 ${ }^{\dagger}$ & $0.5 \mathrm{pCi} / \mathrm{g}^{\mathrm{e}}$ & $7.3 \mathrm{pCi} / \mathrm{g}$ & & \\
\hline Cobalt-60 & Soil & HASL- $300^{\dagger}$ & $0.5 \mathrm{pCi} / \mathrm{g}^{\mathrm{e}}$ & $1.61 \mathrm{pCi} / \mathrm{g}$ & & \\
\hline Sb-125 & Soil & HASL- $300^{\dagger}$ & $2.0 \mathrm{pCi} / \mathrm{g}^{\mathrm{e}}$ & $10.9 \mathrm{pCi} / \mathrm{g}$ & & \\
\hline Eu-152, 154, and 155 & Soil & HASL- $300^{\dagger}$ & $3.0,3.0,2.0 \mathrm{pCi} / \mathrm{g}^{\mathrm{e}}$ & $3.4,3.2,81.1 \mathrm{pCi} / \mathrm{g}$ & & \\
\hline \multicolumn{7}{|c|}{ Other Radionuclides } \\
\hline Tritium & Soil & Lab specific & $400 \mathrm{pCi} / \mathrm{L}^{\mathrm{d}}$ & $4.0 \mathrm{E}+05 \mathrm{pCi} / \mathrm{L}^{\mathrm{d}}$ & \multirow{7}{*}{$\begin{array}{c}\text { Relative Percent } \\
\text { Difference (RPD) } 35 \% \\
\\
\text { Normalized } \\
\text { Difference } \\
-2<N D<2^{9}\end{array}$} & \multirow{7}{*}{$\begin{array}{c}\text { Laboratory Control } \\
\text { Sample Recovery } \\
80-120^{h} \text { Percent } \\
\text { Recovery (\%R) } \\
\text { Chemical Yield } \\
30-105^{\mathrm{j}} \% \mathrm{R}\end{array}$} \\
\hline Plutonium-238 & Soil & $\begin{array}{c}\text { ASTM } \\
\text { C1001-00k }\end{array}$ & $0.05 \mathrm{pCi} / \mathrm{g}$ & $7.78 \mathrm{pCi} / \mathrm{g}$ & & \\
\hline Plutonium-239/240 & Soil & $\begin{array}{c}\text { ASTM } \\
\text { C1001-00k }\end{array}$ & $0.05 \mathrm{pCi} / \mathrm{g}$ & $7.62 \mathrm{pCi} / \mathrm{g}$ & & \\
\hline Strontium-90 & Soil & HASL $300^{\dagger}$ & $0.5 \mathrm{pCi} / \mathrm{g}$ & $503.0 \mathrm{pCi} / \mathrm{g}$ & & \\
\hline Uranium-234 & Soil & $\begin{array}{c}\text { ASTM } \\
\text { C1000-02 }\end{array}$ & $0.05 \mathrm{pCi} / \mathrm{g}$ & $85.9 \mathrm{pCi} / \mathrm{g}$ & & \\
\hline Uranium-235 & Soil & $\begin{array}{c}\text { ASTM } \\
\text { C1000-02 }^{m}\end{array}$ & $0.05 \mathrm{pCi} / \mathrm{g}$ & $10.5 \mathrm{pCi} / \mathrm{g}$ & & \\
\hline Uranium-238 & Soil & $\begin{array}{c}\text { ASTM } \\
\text { C1000-02 }\end{array}$ & $0.05 \mathrm{pCi} / \mathrm{g}$ & $63.2 \mathrm{pCi} / \mathrm{g}$ & & \\
\hline
\end{tabular}

${ }^{\mathrm{a}}$ The MDC is the lowest concentration of a radionuclide, if present in a sample, that can be detected with a 95 percent confidence level.

${ }^{\mathrm{b}}$ The PALs for soil are based on the NCRP Report No. 129, Recommended Screening Limits for Contaminated Soil and Review of Factors Relevant to Site-Specific Studies (NCRP, 1999) scaled from 25 to $15 \mathrm{mrem} / \mathrm{yr}$ dose and the guidelines for residual concentration of radionuclides in DOE Order 5400.5 (DOE, 1993).

${ }^{\mathrm{C}} \mathrm{PALs}$ for liquids will be developed as needed

${ }^{\mathrm{d}}$ Units of $\mathrm{pCi} / \mathrm{L}$ will be reported by the analytical laboratory based on the activity of the tritium in the soil moisture. The PAL for tritium in soil is based on the Underground Test Area Project limit of $400,000 \mathrm{pCi} / \mathrm{L}$ for discharge of water containing tritium to an infiltration basin/area (NNSA/NV, 2002b).

${ }^{\mathrm{e}} \mathrm{MDC}$ s vary depending on the presence of other gamma-emitting radionuclides in the sample and are relative to the MDC for Cs-137.

${ }^{\mathrm{f}}$ The Procedures Manual of the Environmental Measurements Laboratory, HASL-300 (DOE, 1997)

${ }^{9} \mathrm{ND}$ is not RPD, it is another measure of precision used to evaluate duplicate analyses. The ND is calculated as the difference between two results divided by the square root of the sum of the squares of their total propagated uncertainties. Evaluation of Radiochemical Data Usability (Paar and Porterfield, 1997)

hEPA Contract Laboratory Program Statement of Work for Inorganic Analysis (EPA, 1988a; 1994a; and 1995)

'Standard Test Method for Plutonium in Water (ASTM, 2002b)

${ }^{j}$ General Radiochemistry and Routine Analytical Services Protocol (GRASP) (EG\&G Rocky Flats, 1991). The chemical yield only applies to plutonium, uranium and strontium.

${ }^{k}$ Standard Test Method for Radiochemical Determination of Plutonium in Soil by Alpha Spectroscopy (ASTM, 2000a)

'Standard Test Method for Isotopic Uranium in Water by Radiochemistry (ASTM, 2002a)

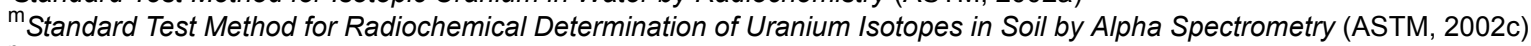

${ }^{\mathrm{n}}$ Standard Test Method for Strontium-90 in Water (ASTM, 2000b).

ASTM = American Society for Testing and Materials

MDC = Minimum detectable concentration

$\mathrm{PAL}=$ Preliminary action level

$\mathrm{pCi} / \mathrm{g}=$ Picocuries per gram

ND $=$ Normalized difference

$\mathrm{pCi} / \mathrm{L}=$ Picocuries per liter 
- Decision II: "If a COC is present, is sufficient information available to evaluate potential corrective action alternatives?" Sufficient information is defined to include:

- Identification of the volume of media containing any COC bounded by analytical sample results in lateral and vertical directions.

- Collection of the information needed to characterize IDW and/or potential remediation waste for disposal.

Because the investigation of the fallout plume follows a more typical CAI, Decisions I and II given above are precise as presented and no further development is needed. Due to the slope instability of the CAU 309 muckpiles, the investigation of these features follows the model developed for the CAU 551 muckpile CAI, and further development of the Decision I statement is required. The investigation of the CAU 309 muckpiles will assume COCs identified at similar muckpile sites are present at the CAU 309 muckpiles. To contend with the two types of analytical data inputs (i.e., historical and newly acquired data), the Decision I statement has been further broken out into three supporting decision statements.

The Decision Ia statement is:

- Are COPCs present in muck samples collected during previous muckpile investigations at levels above current PALs?

The two Decision I statements addressing newly acquired muckpile data are:

- Decision Ib statement is: Are COCs present in the samples that can be collected at CAU 309 muckpiles?

- Decision Ic statement is: Does the data acquired at CAU 309 muckpiles support the CSM, including the outputs of Decisions Ia and Ib?

Decision Ia, which only addresses historical data, can be answered by examining data from the previous muckpile investigations at the NTS. Based on the comparative evaluation of the CAU 309 muckpiles to the previously investigated muckpile in these key areas as presented in Appendix B, it was determined there is sufficient similarity in the CSMs to accept this assumption. Differences in the release scenarios (i.e., the massive containment failure) will be addressed by the collection of additional soil samples in areas most likely to be impacted. 
To answer Decision Ib (Are COCs present in CAU 309 muckpiles from areas that can be sampled?), samples will be collected from accessible portions of the CAU 309 muckpiles that are most likely to contain the highest concentrations of contaminants, and evaluated against the PALs.

To answer Decision Ic (Does the new data fit within the CSM?), the CAU 309 muckpile sample COC data will be evaluated against muckpile CSM parameters for both COC status and concentrations.

Decision I samples will be submitted to analytical laboratories for the analyses listed in Table 3-6. Decision II samples will be submitted for the analysis of all unbounded COCs. In addition, samples will be submitted for analyses as needed to support waste management or health and safety decisions.

The DQIs of precision, accuracy, representativeness, completeness, comparability, and sensitivity needed to satisfy DQO requirements are discussed in Section 6.2. Laboratory data will be assessed in the investigation report to confirm or refute the CSM and determine if the DQO data needs were met.

To satisfy the DQI of sensitivity (presented in Section 6.2.8), the analytical methods must be sufficient to detect contamination that is present in the samples at concentrations equal to the corresponding PAL concentrations. Analytical methods and minimum reporting limits (MRLs) or minimum detectable concentrations (MDCs) for each CAU 309 COPC are provided in Table 3-5 and Table 3-6. The MRL is the lowest concentration of a particular chemical parameter that can be detected in a sample within an acceptable level of error. The MDC is the lowest concentration of a particular radionuclide parameter that can be detected in a sample within an acceptable level of error. 
Table 3-6

Analytical Requirements for Chemical COPCs for CAU 309 (Page 1 of 2)

\begin{tabular}{|c|c|c|c|c|c|}
\hline Parameter/Analyte & $\begin{array}{l}\text { Medium or } \\
\text { Matrix }\end{array}$ & $\begin{array}{l}\text { Analytical } \\
\text { Method }\end{array}$ & $\begin{array}{l}\text { Minimum } \\
\text { Reporting Limit } \\
\text { (MRL) }\end{array}$ & $\begin{array}{l}\text { Laboratory } \\
\text { Precision } \\
\text { (RPD) }^{\mathrm{a}}\end{array}$ & $\begin{array}{l}\text { Percent Recovery } \\
(\% R)^{b}\end{array}$ \\
\hline \multicolumn{6}{|c|}{ ORGANICS } \\
\hline \multirow{2}{*}{$\begin{array}{l}\text { Total Volatile Organic Compounds } \\
\text { (VOCs) }\end{array}$} & Aqueous & \multirow{2}{*}{$8260 B^{C}$} & \multirow{2}{*}{$\begin{array}{l}\text { Parameter-specific } \\
\text { EQLs }\end{array}$} & \multirow{2}{*}{ Lab-specific $^{\mathrm{e}}$} & \multirow{2}{*}{ Lab-specific $^{\mathrm{e}}$} \\
\hline & Soil & & & & \\
\hline \multirow{2}{*}{$\begin{array}{l}\text { Total Semivolatile Organic } \\
\text { Compounds (SVOCs) }\end{array}$} & Aqueous & \multirow{2}{*}{$8270 C^{c}$} & \multirow{2}{*}{$\begin{array}{l}\text { Parameter-specific } \\
\text { EQLs }\end{array}$} & \multirow{2}{*}{ Lab-specific $^{\mathrm{e}}$} & \multirow{2}{*}{ Lab-specific $^{\mathrm{e}}$} \\
\hline & Soil & & & & \\
\hline \multirow{2}{*}{ Polychlorinated Biphenyls (PCBs) } & Aqueous & \multirow{2}{*}{$8082^{C}$} & \multirow{2}{*}{$\begin{array}{l}\text { Parameter-specific } \\
\text { EQLs }\end{array}$} & \multirow{2}{*}{ Lab-specific $^{e}$} & \multirow{2}{*}{ Lab-specific $^{e}$} \\
\hline & Soil & & & & \\
\hline $\begin{array}{l}\text { Total Petroleum Hydrocarbons } \\
\text { (TPH) } \\
\text { Diesel Range Organics }\end{array}$ & Soil & $\begin{array}{l}8015 B \\
\text { modified }^{C}\end{array}$ & $25 \mathrm{mg} / \mathrm{kg}^{\mathrm{g}}$ & Lab-specific $^{e}$ & Lab-specific $^{e}$ \\
\hline \multicolumn{6}{|c|}{ INORGANICS } \\
\hline \multicolumn{6}{|c|}{ Total RCRA Metals, plus Beryllium } \\
\hline \multirow{2}{*}{ Arsenic } & Aqueous & $6010 B^{C}$ & $0.01 \mathrm{mg} / \mathrm{L}^{\mathrm{g}, \mathrm{h}}$ & $20^{h}$ & \multirow{18}{*}{$\begin{array}{c}\text { Matrix Spike Recovery } \\
\text { at } \\
75-125^{\mathrm{h}}\end{array}$} \\
\hline & Soil & $6010 B^{C}$ & $1 \mathrm{mg} / \mathrm{kg}^{\mathrm{g}, \mathrm{h}}$ & $35^{\mathrm{g}}$ & \\
\hline \multirow{2}{*}{ Barium } & Aqueous & $6010 B^{C}$ & $0.20 \mathrm{mg} / \mathrm{L}^{\mathrm{g}, \mathrm{h}}$ & $20^{h}$ & \\
\hline & Soil & $6010 B^{C}$ & $20 \mathrm{mg} / \mathrm{kg}^{\mathrm{g}, \mathrm{h}}$ & $35^{\mathrm{g}}$ & \\
\hline \multirow{2}{*}{ Beryllium } & Aqueous & $6010 B^{C}$ & $0.005 \mathrm{mg} / \mathrm{L}^{\mathrm{g}, \mathrm{h}}$ & $20^{h}$ & \\
\hline & Soil & $6010 B^{C}$ & $0.5 \mathrm{mg} / \mathrm{kg}^{\mathrm{g}, \mathrm{h}}$ & $35^{\mathrm{g}}$ & \\
\hline \multirow{2}{*}{ Cadmium } & Aqueous & $6010 B^{C}$ & $0.005 \mathrm{mg} / \mathrm{L}^{\mathrm{g}, \mathrm{h}}$ & $20^{h}$ & \\
\hline & Soil & $6010 B^{C}$ & $0.5 \mathrm{mg} / \mathrm{L}^{\mathrm{g}, \mathrm{h}}$ & $35^{\mathrm{g}}$ & \\
\hline \multirow{2}{*}{ Chromium } & Aqueous & $6010 B^{C}$ & $0.01 \mathrm{mg} / \mathrm{L}^{\mathrm{g}, \mathrm{h}}$ & $20^{h}$ & \\
\hline & Soil & $6010 B^{C}$ & $1 \mathrm{mg} / \mathrm{kg}^{\mathrm{g}, \mathrm{h}}$ & $35^{\mathrm{g}}$ & \\
\hline \multirow{2}{*}{ Lead } & Aqueous & $6010 B^{C}$ & $0.003 \mathrm{mg} / \mathrm{L}^{\mathrm{g}, \mathrm{h}}$ & $20^{h}$ & \\
\hline & Soil & $6010 B^{C}$ & $0.3 \mathrm{mg} / \mathrm{kg}^{\mathrm{g}, \mathrm{h}}$ & $35^{g}$ & \\
\hline \multirow{2}{*}{ Mercury } & Aqueous & $7470 A^{C}$ & $0.0002 \mathrm{mg} / \mathrm{L}^{\mathrm{g}, \mathrm{h}}$ & $20^{h}$ & \\
\hline & Soil & $7471 A^{C}$ & $0.1 \mathrm{mg} / \mathrm{kg}^{\mathrm{g}, \mathrm{h}}$ & $35^{\mathrm{g}}$ & \\
\hline \multirow{2}{*}{ Selenium } & Aqueous & $6010 B^{C}$ & $0.005 \mathrm{mg} / \mathrm{L}^{\mathrm{g}, \mathrm{h}}$ & $20^{h}$ & \\
\hline & Soil & $6010 B^{C}$ & $0.5 \mathrm{mg} / \mathrm{kg}^{\mathrm{g}, \mathrm{h}}$ & $35^{\mathrm{g}}$ & \\
\hline \multirow{2}{*}{ Silver } & Aqueous & $6010 B^{C}$ & $0.01 \mathrm{mg} / \mathrm{L}^{\mathrm{g}, \mathrm{h}}$ & $20^{h}$ & \\
\hline & Soil & $6010 B^{C}$ & $1 \mathrm{mg} / \mathrm{kg}^{\mathrm{g}, \mathrm{h}}$ & $35^{\mathrm{g}}$ & \\
\hline
\end{tabular}

*Footnotes:

1. See Table 3-5 for the analytical requirements for radionuclides. 


\title{
Table 3-6 \\ Analytical Requirements for Chemical COPCs for CAU 309 (Page 2 of 2)
}

\author{
${ }^{a}$ Relative percent difference (RPD) is used to calculate precision. Precision is estimated from the RPD of the concentrations \\ measured for the matrix spike and matrix spike duplicate or of laboratory, or field duplicates of unspiked samples. It is calculated by: \\ $\operatorname{RPD}=100 \times\left\{\left(\left|A_{1}-A_{2}\right|\right) /\left[\left(A_{1}+A_{2}\right) / 2\right]\right\}$, where $A_{1}=$ Concentration of the parameter in the initial sample aliquot, $A_{2}=$ Concentration of the \\ parameter in the duplicate sample aliquot. \\ ${ }^{b}$ The $\% R$ is used to calculate accuracy. Accuracy is assessed from the recovery of parameters spiked into a blank or sample matrix \\ of interest, or from the recovery of surrogate compounds spiked into each sample. The recovery of each spiked parameter is \\ calculated by: $\% R=100 \times\left(A_{s}-A_{u} / A_{n}\right)$, where $A_{s}=$ Concentration of the parameter in the spiked sample, $A_{u}=$ Concentration of the \\ parameter in the unspiked sample, $A_{n}=$ Concentration increase that should result from spiking the sample. \\ ${ }^{c}$ EPA Test Methods for Evaluating Solid Waste Physical/Chemical Methods, 3rd Edition, Parts 1-4, (SW-846) CD ROM, Washington, \\ DC (EPA,1996). \\ ${ }^{d}$ Estimated Quantitation Limit as given in SW-846 (EPA, 1996). \\ ${ }^{\mathrm{e}}$ In-House Generated RPD and \%R Performance Criteria. It is necessary for laboratories to develop in-house performance criteria \\ and compare them to those in the methods. The laboratory begins by analyzing 15 to 20 samples of each matrix and calculating the \\ mean $\% \mathrm{R}$ for each parameter. The standard deviation (SD) of each \%R is then calculated, and the warning and control limits for each \\ parameter are established at $\pm 2 \mathrm{SD}$ and $\pm 3 \mathrm{SD}$ from the mean, respectively. If the warning limit is exceeded during the analysis of \\ any sample delivery group (SDG), the laboratory institutes corrective action to bring the analytical system back into control. If the \\ control limit is exceeded, the sample results for that SDG are considered unacceptable. These limits are reviewed after every quarter \\ and are updated when necessary. The laboratory tracks trends in both performance and control limits by the use of control charts. \\ The laboratory's compliance with these requirements is confirmed as part of an annual laboratory audit. Similar procedures are \\ followed in order to generate acceptance criteria for precision measurements. \\ ${ }^{f}$ EPA Contract Laboratory Program (CLP) Statement of Work for Organic Analysis (EPA, 1988b; 1991; and 1994b) \\ ${ }^{g}$ Industrial Sites Quality Assurance Project Plan (NNSA/NV, 2002) \\ ${ }^{\mathrm{h}}$ EPA Contract Laboratory Program Statement of Work for Inorganic Analysis (EPA, 1988a; 1994a; and 1995) \\ Definitions: \\ EQLs = Estimated quantitation limits \\ $\mathrm{mg} / \mathrm{L}=$ Milligrams per liter \\ $\mathrm{mg} / \mathrm{kg}=$ Milligrams per kilogram \\ $\mathrm{NA}=$ Not applicable \\ RPD = Relative percent difference \\ $\% \mathrm{R}=$ Percent recovery
}




\subsection{Field Investigation}

This section contains a description of the activities to be conducted to gather and document information from the CAU 309 field investigation.

\subsection{Technical Approach}

The information necessary to satisfy the DQO data needs will be generated for each CAU 309 CAS by collecting and analyzing samples generated during a field investigation. The presence and nature of contamination at each CAS will be evaluated by collecting samples at biased locations that are determined to be most probable to contain COCs if they are present anywhere within the CAS. These locations will be determined based on their identification using the biasing factors listed in Section A.5.3.1 of Appendix A. If while defining the nature of contamination it is determined that COCs are present at a CAS, that CAS will be further addressed by determining the extent of contamination before evaluating corrective action alternatives.

Sample locations may be modified based on site conditions, obvious debris or staining of soils, field-screening results, or professional judgement. The Task Manager or Site Supervisor has the discretion to modify the biased locations if the modified locations meet the DQO decision needs and criteria stipulated in Appendix A.

The scope of CAU 309 is to determine the nature and extent of contamination associated with the releases described in the CAU 309 CSM (i.e., release of contaminants to the environment by placement on the muckpile, erosion of the muckpile, and/or the containment failure of $\mathrm{J}$ - and K-Tunnels). Generally, contamination identified in the valley below the I-, J-, and K-Tunnel portals is assumed to be from one of these sources except for contamination associated with the T-Tunnel Muckpile and Ponds as described in the CADDs for CAU 476, Area 12 T-Tunnel Muckpile and CAU 478, Area 12 T-Tunnel Ponds. However, if contamination can be identified as coming from a source outside CAU 309, such as fallout from atmospheric testing, the extent of such contamination may not be investigated as part of CAU 309. Such a determination may be difficult to make; however, identification of contaminants in background locations and/or the identification of increasing concentrations of contaminants with increasing distance from CAU 309 may indicate 
contamination from a release outside the scope of CAU 309. If contamination is discovered that is outside the spatial boundaries of CAU 309 or is believed to be outside the scope of the CAU 309 CSM, the situation will be reviewed and a recommendation will be made as to how best to proceed (e.g., revise the CSM or create a new CAS). In such cases, NDEP and NNSA/NSO will be notified and given the opportunity to comment on, or concur with, the recommendation.

Modifications to the investigative strategy may be required should unexpected field conditions be encountered at any CAS. Significant modifications shall be justified and documented on a Record of Technical Change (ROTC) prior to implementation. If an unexpected condition indicates that conditions are significantly different than the corresponding CSM, the activity will be rescoped and the identified decision makers will be notified.

\subsection{Field Activities}

Field activities at CAU 309 include site preparation, sample location selection, and sample collection activities.

\subsubsection{Site Preparation Activities}

Site preparation will be conducted by the NTS Management and Operating (M\&O) Contractor prior to the investigation. Site preparation may include, but not be limited to: relocation or removal of surface debris, equipment, and structures; the construction of hazardous waste accumulation areas (HWAAs) and site exclusion zones; providing sanitary facilities; and the construction of decontamination facilities.

Prior to mobilization for collecting investigation samples, the following preparatory activities will also be conducted:

- Perform surface radiological surveys (e.g., walk-over and/or fly-over).

- Perform visual surveys at all CASs within CAU 309 to identify any staining, discoloration, disturbance of native soils, or any other indication of potential contamination. 


\subsubsection{Sample Location Selection}

Biasing factors (including field-screening results [FSRs]) will be used to select the most appropriate samples from a particular location for submittal to the analytical laboratory. Biasing factors to be used for selection of sampling locations are listed in Section A.5.3.1 of Appendix A.

As biasing factors are identified and used for selection of sampling locations, they will be documented in the appropriate field documents. The CAS-specific sampling strategy and the estimated locations of biased samples for each CAS are presented in Appendix A.

\subsubsection{Sample Collection}

The CAU 309 sampling program will consist of the following activities:

- Collect and analyze samples from locations as described in this section and Section A.9.0.

- Collect required QC samples.

- Collect waste management samples, as necessary.

- Collect soil samples from background locations, if necessary.

- Perform radiological characterization surveys of construction materials and debris as necessary for disposal purposes, as needed

- Record sample location coordinates using GPS technology.

Decision I surface soil samples ( 0 to 2 in. bgs in fallout plume and 0 to 6 in. bgs in muckpiles) will be collected from selected locations based on the CSM, biasing factors, FSRs, and existing data. Deeper bounding samples ( 1 to $3 \mathrm{ft}$ bgs) will be collected at several locations in the fallout plume to confirm contaminants are not migrating vertically. Deeper samples will also be collected in the muckpiles to the maximum depth of hand sampling techniques (i.e., approximately 4 to $5 \mathrm{ft}$ bgs) or until a clean sample is obtained. Decision I subsurface soil samples will be collected at depth intervals selected by the Task Manager or Site Supervisor based on biasing factors to a depth where the biasing factors are no longer present.

Decision II sampling will consist of further defining the extent of contamination where COCs have been confirmed. Step-out (Decision II) sampling locations at each CAS will be selected based on the 
CSM, biasing factors, FSRs, existing data, and the outer boundary sample locations where COCs were detected. In general, step-out sample locations will be arranged in a triangular pattern around areas containing a COC at distances based on site conditions, COC concentrations, process knowledge, and biasing factors. If COCs extend beyond step-out locations, additional Decision II samples will be collected from locations further from the source. If a spatial boundary is reached, the CSM is shown to be inadequate, or the Site Supervisor determines that extent sampling needs to be re-evaluated; work will be temporarily suspended, NDEP will be notified, and the investigation strategy will be reevaluated. A minimum of one analytical result less than the action level from each lateral and vertical direction will be required to define the extent of COC contamination. The lateral and vertical extent of COCs will only be established based on validated laboratory analytical results (i.e., not field screening).

The number, location, and spacing of step-outs may be modified by the Task Manager or Site Supervisor, as warranted by site conditions. Where sampling locations are modified by the Task Manager or Site Supervisor, the justification for these modifications will be documented in the field logbook. Section 3.4 provides the analytical methods and laboratory requirements (i.e., detection limits, precision, and accuracy requirements) to be used when analyzing the COPCs. The analytical program for each CAS is presented in Table 4-1. All sampling activities and quality control requirements for field and laboratory environmental sampling will be conducted in compliance with the Industrial Sites QAPP (NNSA/NV, 2002a) and other applicable, approved procedures.

\subsection{Safety}

A current version of the Environmental Engineering Services Contractor's programmatic HASP and IS HASP will accompany the field documents. A FWP, or equivalent, will be prepared and approved prior to the field effort. As required by the DOE Integrated Safety Management System (ISMS) (DOE/NV, 1997), these documents outline the requirements for protecting the health and safety of the workers and the public, and the procedures for protecting the environment. The ISMS program requires that site personnel will reduce or eliminate the possibility of injury, illness, or accidents, and to protect the environment during all project activities. The following safety issues will be taken into consideration when evaluating the hazards and associated control procedures for field activities discussed in the IS HASP and FWP: 
Table 4-1

Analytical Programa

\begin{tabular}{|c|c|c|c|}
\hline Analyses $^{b}$ & 12-06-09 & 12-08-02 & 12-28-01 \\
\hline \multicolumn{4}{|c|}{ Organic COPCs } \\
\hline Total Petroleum Hydrocarbons (Diesel-Range Organics) & $\mathrm{X}$ & $\mathrm{X}$ & $\mathrm{NA}$ \\
\hline Polychlorinated Biphenyls & $\mathrm{X}$ & $\mathrm{X}$ & NA \\
\hline Semivolatile Organic Compounds ${ }^{\mathrm{C}}$ & $\mathrm{X}$ & $\mathrm{X}$ & NA \\
\hline Volatile Organic Compounds ${ }^{c}$ & $\mathrm{x}$ & $\mathrm{x}$ & NA \\
\hline \multicolumn{4}{|c|}{ Inorganic COPCs } \\
\hline RCRA Metals $^{\mathrm{C}}$ & $\mathrm{X}$ & $\mathrm{X}$ & NA \\
\hline \multicolumn{4}{|c|}{ Radionuclide COPCs } \\
\hline Gamma Spectrometry & $\mathrm{X}$ & $\mathrm{X}$ & $\mathrm{X}$ \\
\hline Isotopic Uranium & $\mathrm{X}$ & $\mathrm{X}$ & $\mathrm{X}$ \\
\hline Isotopic Plutonium & $X$ & $X$ & $X$ \\
\hline Strontium-90 & $X$ & $X$ & $X$ \\
\hline
\end{tabular}

$X$ - Required analytical method, NA = Not applicable

See Tables 3-1, 3-2, and 3-3 for VOC, SVOC, PCB, metals, and radionuclide-specific compounds.

${ }^{\mathrm{a}}$ The contaminants of potential concern are the analytes reported from the analytical methods listed.

${ }^{b}$ If the volume of material is limited, prioritization of the analyses will be necessary.

'May also include Toxicity Characteristic Leaching Procedure analytes if sample is collected for waste management purposes.

- Potential hazards to site personnel and the public include, but are not limited to: radionuclides, chemicals (e.g., heavy metals, volatile organic compounds [VOCs], semivolatile organic compounds [SVOCs], and petroleum hydrocarbons), adverse and rapidly changing weather, remote location, and motor vehicle and heavy equipment operations.

- Proper training of all site personnel to recognize and mitigate the anticipated hazards.

- Work controls to reduce or eliminate the hazards including engineering controls, substitution of less hazardous materials, and use of appropriate PPE.

- Occupational exposure monitoring to prevent overexposures to hazards such as radionuclides, chemicals, and physical agents (e.g., heat, cold, and high wind).

- Radiological surveying for alpha/beta and gamma emitters to minimize and/or control personnel exposures; use of the "as-low-as-reasonably-achievable" principle when addressing radiological hazards. 
- Emergency and contingency planning to include medical care and evacuation, decontamination, spill control measures, and appropriate notification of project management. The same principles apply to emergency communications.

- If potential asbestos containing material is identified (CFR, 2003c; NAC, 2002d), it will be inspected and/or samples collected by trained personnel. 


\subsection{Waste Management}

Management of IDW will be based on regulatory requirements, field observations, process knowledge, and laboratory results from CAU 309 investigation samples.

Disposable sampling equipment, PPE, and rinsate are considered potentially contaminated waste only by virtue of contact with potentially contaminated media (e.g., soil) or potentially contaminated debris (e.g., construction materials). Therefore, sampling and analysis of IDW, separate from analyses of site investigation samples, may not be necessary for all IDW. However, if associated investigation samples are found to contain contaminants above regulatory levels, direct samples of IDW may be taken to support waste characterization.

Sanitary, hazardous, radioactive, and/or mixed waste, if generated, will be managed and disposed of in accordance with DOE Orders, U.S. Department of Transportation (DOT) regulations, state and federal regulations, and agreements and permits between DOE and NDEP.

\subsection{Waste Minimization}

Investigation activities are planned to minimize IDW generation. This will be accomplished by incorporating the use of process knowledge, visual examination, and/or radiological survey and swipe results. When possible, disturbed media (such as soil removed during hand augering) or debris will be returned to its original location. Contained media (e.g., soil managed as waste) as well as other IDW will be segregated to the greatest extent possible to minimize generation of hazardous, radioactive, or mixed waste. Hazardous material used at the sites will be controlled in order to limit unnecessary generation of hazardous or mixed waste. Administrative controls, including decontamination procedures and waste characterization strategies, will minimize waste generated during investigations.

\subsection{Potential Waste Streams}

Waste generated during the investigation activities will include the following potential waste streams:

- $\quad$ PPE and disposable sampling equipment (e.g., plastic, paper, sample containers, aluminum foil, spoons, bowls) 
- Decontamination rinsate

- Environmental media (e.g., soil)

- Surface debris in investigation area (e.g., potential lead brick)

- $\quad$ Field-screening waste (e.g., spent solvent, disposable sampling equipment, and/or PPE contaminated by field-screening activities)

\subsection{Investigation-Derived Waste Management}

The on-site management and ultimate disposition of IDW will be determined based on a determination of the waste type (e.g., sanitary, low-level, hazardous, hydrocarbon, mixed), or the combination of waste types. A determination of the waste type will be guided by several factors, including, but not limited to: the analytical results of samples either directly or indirectly associated with the waste, historical site knowledge, knowledge of the waste generation process, field observations, field-monitoring/screening results, and/or radiological survey/swipe results.

Table 4-2 of the NV/YMP RadCon Manual (DOE/NV, 2000) shall be used to determine if such materials may be released to uncontrolled areas. On-site IDW management requirements by waste type are detailed in the following sections. Applicable waste management regulations and requirements are listed in Table 5-1.

\subsubsection{Sanitary Waste}

Sanitary IDW generated during the investigation of CAU 309 will be collected and disposed in accordance with the permits for operation of the sanitary landfills at the NTS.

\subsubsection{Special Sanitary Waste}

Hydrocarbon waste containing more than $100 \mathrm{mg} / \mathrm{kg}$ of TPH will be managed on site in a drum or other appropriate container until fully characterized. Hydrocarbon waste may be disposed of at a designated hydrocarbon landfill (NDEP, 1997b), an appropriate hydrocarbon waste management facility (e.g., recycling facility), or other method in accordance with State of Nevada regulations. 
Table 5-1

Waste Management Regulations and Requirements

\begin{tabular}{|c|c|c|}
\hline Waste Type & Federal Regulation & Additional Requirements \\
\hline Solid (nonhazardous) & NA & $\begin{array}{c}\text { NRS }^{\mathrm{a}} 444.440-444.620 \\
\text { NAC }^{\mathrm{b}} 444.570-444.7499 \\
\text { NTS Landfill Permit SW13.097.04 } \\
\text { NTS Landfill Permit SW13.097.03 }\end{array}$ \\
\hline Liquid/Rinsate (nonhazardous) & NA & $\begin{array}{l}\text { Water Pollution Control General Permit } \\
\text { GNEV93001, Rev. 3iii }\end{array}$ \\
\hline Hazardous & $\begin{array}{c}\text { RCRA }^{f} \\
40 \text { CFR } 260-282\end{array}$ & $\begin{array}{c}\text { NRS }^{a} 459.400-459.600 \\
\text { NAC }^{b} 444.850-444.8746 \\
\text { POC }^{g}\end{array}$ \\
\hline Low-Level Radioactive & NA & DOE Orders and NTSWAC ${ }^{h}$ \\
\hline Mixed & $\begin{array}{c}\text { RCRA }^{f} \\
40 \text { CFR 260-282 }\end{array}$ & $\begin{array}{l}\text { NTSWAC } \\
\text { POC }^{\mathrm{h}}\end{array}$ \\
\hline Hydrocarbon & NA & NTS Landfill Permit SW13.097.02 \\
\hline Polychlorinated Biphenyls & $\begin{array}{l}\text { TSCA }^{\mathrm{j}} \\
40 \text { CFR } 761\end{array}$ & $\begin{array}{l}\text { NRS }^{a} 459.400-459.600 \\
\text { NAC }^{b} 444.940-444.9555\end{array}$ \\
\hline Asbestos & $\begin{array}{c}\text { TSCA }^{\mathrm{j}} \\
40 \text { CFR } 763\end{array}$ & $\begin{array}{l}\text { NRS }^{a} 618.750-618.840 \\
\text { NAC }^{b} 444.965-444.976\end{array}$ \\
\hline
\end{tabular}

${ }^{a}$ Nevada Revised Statutes (NRS, 2003a, b, and c)

${ }^{\mathrm{b}}$ Nevada Administrative Code (NAC, 2002a, b, c, and d)

${ }^{\mathrm{C}}$ Area 23 Class II Solid Waste Disposal Site (NDEP, 1997a)

dArea 9 Class III Solid Waste Disposal Site (NDEP, 1997c)

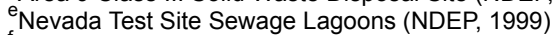

${ }_{\mathrm{f}}^{\mathrm{R}}$ Resource Conservation and Recovery Act (CFR, 2003a)

${ }^{9}$ Nevada Test Site Performance Objective for the Certification of Nonradioactive Hazardous Waste (BN, 1995)

${ }^{\mathrm{h}}$ Nevada Test Site Waste Acceptance Criteria, Revision 5 (NNSA/NSO, 2003)

'Area 6 Class III Solid Waste Disposal Site for hydrocarbon waste (NDEP, 1997b)

${ }^{\mathrm{j}}$ Toxic Substance Control Act (CFR, 2003b, and c)

CFR $=$ Code of Federal Regulations

$\mathrm{DOE}=$ U.S. Department of Energy

NA $=$ Not applicable

NAC $=$ Nevada Administrative Code

NDEP $=$ Nevada Division of Environmental Protection

NRS = Nevada Revised Statutes

NTS $=$ Nevada Test Site

NTSWAC $=$ Nevada Test Site Waste Acceptance Criteria

$\mathrm{POC}=$ Nevada Test Site Performance Objective for the Certification of Nonradioactive Hazardous Waste

$\mathrm{RCRA}=$ Resource Conservation and Recovery Act

TSCA = Toxic Substance Control Act 
Regulated asbestos-containing materials (ACM) that may be encountered or generated during this investigation will be managed and disposed of in accordance with appropriate federal (CFR, 2003c) and State of Nevada (NAC, 2002d) regulations.

Materials that are thought to potentially contain the hantavirus will be managed and disposed of in accordance with appropriate health and safety procedures.

\subsubsection{Hazardous Waste}

The CAU will have waste accumulation areas established according to the needs of the project. Satellite accumulation areas (SAAs) and HWAAs will be managed consistent with the requirements of federal and state regulations (CFR, 2003a; NAC, 2002b). The HWAAs will be properly controlled for access and will be equipped with spill kits and appropriate spill containment. Suspected hazardous wastes will be placed in DOT-compliant containers. All containerized waste will be handled, inspected, and managed in accordance with Title 40 CFR 265 Subpart I (CFR, 2003a). These provisions include managing the waste in containers compatible with the waste type, and segregating incompatible waste types so that in the event of a spill, leak, or release, incompatible wastes shall not contact one another. The HWAAs will be covered under a site-specific emergency response and contingency action plan until such time that the waste is determined to be nonhazardous or all containers of hazardous waste have been removed from the storage area. Hazardous waste will be characterized in accordance with the requirement of Title 40 CFR 261. The RCRA-"listed" waste has not been identified at CAU 309. Any waste determined to be hazardous will be managed and transported in accordance with RCRA and DOT requirements to a permitted treatment, storage, and disposal facility (CFR, 2003a). Analyses that may be required for the disposal of IDW and respective regulatory levels are identified in Table 3-6.

\subsubsection{Management of Personal Protective Equipment}

The PPE and disposable sampling equipment will be visually inspected for stains, discoloration, and gross contamination as the waste is generated, and also evaluated for radiological contamination. Staining and/discoloration will be assumed to be the result of contact with potentially contaminated media such as soil, sludge, or liquid. Gross contamination is the visible contamination of an item (e.g., clumps of soil/sludge on a sampling spoon or free liquid smeared on a glove). While gross 
contamination can often be removed through decontamination methods, removal of gross contamination from small items, such as gloves or booties is not typically conducted. Any IDW that meets this description will be segregated and managed as potentially "characteristic" hazardous waste. This segregated population of waste will either be: (1) assigned the characterization of the soil/sludge that was sampled, (2) sampled directly, or (3) undergo further evaluation using the soil/sludge sample results to determine how much soil/sludge would need to be present in the waste to exceed regulatory levels. Waste that is determined to be hazardous will be entered into an approved waste management system, where it will be managed and dispositioned according to RCRA requirements or subject to agreements between NNSA/NSO and the State of Nevada. The PPE and equipment that is not visibly stained, discolored, or grossly contaminated will be managed as nonhazardous sanitary waste.

\subsubsection{Management of Decontamination Rinsate}

Rinsate at CAU 309 will not be considered hazardous waste unless there is evidence that the rinsate may display a RCRA characteristic. Evidence may include such things as the presence of a visible sheen, $\mathrm{pH}$, or association with equipment/materials used to respond to a release/spill of a hazardous waste/substance. Decontamination rinsate that is potentially hazardous (using associated sample results and/or process knowledge) will be managed as "characteristic" hazardous waste (CFR, 2003a). The regulatory status of the potentially hazardous rinsate will be determined through the application of associated sample results or through direct sampling. If determined to be hazardous, the rinsate will be entered into an approved waste management system, where it will be managed and dispositioned according to RCRA requirements or subject to agreements between NNSA/NSO and the State of Nevada. If the associated samples do not indicate the presence of hazardous constituents, then the rinsate will be considered to be nonhazardous.

The disposal of nonhazardous rinsate will be consistent with guidance established in current NNSA/NSO Fluid Management Plans for the NTS as follows:

- Rinsate that is determined to be nonhazardous and contaminated to less than 5x Safe Drinking Water Standards (SDWS) is not restricted as to disposal. Nonhazardous rinsate which is contaminated at $5 \mathrm{x}$ to $10 \mathrm{x}$ SDWS will be disposed of in an established infiltration basin or solidified and disposed of as sanitary waste or low-level waste in accordance with the respective sections of this document. 
- Nonhazardous rinsate which is contaminated at greater than 10x SDWS will be disposed of in a lined basin or solidified and disposed of as sanitary waste or low-level waste in accordance with the respective sections of this document.

\subsubsection{Management of Muck and Soil}

This waste stream consists of soil/muck produced during soil sampling, excavation, and/or drilling. This waste stream is considered to have the same COPCs as the material remaining in the ground. The preferred method for managing this material is to place the material back into the borehole/excavation in the same approximate location from which it originated. If this cannot be accomplished, the material will either be managed on site by berming and covering next to the excavation, or by placement in a container(s). The disposal of soil may be deferred until implementation of corrective action at the site.

\subsubsection{Management of Debris}

This waste stream can vary depending on site conditions. Debris that requires removal for the investigation activities (soil sampling, excavation, and/or drilling) must be characterized for proper management and disposition. Historical site knowledge, knowledge of the waste generation process, field observations, field-monitoring/screening results, radiological survey/swipe results and/or the analytical results of samples either directly or indirectly associated with the waste will be used to characterized the debris. Debris will be visually inspected for stains, discoloration, and gross contamination. Debris may be deemed reusable, recyclable, sanitary waste, hazardous waste, PCB waste, mixed waste, or low-level waste. Waste that is not sanitary will be entered into an approved waste management system, where it will be managed and dispositioned according to federal, state requirements, and agreements between NNSA/NSO and the State of Nevada. The debris will either be managed on site by berming and covering next to the excavation, by placement in a container(s), or left on the footprint of the CAS and its disposition deferred until implementation of corrective action at the site.

\subsubsection{Field-Screening Waste}

The use of field test kits and/or instruments may result in the generation of small quantities of hazardous wastes. If hazardous waste is produced by field screening, it will be segregated from other 
IDW and managed in accordance with the hazardous waste regulations (CFR, 2003a). On radiological sites, this may increase the potential to generate mixed waste; however, the generation of a mixed waste will be minimized as much as practicable. In the event a mixed waste is generated, the waste will be managed in accordance with Section 5.3.11 of this document.

\subsubsection{Polychlorinated Biphenyls}

The management of PCBs is governed by the Toxic Substances Control Act (TSCA) (USC, 1976) and its implementing regulations at 40 CFR 761 (CFR, 2003b). Polychlorinated biphenyls contamination may be found as a sole contaminant or in combination with any of the types of waste discussed in this document. For example, PCBs may be a co-contaminant in soil that contains a RCRA "characteristic" waste (PCB/hazardous waste), or in soil that contains radioactive wastes (PCB/radioactive waste), or even in mixed waste (PCB/radioactive/hazardous waste). The IDW will initially be evaluated using analytical results for media samples from the investigation. If any type of PCB waste is generated, it will be managed according to 40 CFR 761 (CFR, 2003b) as well as State of Nevada requirements, (NAC, 2002c) guidance, and agreements with NNSA/NSO.

\subsubsection{Low-Level Waste}

Radiological swipe surveys and/or direct-scan surveys may be conducted on reusable sampling equipment and the PPE and disposable sampling equipment waste streams exiting a radiologically controlled area. This allows for the immediate segregation of radioactive waste from waste that may be unrestricted regarding radiological release. Removable contamination limits, as defined in Table 4-2 of the current version of the NV/YMP RadCon Manual (DOE/NV, 2000), will be used to determine if such waste may be declared unrestricted regarding radiological release versus being declared radioactive waste. Direct sampling of the waste may be conducted to aid in determining if a particular waste unit (e.g., drum of soil) contains low-level radioactive waste, as necessary. Waste that is determined to be below the values of Table 4-2 of the NV/YMP RadCon Manual (DOE/NV, 2000) by either direct radiological survey/swipe results or through process knowledge, will not be managed as potential radioactive waste but will be managed in accordance with the appropriate section of this document. Wastes in excess of Table 4-2 values will be managed as potential radioactive waste and be managed in accordance with this section and any other applicable sections of this document. 
Low-level radioactive waste, if generated, will be managed in accordance with the contractor-specific waste certification program plan, DOE Orders, and the requirements of the current version of the Nevada Test Site Waste Acceptance Criteria (NTSWAC) (NNSA/NSO, 2003). Potential radioactive waste drums containing soil, PPE, disposable sampling equipment, and/or rinsate may be staged at a designated radioactive materials area (RMA) or radiologically controlled area when full or at the end of an investigation phase. The waste drums will remain at the RMA pending certification and disposal under NTSWAC requirements (NNSA/NSO, 2003).

\subsubsection{Mixed Waste}

Mixed waste, if generated, shall be managed and dispositioned according to the requirements of RCRA (CFR, 2003a) or subject to agreements between NNSA/NSO and the State of Nevada, as well as DOE requirements for radioactive waste. Suspect mixed waste will be marked with the words "Hazardous Waste Pending Analysis and Radioactive Waste Pending Analysis" until such time as the waste is fully characterized. Waste characterized as mixed will not be stored for a period of time that exceeds the requirements of RCRA unless subject to agreements between NNSA/NSO and the State of Nevada. The mixed waste shall be transported via an approved hazardous waste/radioactive waste transporter to the NTS transuranic waste storage pad for storage pending treatment or disposal.

Mixed waste with hazardous waste constituent concentrations below land disposal restrictions may be disposed of at the NTS Area 5 Radioactive Waste Management Site (RWMS) if the waste meets the requirements of the NTSWAC (NNSA/NSO, 2003). Mixed waste not meeting land disposal restrictions will require development of a treatment and disposal plan under the requirements of the Mutual Consent Agreement between DOE and the State of Nevada (NDEP, 1995). 


\subsection{Quality Assurance/Quality Control}

The overall objective of the characterization activities described in this CAIP is to collect accurate and defensible data to support the selection and implementation of a closure alternative for each CAS in CAU 309. Section 6.1 and Section 6.2 discuss the collection of required QC samples in the field and QA requirements for laboratory/analytical data to achieve closure. Unless otherwise stated in this CAIP or required by the results of the DQO process (see Appendix A), this investigation will adhere to the Industrial Sites QAPP (NNSA/NV, 2002).

\subsection{Quality Control Field Sampling Activities}

Field QC samples will be collected in accordance with established procedures. Field QC samples are collected and analyzed to aid in determining the validity of environmental sample results. The number of required QC samples depends on the types and number of environmental samples collected. The minimum frequency of collecting and analyzing QC samples for this investigation, as determined in the DQO process, include:

- Trip blanks (one per sample cooler containing VOC environmental samples)

- Equipment rinsate blanks (one per sampling event for each type of decontamination procedure)

- Field duplicates (1 per CAS per matrix for environmental samples)

- Field blanks (minimum of 1 per CAS depending on site conditions)

- Laboratory QC samples (1 per 20 environmental samples or 1 per CAS per matrix, if less than 20 collected)

Additional QC samples may be submitted based on site conditions at the discretion of the Task Manager or Site Supervisor. Field QC samples shall be analyzed using the same analytical procedures implemented for associated environmental samples. Additional details regarding field QC samples are available in the Industrial Sites QAPP (NNSA/NV, 2002). 


\subsection{Laboratory/Analytical Quality Assurance}

Criteria for the investigation, as stated in the DQOs (Appendix A) and except where noted, require laboratory analytical quality data be used for making critical decisions. Rigorous QA/QC will be implemented for all laboratory samples including documentation, data verification and validation of analytical results, and an assessment of data quality indicators (DQIs) as they relate to laboratory analysis.

\subsubsection{Data Validation}

Data verification and validation will be performed in accordance with the Industrial Sites QAPP (NNSA/NV, 2002a), except where otherwise stipulated in this CAIP. All chemical laboratory data from samples collected and analyzed will be evaluated for data quality according to EPA Functional Guidelines (EPA, 1999 and 2004). Radiological laboratory data from samples that are collected and analyzed will be evaluated for data quality according to contractor-specific procedures. The data will be reviewed to ensure that all suspected samples were appropriately collected, analyzed, and the results passed data validation criteria. Validated data, including estimated data (i.e., J-qualified), will be assessed to determine if they meet the DQO requirements of the investigation and the performance criteria for the DQIs. The results of this assessment will be documented in the CADD. If the DQOs were not met, corrective actions will be evaluated, selected, and implemented (e.g., refine CSM or resample to fill data gaps).

\subsubsection{Data Quality Indicators}

The DQIs are qualitative and quantitative descriptors used in interpreting the degree of acceptability or utility of data. Data quality indicators are used to evaluate the entire measurement system and laboratory measurement processes (i.e., analytical method performance) as well as to evaluate individual analytical results (i.e., parameter performance). The quality and usability of data used to make DQO decisions will be assessed based on the following DQIs:

- Precision

- Accuracy/bias

- Representativeness

- Comparability 
- Completeness

- Sensitivity.

Table 6-1 provides the established analytical method/measurement system performance criteria for each of the DQIs and the potential impacts to the decision if the criteria are not met. The following subsections discuss each of the DQIs that will be used to assess the quality of laboratory data.

\subsubsection{Precision}

Precision is used to assess the variability between two equal samples. This is a measure of the repeatability of the analysis process from sample collection through analysis results. Precision is measured as the relative percent difference (RPD) of duplicate samples as presented in the Industrial Sites QAPP (NNSA/NV, 2002).

Determinations of precision will be made for field duplicate samples and laboratory duplicate samples. Field duplicate samples will be collected simultaneously with samples from the same source under similar conditions in separate containers. The duplicate sample will be treated independently of the original sample in order to assess field impacts and laboratory performance on precision through a comparison of results. Laboratory precision is evaluated as part of the required laboratory internal QC program to assess performance of analytical procedures. The laboratory sample duplicates are an aliquot, or subset, of a field sample generated in the laboratory. They are not a separate sample but a split, or portion, of an existing sample. Typically, laboratory duplicate QC samples include matrix spike duplicate (MSD) and laboratory control sample (LCS) duplicate samples for organic, inorganic, and radiological analyses.

Precision is a quantitative measure used to assess overall analytical method and field sampling performance as well as to assess the need to "flag" (qualify) individual parameter results when corresponding QC sample results are not within established control limits. Therefore, performance metrics have been established for both analytical methods and individual analytical results (see Table 6-1).

The RPD criteria to be used for assessment of precision for laboratory duplicates and field duplicates are the parameter-specific criteria listed in Table 3-6. The RPD values that are outside the criteria do 
Table 6-1

Laboratory and Analytical Performance Criteria for CAU 309 Data Quality Indicators

\begin{tabular}{|c|c|c|}
\hline $\begin{array}{l}\text { Data Quality } \\
\text { Indicator }\end{array}$ & Performance Criteria & $\begin{array}{l}\text { Potential Impact on Decision if } \\
\text { Performance Criteria Not Met }\end{array}$ \\
\hline Precision & $\begin{array}{l}\text { Variations between laboratory and field } \\
\text { duplicates should not exceed analytical } \\
\text { method-specific and laboratory-specific criteria } \\
\text { presented in Table 3-5 and Table 3-6. }\end{array}$ & $\begin{array}{l}\text { Data that do not meet the performance } \\
\text { criteria will not be used for decisions. } \\
\text { Decisions may not be valid if analytical } \\
\text { method performance criteria for precision } \\
\text { are not met. Evaluate the effect on } \\
\text { meeting the DQI of completeness. }\end{array}$ \\
\hline Accuracy & $\begin{array}{l}\text { Laboratory control sample, matrix spike, and } \\
\text { surrogate results should be within the } \\
\text { method-specific and laboratory-specific criteria } \\
\text { presented in Table 3-5 and Table 3-6. } \\
\text { Laboratory method blanks should be below the } \\
\text { required detection limit. }\end{array}$ & $\begin{array}{l}\text { Data that do not meet the performance } \\
\text { criteria will not be used for decisions. } \\
\text { Decisions may not be valid if analytical } \\
\text { method performance criteria for accuracy } \\
\text { are not met. Evaluate the effect on } \\
\text { meeting the DQI of completeness. }\end{array}$ \\
\hline Sensitivity & $\begin{array}{l}\text { Laboratory detection limits must be less than } \\
\text { or equal to respective PALs. }\end{array}$ & $\begin{array}{l}\text { Cannot determine if COCs are present or } \\
\text { migrating at levels of concern; therefore, } \\
\text { the affected data will be assessed for } \\
\text { usability and potential impacts on meeting } \\
\text { the DQI of completeness. }\end{array}$ \\
\hline Comparability & $\begin{array}{l}\text { Sampling, handling, preparation, analysis, } \\
\text { reporting, and data validation must be } \\
\text { performed using approved standard methods } \\
\text { and procedures. }\end{array}$ & $\begin{array}{l}\text { Inability to combine data with data } \\
\text { obtained from other sources and/or } \\
\text { inability to compare data to regulatory } \\
\text { action levels. }\end{array}$ \\
\hline Representativeness & $\begin{array}{l}\text { Decision I samples identify COCs if present } \\
\text { anywhere within the CAS. Analyses will be } \\
\text { sufficient to detect any COCs present in the } \\
\text { samples. Decision II samples identify true } \\
\text { extent of COCs. }\end{array}$ & $\begin{array}{l}\text { Analytical results will not represent true } \\
\text { site conditions. Inability to make } \\
\text { appropriate DQO decisions. }\end{array}$ \\
\hline $\begin{array}{c}\text { Nature } \\
\text { Completeness }\end{array}$ & $\begin{array}{l}80 \% \text { of the CAS-specific COPC analytes have } \\
\text { valid results. } 90 \% \text { of targeted analytes are } \\
\text { valid. }\end{array}$ & $\begin{array}{l}\text { Cannot support/defend decision on } \\
\text { whether COCs are present. }\end{array}$ \\
\hline $\begin{array}{c}\text { Extent } \\
\text { Completeness }\end{array}$ & $\begin{array}{l}100 \% \text { of targeted analytes used to define } \\
\text { extent of COCs are valid. }\end{array}$ & $\begin{array}{l}\text { Extent of contamination cannot be } \\
\text { accurately determined. }\end{array}$ \\
\hline $\begin{array}{l}\text { Clean Closure } \\
\text { Completeness }\end{array}$ & $100 \%$ of targeted analytes are valid. & Cannot determine if COCs remain in soil. \\
\hline
\end{tabular}


not necessarily result in the qualification of analytical data. It is only one factor in making an overall judgement about the quality of the reported analytical results.

\subsubsection{Accuracy}

Accuracy is determined by analyzing a reference material of known parameter concentration or by reanalyzing a sample to which a material of known concentration or amount of parameter has been added (spiked). For organic analyses, laboratory control limits are used for evaluation of percent recovery. The acceptable control limits for inorganic analyses are established in the EPA Contract Laboratory Program National Functional Guidelines for Inorganic Data Review (EPA, 1994a). Accuracy for chemical analyses will be evaluated based on results from three types of spiked samples: matrix spike (MS), LCS, and surrogates. Accuracy for radiochemical analyses will be evaluated based on results from LCS and MS samples. The LCS sample is analyzed with the field samples using the same sample preparation, reagents, and analytical methods employed for the samples. One LCS will be prepared with each batch of samples for analysis by a specific measurement.

Accuracy is a measure of the closeness of an individual measurement or the average of a number of measurements to the true value. It is used to assess the performance of laboratory measurement processes as well as to evaluate individual groups of analyses (i.e., sample delivery groups).

The criteria for chemical analyses to be used for assessment of accuracy are the parameter-specific criteria listed in Table 3-6. The percent recovery criteria for radiochemical analyses to be used for assessment of accuracy will be the control limits listed in Table 3-5.

The percent recovery parameter performance criteria for accuracy will be compared to percent recovery results of spiked samples. This will be accomplished as part of the data validation process. The percent recovery values that are outside the criteria do not necessarily result in the qualification of analytical data. It is only one factor in making an overall judgment about the quality of the reported analytical results. Factors beyond the laboratory's control, such as sample matrix effects, can cause the measured values to be outside of the established criteria. Therefore, the entire sampling and analytical process must be evaluated when determining the quality of the analytical data provided. 


\subsubsection{Representativeness}

Representativeness is the degree to which sample characteristics accurately and precisely represent a characteristics of a population or an environmental condition (EPA, 1987). Representativeness is assured by a carefully developing the sampling strategy during the DQO process such that false negative and false positive decision errors are minimized. The criteria listed in DQO Step 6 - Specify the Tolerable Limits on Decision Errors are:

- For Decision I, having a high degree of confidence that the sample locations selected will identify COCs if present anywhere within the CAS.

- Having a high degree of confidence that analyses conducted will be sufficient to detect any COCs present in the samples.

- For Decision II, having a high degree of confidence that the sample locations selected will identify the extent of COCs.

These are qualitative measures that will be used to assess measurement system performance for representativeness. The assessment of this qualitative criterion will be presented in the investigation report.

\subsubsection{Completeness}

Completeness is defined as generating sufficient data of the appropriate quality to satisfy the data needs identified in the DQOs. For judgemental sampling, completeness will be evaluated using both a quantitative measure and a qualitative assessment. The quantitative measurement to be used to evaluate completeness is presented in Table 6-1 and is based on the percentage of measurements made that are judged to be valid. The completeness goal for targeted analytes and the remaining COPCs is 100 and 80 percent, respectively. If these criteria are not achieved, the dataset will be assessed for potential impacts on making DQO decisions.

The qualitative assessment of completeness is an evaluation of the sufficiency of information available to make DQO decisions. This assessment will be based on meeting the data needs identified in the DQOs and will be presented in the investigation report. 


\subsubsection{Comparability}

Comparability is a qualitative parameter expressing the confidence with which one dataset can be compared to another (EPA, 1987). The criteria for the evaluation of comparability will be that all sampling, handling, preparation, analysis, reporting, and data validation were performed using approved standard methods and procedures. This will ensure that data from this project can be compared to regulatory action levels that were developed based on data generated using the same or comparable methods and procedures. An evaluation of comparability will be presented in the investigation report.

\subsubsection{Sensitivity}

Sensitivity is the capability of a method or instrument to discriminate between measurement responses representing different levels of the variable of interest (EPA, 2001a). The evaluation criteria for this parameter will be that measurement sensitivity (detection limits) will be less than or equal to the corresponding PALs. If this criterion is not achieved, the affected data will be assessed for usability and potential impacts on meeting site characterization objectives. This assessment will be presented in the investigation report. 


\subsection{Duration and Records Availability}

\subsection{Duration}

Table 7-1 provides a tentative duration of activities (in calendar days) for corrective action investigation activities.

Table 7-1

Tentative Activity Durations

\begin{tabular}{|c|l|}
\hline Duration (days) & \multicolumn{1}{|c|}{ Activity } \\
\hline \hline 10 & Site Preparation \\
\hline 76 & Field Work Preparation and Mobilization \\
\hline 55 & Sampling \\
\hline 160 & Data Assessment \\
\hline 180 & Waste Management \\
\hline
\end{tabular}

\subsection{Records Availability}

Historic information and documentation referenced in this plan are retained in the NNSA/NSO project files in Las Vegas, Nevada, and can be obtained through written request to the NNSA/NSO Project Manager. This document is available in the DOE public reading facilities located in Las Vegas and Carson City, Nevada, or by contacting the DOE Project Manager. The NDEP maintains the official Administrative Record for all activities conducted under the auspices of the FFACO. 


\subsection{References}

AASI, see American Aerial Surveys, Inc.

AEC, see U.S. Atomic Energy Commission.

ASTM, see American Society for Testing and Materials.

Alderson, S.L., Stoller-Navarro Joint Venture. 2004. Memorandum to B.S. Bailey (SNJV) entitled, "Preliminary Assessments Radiological Survey 2004," 17 February. Las Vegas, NV.

American Aerial Surveys, Inc. 1964. Aerial photograph N-48_A_U-OP showing the I-, J-, and K-Tunnels area, including the muckpile and CWD, 19 March. Mercury, NV: Archives and Records Center.

American Aerial Surveys, Inc. 1969. Aerial photograph N-59_001 U-OP showing the I-, J-, and K-Tunnels muckpile and CWD, 21 June. Mercury, NV: Archives and Records Center.

American Society for Testing and Materials, 1996. Section 04.08 and 04.09, "Construction," Annual Book of ASTM Standards. Philadelphia, PA.

American Society for Testing and Materials. 2000a. Standard Test Methods for Radiochemical Determination of Plutonium in Soil by Alpha Spectroscopy, C1001-00. Philadelphia, PA.

American Society for Testing and Materials. 2000b. Standard Test Methods for Strontium-90 in Water, D5811-00. Philadelphia, PA.

American Society for Testing and Materials. 2002a. Standard Test Methods for Isotopic Uranium in Water by Radiochemistry, D3972-02. Philadelphia, PA.

American Society for Testing and Materials. 2002b. Standard Test Methods for Plutonium in Water, D3865-02. Philadelphia, PA.

American Society for Testing and Materials. 2002c. Standard Test Methods for Radiochemical Determination of Uranium Isotopes in Soil by Alpha Spectroscopy, C1000-00. Philadelphia, PA.

BN, see Bechtel Nevada.

Bechtel Nevada. 1995. Nevada Test Site Performance Objective for Certification of Nonradioactive Hazardous Waste, Rev. 0, G-E11/96.01. Las Vegas, NV.

CFR, see Code of Federal Regulations. 
Code of Federal Regulations. 2003a. Title 40 CFR Parts 260-268, "Hazardous Waste Management System: General." Washington, DC: U.S. Government Printing Office.

Code of Federal Regulations. 2003b. Title 40 CFR Parts 761, "Polychlorinated Biphenyls (PCBs) Manufacturing, Processing, Distribution in Commerce, and Use Prohibitions." Washington, DC: U.S. Government Printing Office.

Code of Federal Regulations. 2003c. Title 40 CFR Part 763, “Asbestos." Washington, DC:

U.S. Government Printing Office.

DOE, see U.S. Department of Energy.

DOE/NV, see U.S. Department of Energy, Nevada Operations Office.

DRI, see Desert Research Institute.

DTRA, see Defense Threat Reduction Agency.

Defense Threat Reduction Agency. 2000. Corrective Action Decision Document for Corrective Action Unit 477: Area 12 N-Tunnel Muckpile, Nevada Test Site. Las Vegas, NV.

Defense Threat Reduction Agency. 2001. Corrective Action Decision Document for Corrective Action Unit 476: Area 12 T-Tunnel Muckpile, Nevada Test Site. Las Vegas, NV.

Defense Threat Reduction Agency. 2002. Corrective Action Decision Document for Corrective Action Unit 504: 16a-Tunnel Muckpile, Nevada Test Site. Las Vegas, NV.

Defense Threat Reduction Agency. 2003. Corrective Action Decision Document for Corrective Action Unit 482: U15a/e Tunnel Muckpiles and Ponds, Nevada Test Site. Las Vegas, NV.

Desert Research Institute. 1987. Hydrogeologic Investigations of Flow in Fractured Tuffs, Rainier Mesa, Nevada Test Site, 26 May. Prepared by C. Russell. Las Vegas, NV.

Desert Research Institute. 1988. CERCLA Preliminary Assessments of DOE's Nevada Operations Office, Nuclear Weapons Testing Areas, April. Las Vegas, NV.

Desert Research Institute. 1996. ER-12-1 Completion Report, Publication \#45120, December. Prepared for the U.S. Department of Energy, Nevada Operations Office. Las Vegas, NV.

EPA, see U.S. Environmental Protection Agency.

ERDA, see U.S. Energy Research and Development Administration.

EG\&G Rocky Flats. 1991. General Radiochemistry and Routine Analytical Services Protocol (GRASP), Version 2.1, July. Golden, CO: Environmental Management Department. 
FFACO, see Federal Facility Agreement and Consent Order.

Federal Facility Agreement and Consent Order. 1996 (as amended). Agreed to by the State of Nevada, the U.S. Department of Energy, and the U.S. Department of Defense.

GSA, see Geological Society of America.

Geological Society of America. 1968. Nevada Test Site. Boulder, CO.

Moore, J., Science Applications International Corporation. 1999. Memorandum to M. Todd (SAIC) entitled, "Background Concentrations for NTS and TTR Soil Samples," 3 February.

Las Vegas, NV.

NAC, see Nevada Administrative Code.

NBMG, see Nevada Bureau of Mines and Geology.

NCRP, see National Council on Radiation Protection and Measurements.

NDEP, see Nevada Division of Environmental Protection.

NNSA/NV, see U.S. Department of Energy, National Nuclear Security Administration Nevada Operations Office.

NNSA/NSO, see U.S. Department of Energy, National Nuclear Security Administration Nevada Site Office.

NRS, see Nevada Revised Statutes.

National Council on Radiation Protection and Measurements. 1999. Recommended Screening Limits for Contaminated Surface Soil and Review of Factors Relevant to Site-Specific Studies, Report No. 129. Washington, DC.

Nevada Administrative Code. 2002a. NAC 444.570 - 444.7499, "Solid Waste Disposal." Carson City, NV.

Nevada Administrative Code. 2002b. NAC 444.850 - 444.8746, "Disposal of Hazardous Waste." Carson City, NV.

Nevada Administrative Code. 2002c. NAC 444.940 - 444.9555, "Polychlorinated Biphenyl." Carson City, NV.

Nevada Administrative Code. 2002d. NAC 444.965 - 444.976, "Disposal of Asbestos." Carson City, NV. 
Nevada Administrative Code. 2003. NAC 445A, "Water Controls.” Carson City, NV.

Nevada Bureau of Mines and Geology. 1996. Statewide Potential Evapotranspiration Maps for Nevada, NBMG Report 48. Prepared by L. Shevenell. Reno, NV.

Nevada Bureau of Mines and Geology. 1998. Mineral and Energy Resource Assessment of the Nellis Air Force Range, Open-File Report 98-1. Reno, NV.

Nevada Division of Environmental Protection. 1995. Mutual Consent Agreement between the State of Nevada and the U.S. Department of Energy for the Storage of Low-Level Land Disposal Restricted Mixed Waste. Carson City, NV.

Nevada Division of Environmental Protection. 1997a. Class II Solid Waste Disposal Site for Municipal and Solid Waste, Area 23 of the NTS, Permit SW 13-097-04. Carson City NV.

Nevada Division of Environmental Protection. 1997b (as amended in August 2000). Class III Solid Waste Disposal Site for Hydrocarbon Burdened Soils, Area 6 of the NTS, Permit SW 1309702. Carson City, NV.

Nevada Division of Environmental Protection. 1997c (as amended in August 2000). Class III Solid Waste Disposal Site; UIOC, Area 9 of the NTS, Permit SW 13-097-03. Carson City, NV.

Nevada Division of Environmental Protection. 1999. State of Nevada Water Pollution Control General Permit, No. GNEV93001. Carson City, NV.

Nevada Revised Statutes. 2003a. NRS 444.440 - 444.620, "Collection and Disposal of Solid Waste." Carson City, NV.

Nevada Revised Statutes. 2003b. NRS 459.400 - 459.600, “Disposal of Hazardous Waste.” Carson City, NV.

Nevada Revised Statutes. 2003c. NRS 618.750-618.840 "Disposal of Hazardous Waste." Carson City, NV.

Paar, J.G., and D.R. Porterfield. 1997. Evaluation of Radiochemical Data Usability, April, ES/ER/MS-5. Oak Ridge, TN: U.S. Department of Energy.

USC, see United States Code.

USGS and DOE, see U.S. Geological Survey and U.S. Department of Energy.

USGS, see U.S. Geological Survey.

United States Code. 1976. 15 USC 2601 et seq., “Toxic Substances Control Act.” Enacted by Public Law No. 94-469, as amended. Washington, DC: U.S. Government Printing Office. 
U.S. Atomic Energy Commission. 1966. Summary Information on Releases of Radioactive Effluent to the Atmosphere from Underground Nuclear Detonations, 1961 - 1964, October.

Washington, DC.

U.S. Department of Energy. 1993. DOE Order 5400.5, Change 2, "Radiation Protection of the Public and the Environment." Washington, DC.

U.S. Department of Energy. 1997. The Procedures Manual of the Environmental Measurements Laboratory, HASL-300, 28th Ed., Vol. I. New York, NY.

U.S. Department of Energy, National Nuclear Security Administration Nevada Operations Office. 2002a. Industrial Sites Quality Assurance Project Plan, Nevada Test Site, Nevada, Rev. 3, DOE/NV--372. Las Vegas, NV.

U.S. Department of Energy, National Nuclear Security Administration Nevada Operations Office. 2002b. Underground Test Area Project Waste Management Plan, DOE/NV--343-Rev. 2. Las Vegas, NV.

U.S. Department of Energy, National Nuclear Security Administration Nevada Site Office. 2003. Nevada Test Site Waste Acceptance Criteria, DOE/NV--325, Rev. 5. Las Vegas, NV.

U.S. Department of Energy, National Nuclear Security Administration Nevada Site Office. 2004. Project Execution Plan, AMEM04-001. Las Vegas, NV.

U.S. Department of Energy, Nevada Operations Office. 1992. Remedial Investigation and Feasibility Study for the Plutonium Contaminated Soils at Nevada Test Site, Nellis Air Force Range and Tonopah Test Range, April. Las Vegas, NV.

U.S. Department of Energy, Nevada Operation Office. 1996. Final Environmental Impact Statement for the Nevada Test Site and Off-Site Locations in the State of Nevada, DOE/EIS 0243. Las Vegas, NV.

U.S. Department of Energy, Nevada Operations Office. 1997. Integrated Safety Management Policy, DOE Order NV P 450.4. Las Vegas, NV.

U.S. Department of Energy, Nevada Operations Office. 1998. Nevada Test Site Resource Management Plan, DOE/NV--518. Las Vegas, NV.

U.S. Department of Energy, Nevada Operations Office. 2000a. NV/YMP Radiological Control Manual, Rev. 4, DOE/NV/11718-079, UC-702. Prepared by A.L. Gile of Bechtel Nevada. Las Vegas, NV.

U.S. Department of Energy, Nevada Operations Office. 2000b. United States Nuclear Tests, July 1945 to September 1992, DOE/NV--209-REV 15. Las Vegas, NV. 
U.S. Energy Research and Development Administration. 1977. Final Environmental Impact Statement, Nevada Test Site, Nye County, Nevada, ERDA-1551. Washington, DC.

U.S. Environmental Protection Agency. 1987. Data Quality Objectives for Remedial Response Activities, EPA/540/G-87/003. Washington, DC.

U.S. Environmental Protection Agency. 1988a. Contract Laboratory Program Statement of Work for Inorganic Analysis, SOW No. 788, EPA/540/R-94/093. Washington, DC.

U.S. Environmental Protection Agency. 1988b. Contract Laboratory Program Statement of Work for Organic Analysis, SOW No. 2/88, EPA/540/R-94/096. Washington, DC.

U.S. Environmental Protection Agency. 1991. Contract Laboratory Program Statement of Work for Organic Analysis, OLMO 1.8, EPA/540/R-94/078. Washington, DC.

U.S. Environmental Protection Agency. 1994a. Contract Laboratory Program Statement of Work for Inorganic Analysis, ILMO 3.0, EPA/540/R-94/076. Washington, DC.

U.S. Environmental Protection Agency. 1994b. Contract Laboratory Program Statement of Work for Organic Analysis, OLMO 3.1, EPA/540/R-94/073. Washington, DC.

U.S. Environmental Protection Agency. 1995. Contract Laboratory Program Statement of Work for Inorganic Analysis, ILMO 4.0, EPA/540/R-95/121. Washington, DC.

U.S. Environmental Protection Agency. 1996. Test Method for Evaluating Solid Waste Physical/Chemical Methods, SW-846, 3rd Edition. Washington, DC.

U.S. Environmental Protection Agency. 1999. Contract Laboratory Program National Functional Guidelines for Organic Data Review, EPA 540/R-99/008. Washington, DC.

U.S. Environmental Protection Agency. 2001a. Guidance on Data Quality Indicators, EPA QA/G-5i. Washington, DC.

U.S. Environmental Protection Agency. 2004. Contract Laboratory Program National Functional Guidelines for Inorganic Data Review, EPA/540/R-04/004. Washington, DC.

U.S. Environmental Protection Agency. 2002c. Guidance on Data Quality Indicators, EPA QA/G-5i. Washington, DC.

U.S. Environmental Protection Agency. 2002d. Memorandum from S.J. Smucker to PRG table mailing list regarding Region 9 Preliminary Remediation Goals (PRGs), 1 October. San Francisco, CA.

U.S. Environmental Protection Agency. 2002e. Integrated Risk Information System (IRIS) Database. As accessed at http://www.epa.gov/iris/index.html on 16 October 2002. 
U.S. Geological Survey. 1965. Perched Ground Water in Zeolitized-Bedded Tuff, Rainier Mesa and Vicinity, Nevada Test Site, Nevada, USGS Report TEI-862. Prepared by W. Thordarson. Las Vegas, NV.

U.S. Geological Survey. 1990. Geologic Map of the Nevada Test Site, Southern Nevada, USGS Map I-2046. Denver, CO.

U.S. Geological Survey. 1996. Summary of Hydrogeological Controls on Groundwater Flow at the Nevada Test Site, Nye County, Nevada, USGS WRIR 96-4109. Prepared by R.J. Laczniak, J.C. Cole, D.A. Sawyer, and D.A. Trudeau.

U.S. Geological Survey and U.S. Department of Energy. 2003. "USGS/DOE Nevada Well ER-12-1 Site Page." As accessed at http://nevada.usgs.gov/doe_nv/area12/er-12-1.asp on 02 September.

U.S. Nuclear Regulatory Commission. 1983. Radiological Dose Assessment: A Textbook on Environmental Dose Analysis NUREG/CR-3332, ORNL-5968. Edited by J.E. Till and H.R. Meyer. Washington, DC.

Winograd, I.J., and W. Thordarson. 1975. Hydrology and Hydrochemical Framework, South-Central Great Basin, Nevada-California, with Special Reference to the Nevada Test Site, USGS Professional Paper 712-C. Denver, CO. 
Appendix A

Data Quality Objectives Process for CAU 309 


\section{A.1.0 Introduction}

The DQO process described in this appendix is a seven-step strategic systematic planning method based on the scientific method that was used to plan data collection activities and define for defining performance criteria for the field investigation of CAU 309, Area 12 Muckpiles. The DQOs are designed to ensure that the data collected will provide sufficient and reliable information to identify, evaluate, and technically defend recommended corrective actions (i.e., no further action [NFA], closure in place, or clean closure). Existing information about the nature and extent of contamination at the CASs in CAU 309 is insufficient to evaluate and select preferred corrective actions; therefore, a CAI will be conducted.

The CAU 309 investigation will be based on the DQOs presented in this appendix as developed by representatives of the NDEP and the NNSA/NSO. The seven steps of the DQO process presented in Section A.3.0 through Section A.9.0 were developed in accordance with EPA Guidance for the Data Quality Objectives Process (EPA, 2000b) and EPA Guidance for Quality Assurance Project Plans, (EPA, 2002a). The DQO process presented herein is based on the CAS-specific information presented in Section A.3.0 and the EPA Quality System Document for DQOs entitled Data Quality Objectives Process for Hazardous Waste Site Investigations, (EPA, 2000a).

The DQO process presents a judgemental sampling approach based on biasing factors. In general, the procedures used in the DQO process provide:

- A scientific basis for making inferences about a site (or portion of a site) based on environmental data or process knowledge

- A basis for defining decision performance criteria and assessing the achieved decision quality of the data collection design

- Criteria for knowing when site investigators should stop data collection (i.e., when sufficient information is available to support decisions)

- A basis for demonstrating an acceptable level of confidence in the sampling approach to generate the appropriate quantity and quality of information necessary to minimize the potential for making decision errors 


\section{A.2.0 Background Information}

The three CASs in CAU 309 are located in Area 12 of the NTS, as shown in Figure A.2-1. The CASs include:

- CAS 12-06-09, Muckpile

- CAS 12-08-02, CWD

- CAS 12-28-01, I-, J-, and K-Tunnel Debris

Corrective Action Sites 12-06-09 and 12-08-02 will be collectively referred to as muckpiles in this document because the similarities. Corrective Action Site 12-28-01 will be referred to as the fallout plume because of the extensive lateral area of debris and fallout contamination resulting from the containment failures of the J-and K-Tunnels.

The following sections (Section A.2.1 through Section A.2.2) provide a CAS description, physical setting and operational history, release information, and previous investigation results for each CAS in CAU 309.

\section{A.2.1 CAS 12-06-09, Muckpile and CAS 12-08-02, Contaminated Waste Dump}

These two muckpiles were given separate CAS designations based on a geographic separation of approximately $600 \mathrm{ft}$. However, a review of the operational history and existing radiological survey data indicates that the two CASs are expected to contain the same contaminants and exhibit the same release mechanisms. There is no reason to suspect that the two CASs contain material from different sources. For the purposes of this investigation, the two CASs that make up the muckpile and CWD will be treated as one site. The two CASs will be referred to as "muckpile" throughout this document.

Corrective Action Site 12-06-09 consists of a muckpile and debris located on the hillside in front of the I-, J-, and K-Tunnels on the eastern slopes of Rainier Mesa in Area 12. The muckpile includes mining debris (muck) and debris generated during the excavation and construction of the I-, J-, and K-Tunnels. The muckpile also includes reentry mining debris produced during nuclear tests, and possibly includes radioactively contaminated muck. Debris on the muckpile consists of scattered wood, twisted and rusted metal, cables, railroad tracks, and pipes. The top of the muckpile is surrounded by a two-strand, yellow fence, which is posted with "Underground Radioactive Material" 


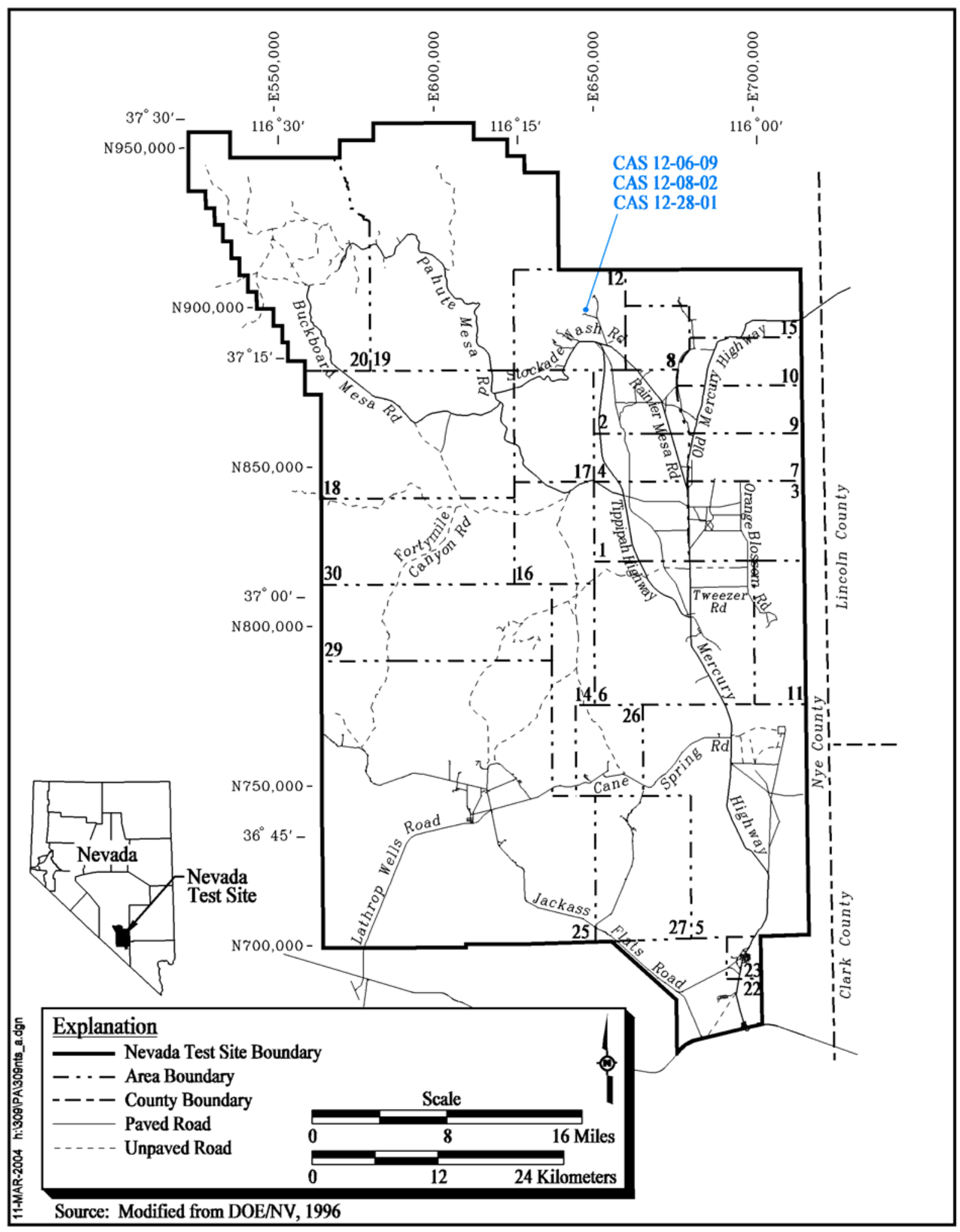

Figure A.2-1

CAU 309, CAS Location Map 
signs. The areas around the portals and additional structures are fenced with three-strand yellow fences and posted with "Caution Contamination Area" signs. Debris within these posted areas is also included in the scope of CAS 12-06-09 and consists of wood, beams, twisted and rusted metal, cables, wooden pallets, wooden tunnel supports, and metal pipes.

Corrective Action Site 12-08-02, CWD, consists of a muckpile and debris and is located on the hillside southeast of the front of the re-entry tunnel for K-Tunnel. During re-entry mining operations, potentially contaminated muck was removed from the tunnel and deposited on the muckpile. Debris on the CWD consists of rusted and twisted metal, wood, cables, a lighting fixture, and railroad tracks still attached to their wooden supports. It is likely that debris may be buried. The CWD is posted, "Caution Contamination Area." The signs are faded and some of them have fallen off the yellow, three-strand fence surrounding the muckpile. Debris is also located off the muckpile, close to the mountainside and K-Tunnel re-entry tunnel. Included in this debris is a wooden, handmade outhouse that is tipped on its side. The collection reservoir consists of a 55-gal drum. The drum appears empty and there is no staining visible beneath the drum. The scope of this investigation does not include the areas within the tunnel portals and/or support areas. The muckpiles of the CASs are delineated in Figure A.2-2.

\section{Physical Setting and Operational History}

The two muckpiles were first identified in the 1991 Reynolds Electrical \& Engineering Co., Inc. (REECo) document entitled Nevada Test Site Inventory of Inactive and Abandoned Facilities and Waste Sites (REECo, 1991). The muckpiles are located along a hillside and extend from west of J-Tunnel, to east of K-Tunnel on the eastern slopes of Rainier Mesa in Area 12. The steep slopes of the natural terrain upon which the muckpiles and access road are built present challenging conditions for site investigation. Mining debris was generated during I-, J-, and K-Tunnel activities such as drilling, tunnel development, cutback, and re-entry operations. The two muckpiles show signs of erosion. Vegetation on the muckpiles is sparse compared to the surrounding area.

Soil within the CWD is medium to fine rock and pebbles, with scattered areas of fine, soft silt. From a distance, the soil in the CWD appears to have a greenish tint. Vegetation in the CWD is scattered, with a larger group of vegetation at the top of the CWD. No staining or odors were observed. The 


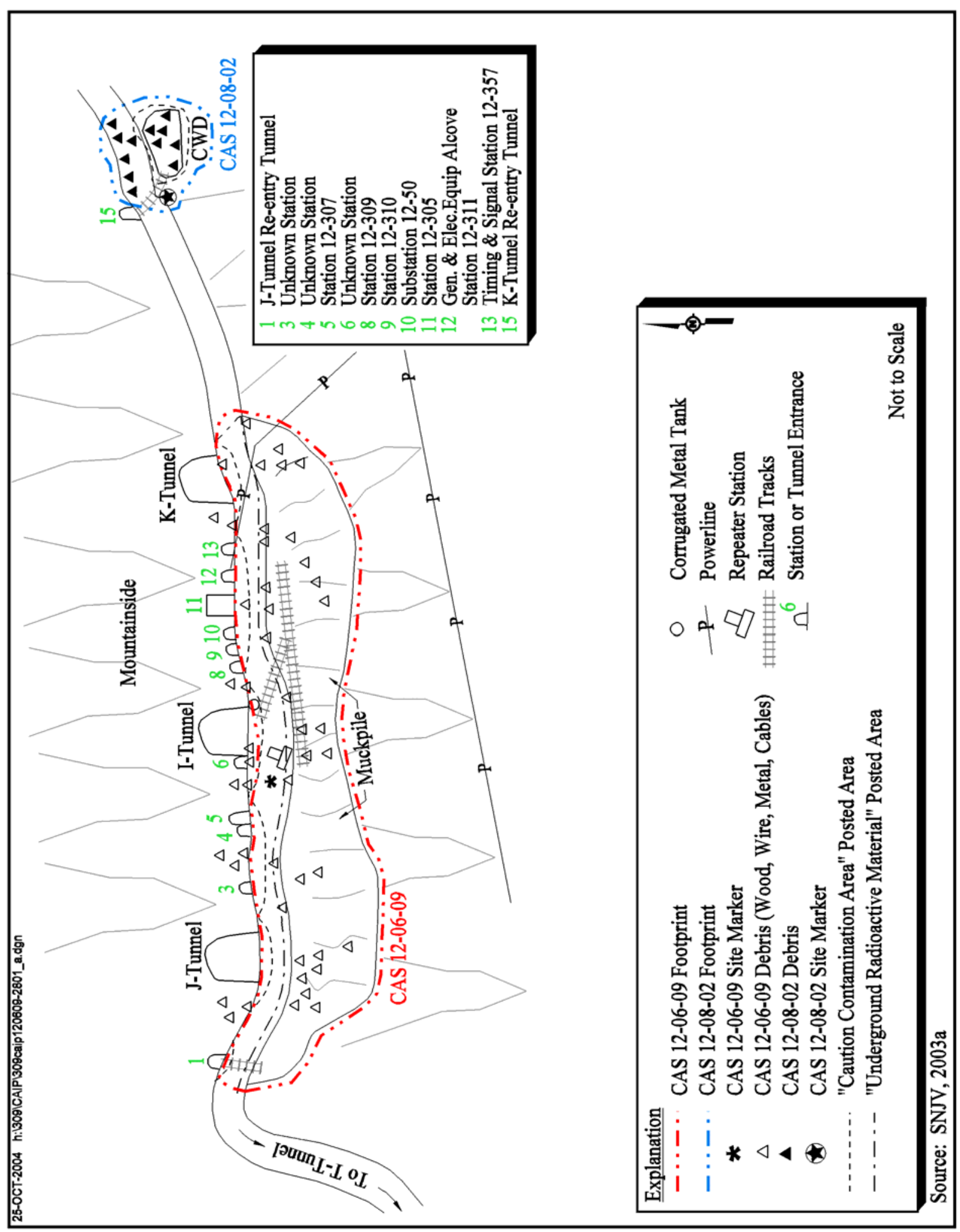

Figure A.2-2

Site Sketch of CAS 12-06-09, Muckpile 


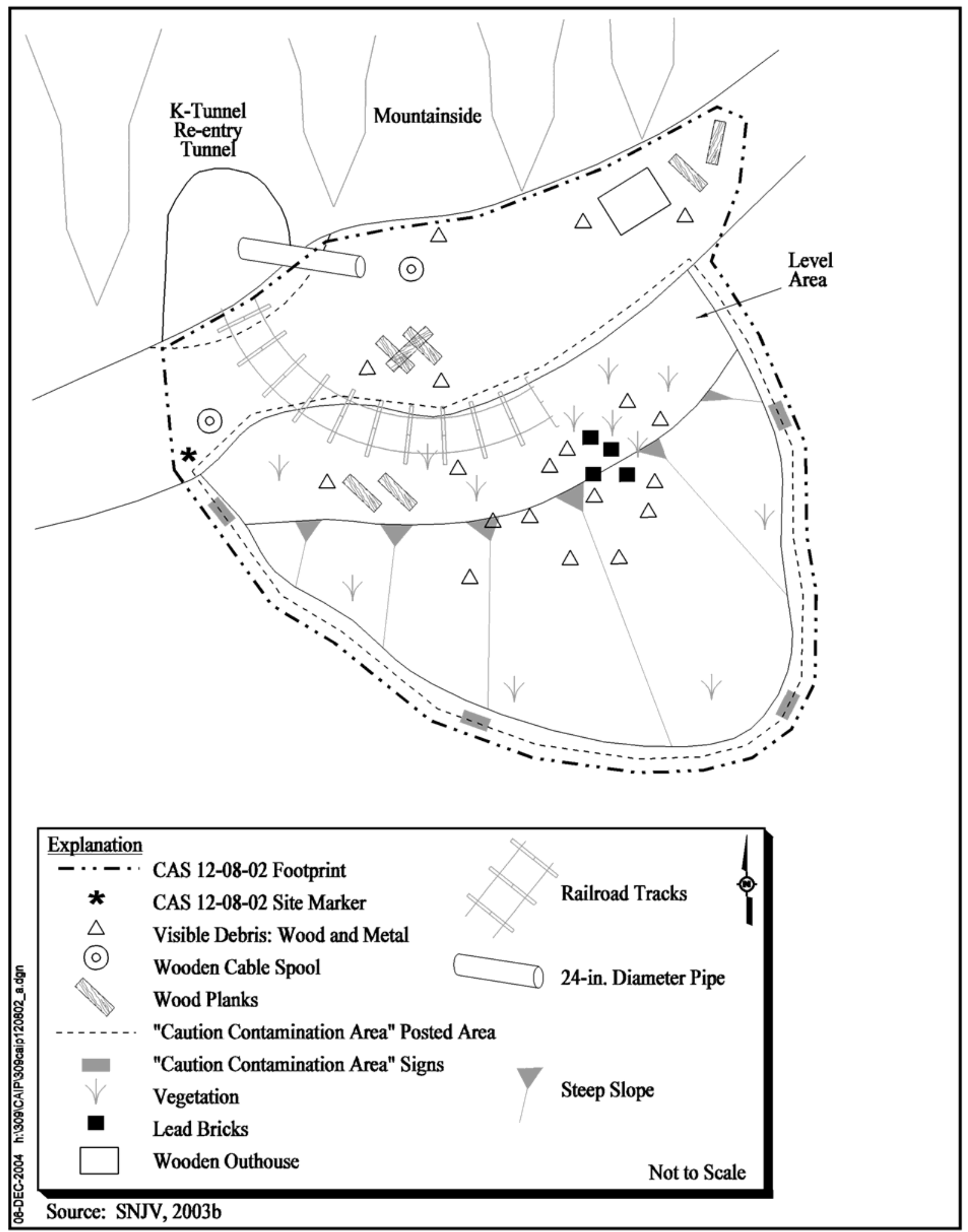

Figure A.2-3

Site Sketch of CAS 12-08-02, CWD 
CWD slopes south down the mountainside. Overhead power lines traverse the western edge of the CWD and run south. It is unknown if the power lines are active.

Construction of the I-, J-, and K-Tunnels started in late 1961. The J- and K-Tunnels were used for weapons-related tests. Testing at both J-Tunnel and K-Tunnel was conducted under Operation Nougat. Only one test was conducted in each of these tunnels. The Platte Test was detonated in K-Tunnel on April 14, 1962, and the Des Moines Test was detonated in J-Tunnel on June 13, 1962 (DOE/NV, 2000c). The engineered containment structures for the tests failed and these tests were not contained. As a result, decontamination and re-entry problems were extensive. When the containment systems were breached, radioactive material and debris was ejected out of the portals onto the muckpile and across the canyon (DOE/NV, 2000a).

No testing was conducted in I-Tunnel, due to the catastrophic failure of the J- and K-Tunnel containment systems. Fissures created in the mountainside from the testing at J-Tunnel caused the area to be unstable. The area containing the I-, J-, and K-Tunnels was abandoned following the Des Moines Test.

\section{Release Information}

The muckpiles at CASs 12-06-09 and 12-08-02 were created as a result of tunneling activities within the I-, J-, and K-Tunnels. Activities associated with the nuclear tests conducted within the tunnels and construction spills are the potential sources of chemical and radioactive contamination. The muckpiles also contain debris removed from the tunnels or support alcoves following the nuclear weapon tests. The J- and K-Tunnels were destroyed by the containment failures at each tunnel. The re-entry activities (conducted through separate re-entry portals) resulted in the potential for buried radioactive and/or hazardous material in the muckpiles.

As a standard work practice, approximately $10 \mathrm{ft}$ of uncontaminated muck is placed atop radioactively contaminated muck for the purpose of providing an adequate cover to prevent worker exposure and prevent the tracking of contaminants to other parts of the NTS (DOE, 1988). In an interview with Dr. Ristvet, Defense Threat Reduction Information Analysis Center, he indicated that after the Platte Test, a layer (approximately 6 in.) of clean soil was placed on top of the muckpile in the areas where work was to be performed. Clean soil was added so that the area could be entered for 
K-Tunnel re-entry activities, and staging operations for the Des Moines Test. Dr. Ristvet was uncertain if a layer of clean soil was placed on top of the muckpile after the Des Moines Test (Ristvet, 2004).

According to historical documentation, no standing water or effluent was ever observed in I-, J-, and K-Tunnels. Additionally, no effluent was observed during recent field visits. If necessary, potential effluent will be considered in the CADD.

\section{Previous Investigation Results}

In August 2004, SNJV personnel collected 26 surface soil samples for in-house analysis of gamma-emitting radionuclides. The purpose of this analysis was to develop a correlation of on-site gamma spectroscopy with off-site laboratory analysis and to assess the general magnitude of the fallout plume. Eleven of these samples were sent to Paragon Analytical Laboratory for gamma-emitting radionuclides, isotopic plutonium, Sr-90, beryllium, and lead analyses. Results were used to determine current site conditions and if beryllium was present at levels that would require additional PPE for site workers.

Results of the soil samples indicate lead and beryllium concentrations well below PALs and safety concerns. Radiological results indicate Am-241, Cs-137, Pu-238, and Pu-239/240 were detected above PALs in samples collected within the fallout plumes from the J-and K-Tunnels.

The document entitled, Preliminary Assessments Radiological Survey 2004, (Alderson, 2004), identifies results of a radiological survey conducted at various CASs on the NTS in January 2004. The objective of the radiological survey was to determine if radiological contamination is present in surficial soil at concentrations statistically greater than surficial soil from undisturbed background locations. Included in this survey was CAU 309, CAS 12-08-02. A radiological walk-over survey was performed on January 21, 2004, at the muckpile and surrounding areas in front of K-Tunnel. The area surveyed covered 20,781 square feet $\left(\mathrm{ft}^{2}\right)$. The maximum gamma radiation emission rate was 8,492 counts per second (cps), which is approximately 26.5 times greater than the mean undisturbed background gamma radiation emission rate. The most elevated gamma emission rates in the survey area were seen at the CWD in the northeast corner of the survey area in front of K-Tunnel re-entry, inside a posted contamination area (Figure A.2-4). According to the survey results, although no 


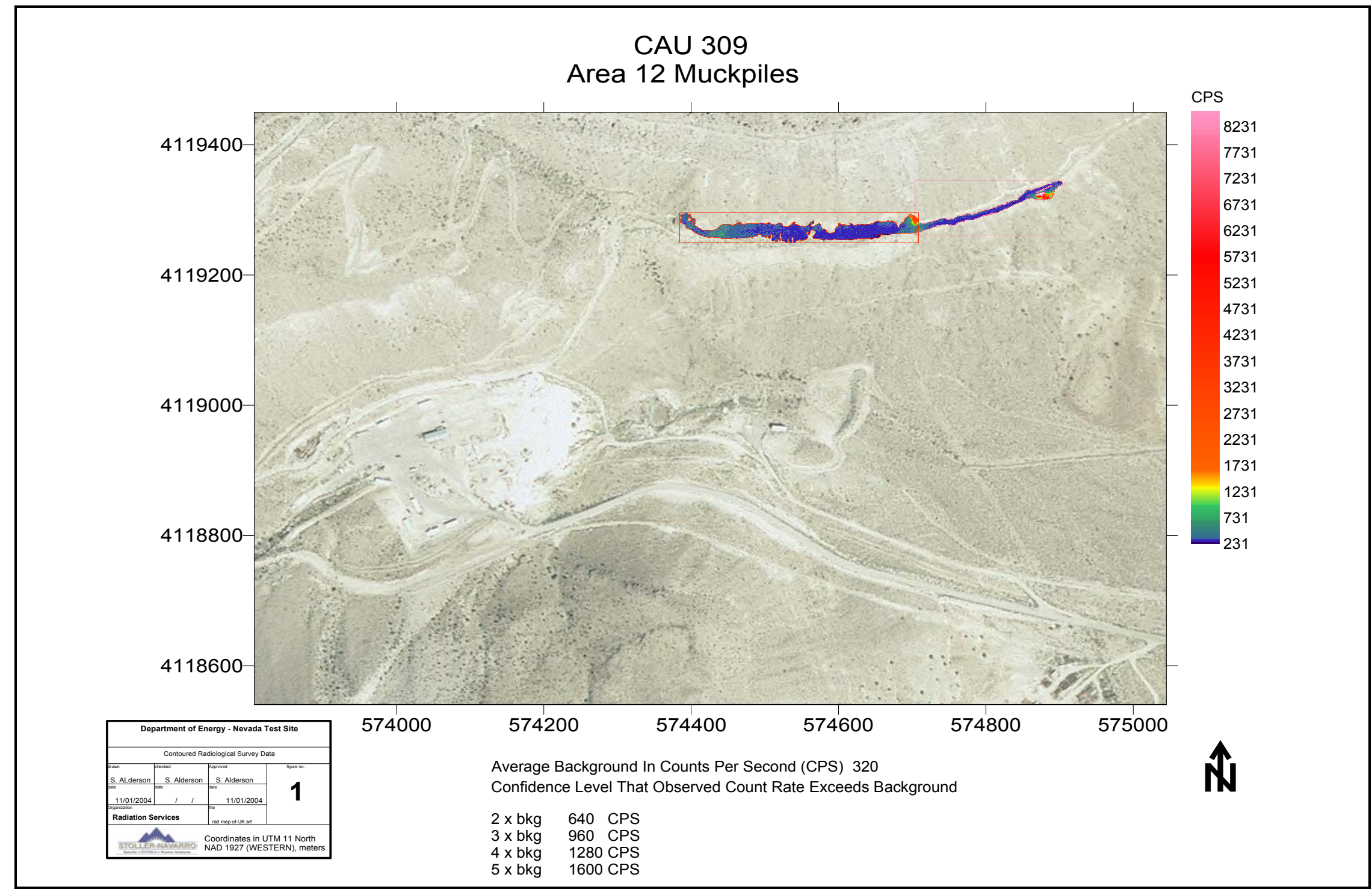

Figure A.2-4

CAU 309 Surface Radiological Survey 
removable contamination was encountered, the elevated gamma radiation emission rate can be possibly attributed to a surface/subsurface source term. This site will require radiological support for any future activities (Alderson, 2004). Although this memorandum states that the area surveyed included only the muckpile and surrounding areas in front of K-Tunnel, the surveyed area actually included the access road leading from K-Tunnel to the K-Tunnel re-entry, and the CWD outside K-Tunnel re-entry.

The document entitled, Nevada Test Site Contaminated Land Areas Report (DOE/NV, 2000a), identifies specific information for the U12I, J, and K-Tunnel complex surveyed in September 1998. The CWD at the U12I, J, and K-Tunnels is fenced and is a posted Contamination Area. This fenced area measures 32,400 $\mathrm{ft}^{2}$. The document states that the U12I, J, and K-Tunnel complexes were used for low-yield weapons related tests. The document states that this is a complex site due to the steep terrain, and the catastrophic failure of the U12I, J, K containment systems. When the containment systems were breached, radioactive material and debris was ejected out of the portals and across the canyon. Re-entry mining also produced substantial amounts of debris contaminated by the tests. Radionuclides in the soil and on the metal debris are a mixture of transuranics and fission products. The report also indicates tunnel portals, contaminated waste dump soil surface, and a soil area in the bottom of the canyon all have removable alpha contamination above 10 CFR 835 Appendix D guidelines at the time of the report (DOE/NV, 2000a).

Data from the CAIs for the previously investigated CAUs was evaluated to aid in the development of the CSM for CAU 309. The DQO approach documented here for the CAU 309 muckpiles employs the explicit assumption that similarities exist between the CAU 309 muckpiles and previously investigated NTS muckpiles, both in terms of activities that contributed to the muckpiles and environmental conditions affecting the muckpiles. The evaluation of the physical setting, waste generating activities and analytical data found that sufficient similarities exist to support the assumption. Refer to Appendix B for further discussion and documentation supporting this assumption.

Several investigations of muckpiles similar to the CAU 309 muckpiles have been completed at the NTS. Sample analytical results for detections of COPCs during CAIs conducted at CAUs 475, 476, 477, 482, and 504 have been summarized in Appendix B. The operational similarities and 
differences that affected the material that was deposited in muckpiles at previously investigated CAUs and the muckpiles in CAU 309 are discussed in Appendix B.

Previous muckpile investigations found that plutonium isotopes were the only alpha-emitting radionuclides present in the muck at concentrations above PALs (NNSA/NSO, 2004). Chemical and radiological COCs identified during previous NTS muckpile investigations have been found within the muck but not at the surface, and have not migrated from within the muckpiles (Appendix B) to the native material underlying the muckpiles, although they have been found in areas downstream at Tunnels U15a and e, and U16a as a result of overland transport (DTRA, 2002 and 2003). Data from the U12 P-Tunnel Muckpile (CAU 475) characterization indicates that plutonium was not present above PALs under the muckpile (McLane, 2004). The data indicates that the plutonium was present on the ground surface at the site prior to starting construction on the U12 P-Tunnel complex (circa 1986). It is theorized that the plutonium was mixed into the native material during initial site construction and the muckpile was subsequently deposited over it. Other muckpile investigations on the NTS have not found plutonium, or any other contaminant, below the muckpiles even when it was found in the muck.

\section{A.2.2 CAS 12-28-01, I-, J-, and K- Tunnel Debris}

Corrective Action Site 12-28-01 was first identified in the 1991 REECo document entitled, Nevada Test Site Inventory of Inactive and Abandoned Facilities and Waste Sites (REECo, 1991). For the purpose of this investigation CAS 12-28-01 is defined as debris ejected during the Des Moines and Platte Tests and the associated contamination that is not covered in the two muckpiles CASs. This site consists of debris scattered south of the I-, J-, and K-Tunnel muckpiles and extends down the hillside, across the valley and onto the adjacent hillside to the south. In addition, the site will cover the potential contamination associated with "ventings" along fractures and various boreholes on the mesa top and face (Figure A.2-5). The T-Tunnel ponds are located in the posted area at the bottom of the canyon. These ponds are covered in CAU 478, CAS 12-23-01 and are excluded from further investigation in CAU 309. 


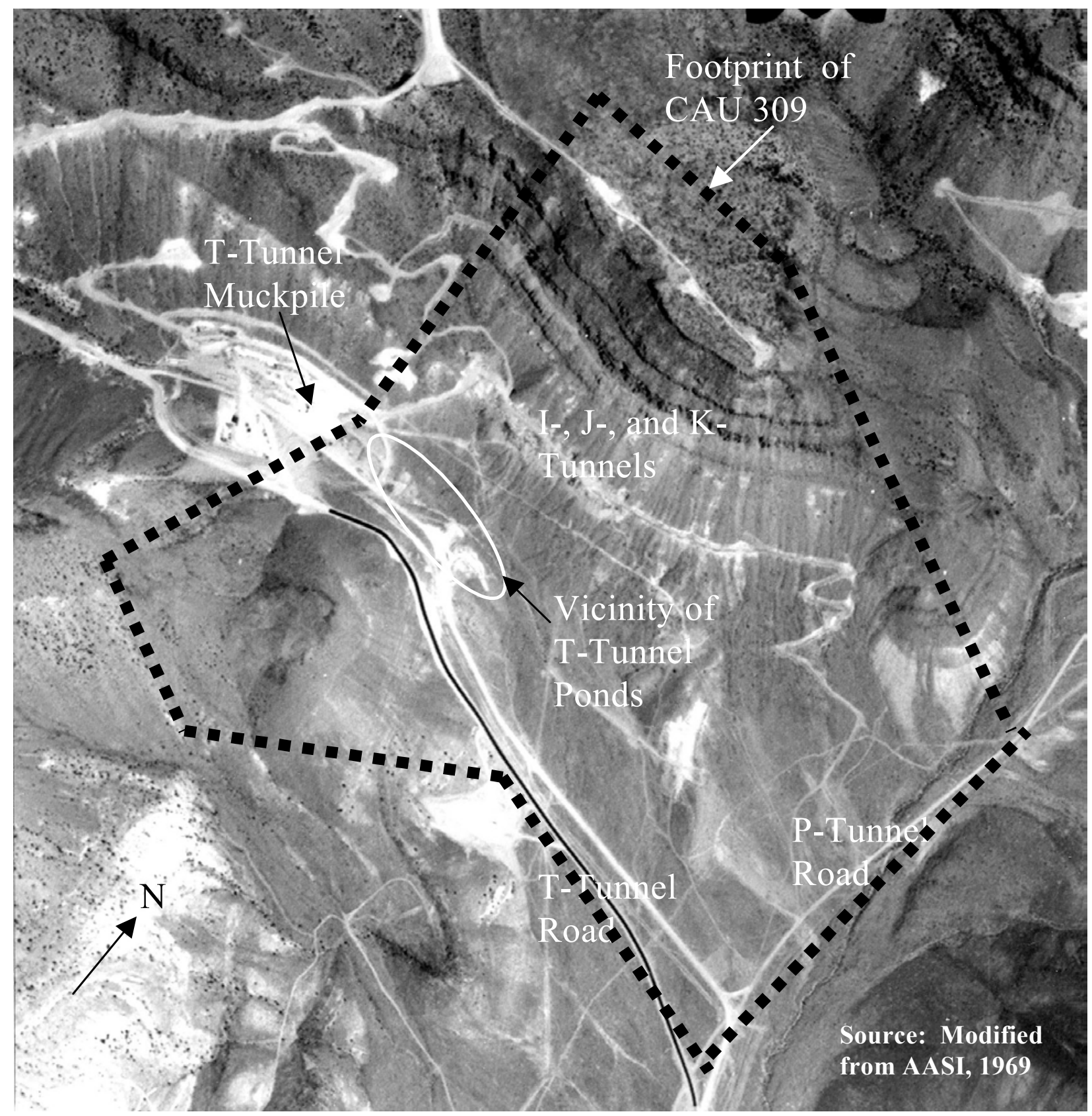

Figure A.2-5

Approximate Footprint of CAS 12-28-01, I-, J-, K-Tunnel Debris 


\section{Physical Setting and Operational History}

The physical setting is similar to the other two CASs except that the CAS boundary extends down the hillside, across the valley, and onto the adjacent hillside, above the tunnels on the face of the mesa, and potentially on top of the mesa. The operational history is also similar to the other two CASs except that T-Tunnel Ponds and other support facilities constructed in impacted areas after the release may have redistributed some contaminants.

\section{Release Information}

The report entitled, Summary Information on Releases of Radioactive Effluent to the Atmosphere from Underground Nuclear Detonations 1961 - 1964 (AEC, 1966), summarizes the information on the releases of radioactive effluent to the atmosphere from underground nuclear tests conducted at the NTS. Des Moines and Platte Tests are both discussed in this document. Platte was detonated on April 14, 1962. Immediately following the detonation, a fissure opened up in the face of the mesa, releasing large amounts of radioactive effluent into the atmosphere over a period of several minutes. Also, effluent escaped from the portal and from the instrumentation pipe on top of the mesa. Winds carried the effluent off site. Radionuclides identified in effluent off site include ruthenium-103/-105, zirconium-niobium-95, cerium-141/-144, iodine-131/-133/-135, and tellurium-132. The on-site external gamma levels at Platte were 20 Roentgens per hour (R/hr) at the portal (AEC, 1966).

Des Moines was detonated on June 13, 1962. Following the detonation, a dense black cloud, apparently containing both gaseous and particulate material, emanated from the portal, the top of the mesa, and a instrumentation hole about halfway up the side of the mesa. The on-site external gamma levels at Des Moines were greater than $100 \mathrm{R} / \mathrm{hr}$ at 9,000 $\mathrm{ft}$ from the portal, caused by complete stemming failure in the tunnel, instrumentation pipe, and ventilation hole (AEC, 1966). Both Platte and Des Moines released sufficient radioactive effluent that resulted in radioactivity being detected off the NTS (DOE/NV, 2000c). Additional radiological survey data is available in this report. Although this document discusses radiological survey results, it does not identify what date the survey was conducted on.

\section{Previous Investigation Results}

Results from an August 2004 SNJV sampling effort are summarized in Section A.2.1. 


\section{Tunnel Surveys, Radiological Conditions and Reentry Requirements; September 1971}

On August 18, 1971, a radiological survey was performed on the K-Tunnel portal area. The K-Tunnel portal area had a reading of $7.0 \times 10^{3}$ counts per minute $(\mathrm{cpm})$ beta and gamma, $4.0 \mathrm{mR} / \mathrm{hr}$ gamma, and $1.5 \times 10^{2} \mathrm{cpm}$ alpha. The muck dump for K-Tunnel was also included in this survey. The muck dump had a reading of $4.8 \times 10^{4} \mathrm{cpm}$ beta and gamma, $20.0 \mathrm{mR} / \mathrm{hr}$ gamma, and $1.0 \times 10^{4}$ cpm alpha (Penwell, 1971). This information contained in a memorandum from C.R. Penwell (REECo) to A.E. Bicker (REECo) outlines the tunnel re-entry requirements, routine radiological and toxicological surveys, and existing radiological hazards. K-Tunnel is included in this report.

Nevada Test Site Radionuclide Inventory and Distribution Program: Report \#5. Areas 5, 11, 12, 15, 17, 18, 19, 25, 26, and 30; June 1989

This document discusses radiological survey results for the area near the upper part of T-Tunnel road. This area was surveyed to check for contamination from ventings at J-Tunnel and K-Tunnel. The area where the tests vented is largely inaccessible to vehicles. The document states that 39 measurements were taken in this area in September 1988. The results of the survey showed that Am-241 and Cs-137 were detected. The highest measured Am-241 activities in nanocuries per square meter $\left(\mathrm{nCi} / \mathrm{m}^{2}\right)$ near the J-, I-, and K-Tunnel portals are as follows: $29,000 \mathrm{nCi} / \mathrm{m}^{2}$ near I-Tunnel portal; and 2,000 $\mathrm{nCi} / \mathrm{m}^{2}$ at $\mathrm{K}$-Tunnel portal. The highest measured $\mathrm{Cs}-137$ activities in $\mathrm{nCi} / \mathrm{m}^{2}$ near the $\mathrm{J}-, \mathrm{I}-$, and $\mathrm{K}$-Tunnel portals are as follows: $3,300 \mathrm{nCi} / \mathrm{m}^{2}$ at $\mathrm{J}$-Tunnel portal and $36,000 \mathrm{nCi} / \mathrm{m}^{2}$ at I-Tunnel portal. In addition to cesium and americium, about half of the survey points had measurable amounts of cobalt-60, europium-152, europium-154, europium-155, and antimony-125 (DRI, 1989).

\section{The T-Tunnel Muckpile and Ponds}

The T-Tunnel Muckpile and Ponds (CAU 478) located within the fallout plume of the J-and K-Tunnels was investigated in 2003 by DTRA. The six ponds and associated channels between them were constructed to receive run-off from perched water from T-Tunnel. These ponds were constructed after the J- and K-Tunnel failures. Contaminants identified during the investigation were TPH-diesel-range organics (DRO), Am-241, Cs-137, and Pu-239. The recommended corrective action is to close in place. 


\section{An Aerial Radiological Survey of the Nevada Test Site}

In 1994, an aerial radiological survey of the NTS performed by the Remote Sensing Laboratory (DOE/NV, 1999). The survey was conducted from a helicopter at an elevation of $200 \mathrm{ft}$ over much of the NTS. In Area 12, the survey indicates a plume of elevated Cs-137 in the vicinity of I-, J-, and K-Tunnels. 


\section{A.3.0 Step 1 - State the Problem}

The problem statement for CAU 309 is: "Existing information on the nature and extent of potential contamination is insufficient to evaluate and recommend corrective action alternatives for the CASs in CAU 309."

\section{A.3.1 Planning Team Members}

The DQO planning team consists of representatives from NDEP, NNSA/NSO, SNJV, and BN. The primary decision makers are the NDEP and NNSA/NSO representatives. Table A.3-1 lists representatives from each organization in attendance for the September 23, 2004, DQO meeting.

Table A.3-1

FinalDQO Meeting Participants for CAU 309 September 29, 2004

\begin{tabular}{||l|c|}
\hline \multicolumn{1}{|c|}{ Participant } & Affiliation \\
\hline \hline Greg Raab & Nevada Division of Environmental Protection \\
\hline Kevin Cabble & $\begin{array}{r}\text { U.S. Department of Energy, National Nuclear Security } \\
\text { Administration Nevada Site Office }\end{array}$ \\
\hline Rob Boehlecke & Stoller-Navarro Joint Venture \\
\hline Allison Urbon & Bechtel Nevada \\
\hline Frank Salvo & Stoller-Navarro Joint Venture \\
\hline Jack Ellis & Stoller-Navarro Joint Venture \\
\hline Stacey Alderson & Stoller-Navarro Joint Venture \\
\hline Al Wickline & Science Applications International Corporation \\
\hline Jeanne Wightman & Stoller-Navarro Joint Venture \\
\hline Bob McCall & Stoller-Navarro Joint Venture \\
\hline
\end{tabular}

\section{A.3.2 Conceptual Site Model}

The CSM is used to organize and communicate information about site characteristics. It reflects the best interpretation of available information at any point in time. The CSM is a primary vehicle for communicating technical data. It provides a good summary of how and where contaminants are expected to move and what impacts such movement may have. It is the basis for assessing how contaminants could reach receptors both in the present and future. The CSM describes the most 
probable scenario for current conditions at each site and define the assumptions that are the basis for identifying appropriate sampling strategy and data collection methods. Accurate CSMs are important as they serve as the basis for all subsequent inputs and decisions throughout the DQO process.

One CSM has been developed for the muckpiles and fallout plume. The CSM has been developed for CAU 309 using information from the physical setting, potential contaminant sources, knowledge from similar sites, release information, historical background information, and physical and chemical properties of the potentially affected media and COPCs.

The CSM represents contamination of soil due to mine tailings discharge and tunnel containment discharge. The CSM is shown in profile view in Figure A.3-1, and in drainage view in Figure A.3-2 and consists of the following elements:

- Potential contaminant releases including media subsequently affected

- Release mechanisms (the conditions associated with the release)

- Potential contaminant source characteristics including contaminants suspected to be present and contaminant-specific properties

- Site characteristics including physical, topographical, and meteorological information

- Migration pathways and transport mechanisms that describe the potential for migration and where the contamination may be transported

- The locations of points of exposure where individuals or populations may come in contact with a COC associated with a CAS

- Routes of exposure where contaminants may enter the receptor

If additional elements are identified during the investigation that are outside the scope of the CSM, the situation will be reviewed and a recommendation will be made as to how to proceed. In such cases, NDEP and NNSA/NSO will be notified and given the opportunity to comment on, or concur with, the recommendation.

Table A.3-2 provides information on additional CSM elements that will be used throughout the remaining steps of the DQO process. 


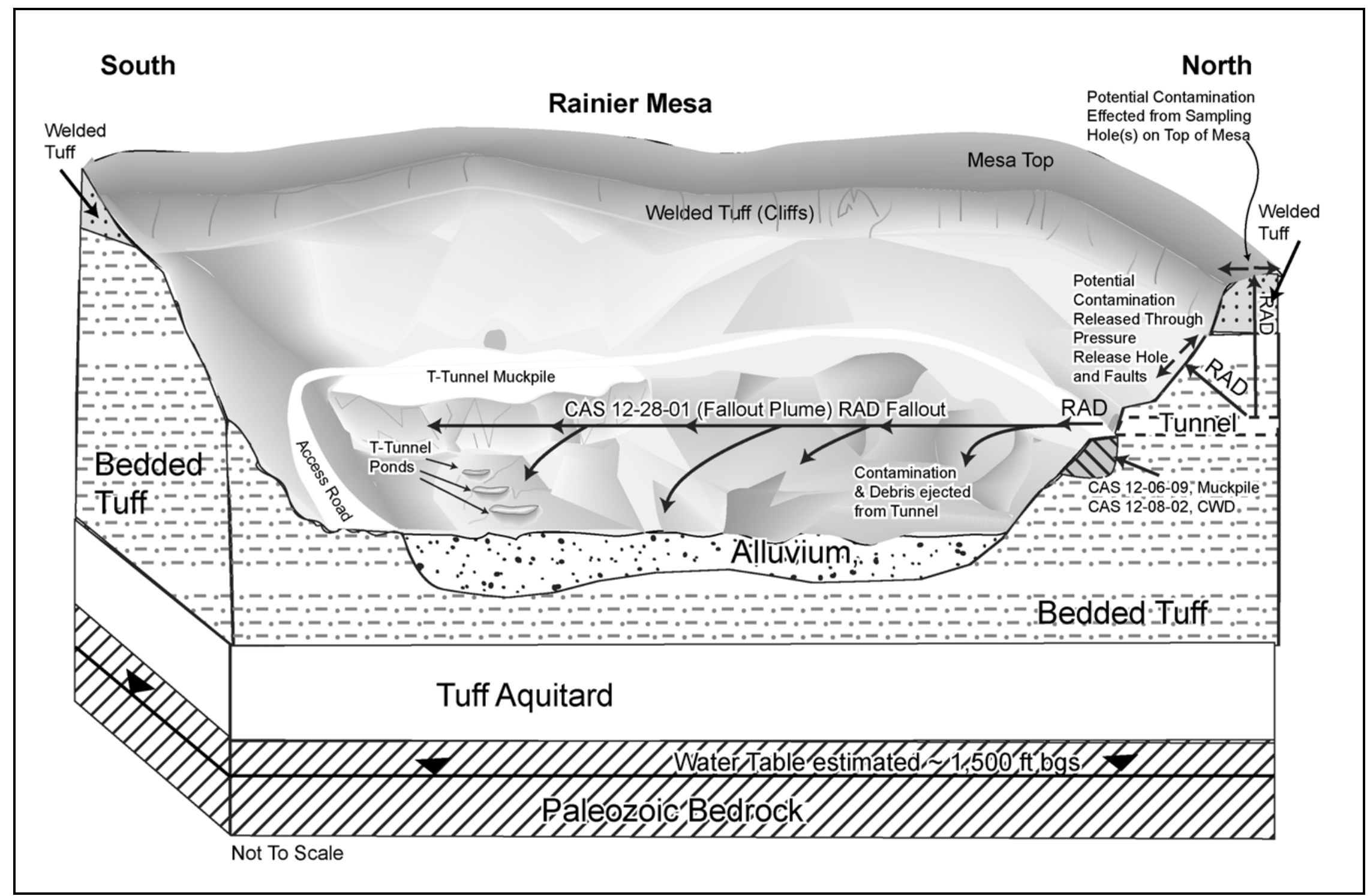

Figure A.3-1

CAU 309 Conceptual Site Model (Profile Model) 


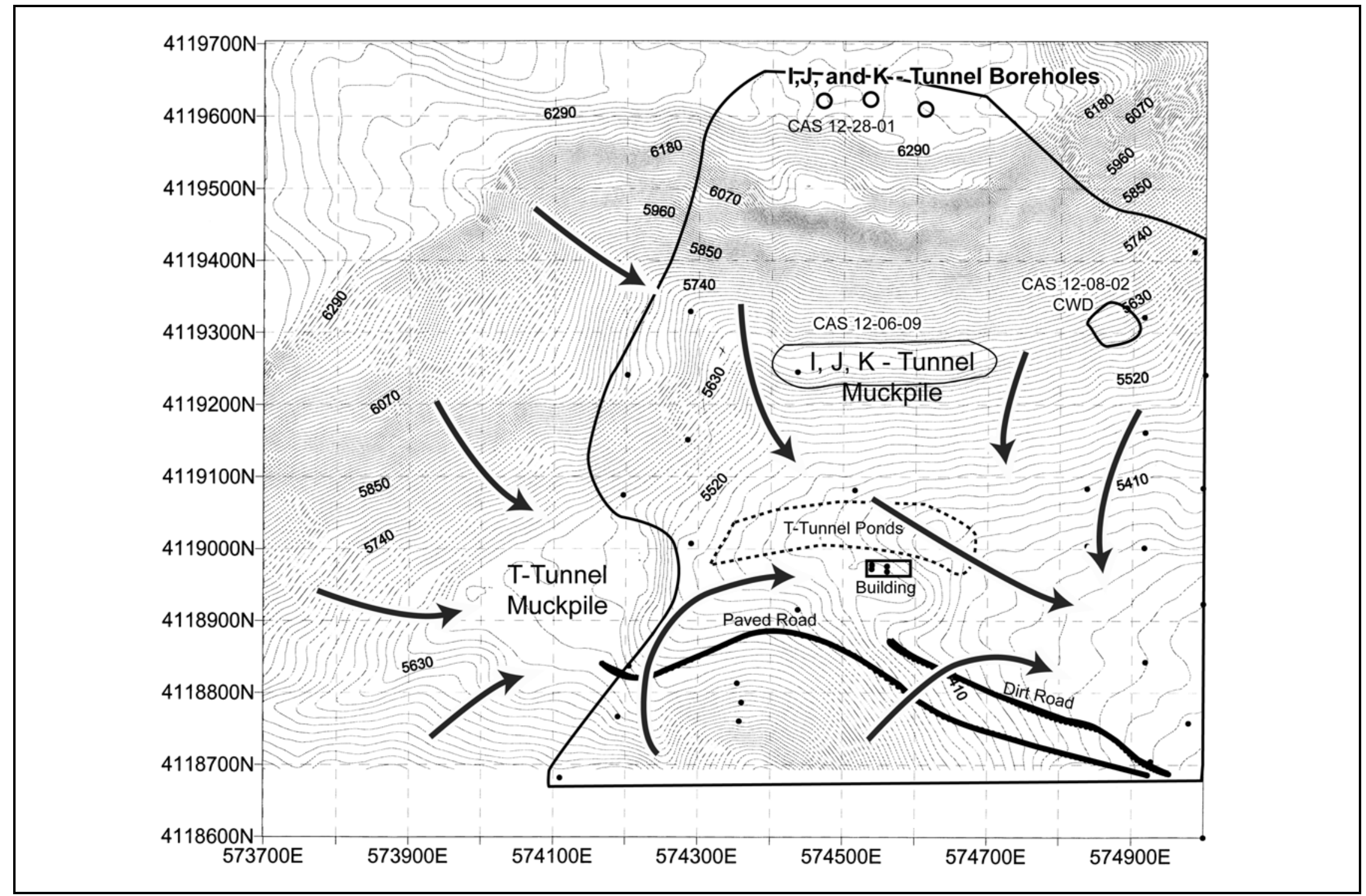

Figure A.3-2

CAU 309 Conceptual Site Model (Drainage Model) 
Table A.3-2

\section{Conceptual Site Model}

Description of Elements for Each CAS in CAU 309

\begin{tabular}{|c|c|c|c|}
\hline CAS Identifier & 12-06-09 & 12-08-02 & 12-28-01 \\
\hline CAS Description & Muckpile & Contaminated Waste Dump & I-, J-, and K-Tunnel Debris \\
\hline Site Status & \multicolumn{3}{|c|}{ Sites are inactive and/or abandoned } \\
\hline Future Land Use & \multicolumn{3}{|c|}{$\begin{array}{l}\text { Nuclear and High Explosives Test Zone. This area is designated within the Nuclear Test Zone for additional } \\
\text { underground nuclear weapons test and outdoor high explosive tests. This zone includes compatible } \\
\text { defense and nondefense research, development, and testing activities. The Nuclear Test Zone is reserved } \\
\text { for dynamic experiments, hydrodynamic tests, and underground nuclear weapons and weapons effects } \\
\text { tests. }\end{array}$} \\
\hline $\begin{array}{l}\text { Sources of Potential } \\
\text { Soil Contamination }\end{array}$ & \multicolumn{2}{|c|}{$\begin{array}{l}\text { Potentially contaminated muck and debris placed on the ground } \\
\text { surface, potential leaks/spills from equipment or materials stored on the } \\
\text { muckpile, and fallouts from J- and K-Tunnels. }\end{array}$} & $\begin{array}{l}\text { Fallout from J-and K-Tunnel } \\
\text { containment failures. }\end{array}$ \\
\hline $\begin{array}{l}\text { Location of } \\
\text { Contamination/ } \\
\text { Release Point }\end{array}$ & \multicolumn{2}{|c|}{ Muckpiles and surface soils surrounding muckpiles } & $\begin{array}{l}\text { Fallout plumes, faults and cracks } \\
\text { on hillside, instrument holes on } \\
\text { top of mesa }\end{array}$ \\
\hline Amount Released & \multicolumn{3}{|l|}{ Unknown } \\
\hline Affected Media & \multicolumn{3}{|c|}{ Surface and shallow subsurface soils; debris such as concrete, metal, and wood. } \\
\hline $\begin{array}{l}\text { Potential } \\
\text { Contaminants }\end{array}$ & \multicolumn{2}{|c|}{$\begin{array}{l}\text { COPCs include radiological and chemical. See Table A.3-3 through } \\
\text { Table A.3-6 }\end{array}$} & $\begin{array}{l}\text { COPCs include radiological } \\
\text { contaminants. See Table A.3-6. }\end{array}$ \\
\hline $\begin{array}{c}\text { Transport } \\
\text { Mechanisms }\end{array}$ & \multicolumn{3}{|c|}{$\begin{array}{l}\text { Percolation of precipitation through subsurface media typically serves as the major driving force for } \\
\text { migration of contaminants. However, due to the arid environment of the NTS, percolation of precipitation is } \\
\text { very small and migration of contaminants has been shown to be very limited. Evaporation potentials } \\
\text { significantly exceed available soil moisture from precipitation (i.e., } 6 \text { to } 12 \text { in.) (USGS, 1965). Surface water } \\
\text { run-off may provide for the transportation of some contaminants within or outside of the footprints of the } \\
\text { CASs. }\end{array}$} \\
\hline Migration Pathways & \multicolumn{3}{|c|}{$\begin{array}{l}\text { Surface drainages down gradient of sources could have impact due to high grade; in general lateral } \\
\text { migration dominate over vertical migration. }\end{array}$} \\
\hline $\begin{array}{l}\text { Lateral and Vertical } \\
\text { Extent of } \\
\text { Contamination }\end{array}$ & \multicolumn{3}{|c|}{$\begin{array}{l}\text { Contamination, if present, may be contiguous to the release points or could be present in isolated areas due } \\
\text { to the nature of the fallout plume. Concentrations are expected to decrease with distance and depth from } \\
\text { the source, except for the fallout plume, a possibility exits the muckpile shielded the initial blast at areas } \\
\text { downhill of the muckpile. Therefore, higher contamination levels could be found on the adjacent hillside } \\
\text { south of the tunnels. Previous muckpile investigations indicate contamination did not migrate vertically } \\
\text { beneath muckpiles. Groundwater contamination is not expected. Depth to groundwater in nearby Well } \\
\text { E-12-1 (approximately } 2.5 \text { miles to the west) has been recorded at a depth of } 1,527 \mathrm{ft} \text { bgs (DRI, 1996). } \\
\text { Depth to groundwater in WW-8 (approximately } 8 \text { mi to the southwest) located in Area } 18 \text { was } 1,081 \mathrm{ft} \text { bgs } \\
\text { (USGS and DOE, 2003). Surface migration may occur as a result of run-off. }\end{array}$} \\
\hline Exposure Scenario & \multicolumn{3}{|c|}{$\begin{array}{l}\text { The potential for contamination exposure is limited to industrial and construction workers, and military } \\
\text { personnel conducting training. These human receptors may be exposed to COPCs through oral ingestion, } \\
\text { inhalation, dermal contact (absorption) of soil and/or debris due to inadvertent disturbance of these materials } \\
\text { or irradiation by radioactive materials. }\end{array}$} \\
\hline
\end{tabular}




\section{A.3.2.1 Contaminant Release}

Contamination at CASs 12-06-09 and 12-08-02 could be found in any part of the muckpiles including the surface. There is also a potential for contamination at the muckpile/native soil interface, at the base of the muckpiles, and in the soils down slope from the muckpiles due to erosion and contaminant transport. The muckpiles were constructed on top of native soil and rock outcroppings. Deep subsurface media are not believed to have been affected by the COPCs.

Contamination at CAS 12-28-01 could be found in the surface and shallow subsurface soils within the fallout plumes to the south of J- and K-Tunnels, on top of the mesa from instrument boreholes, and faults and cracks on the hillside above K-Tunnel. Contamination could also be found down slope from these features due to erosion and contaminant transport.

Contaminants migrating to regional aquifers are not considered a likely scenario at CAU 309 based on the low annual average precipitation rates, high potential evapotranspiration, and low mobility of expected COPCs. Depth to groundwater in nearby Well E-12-1 (approximately 2.5 miles to the west) has been recorded at a depth of 1,527 ft bgs (DRI, 1996; USGS and DOE, 2003). Depth to groundwater in WW-8 (approximately $8 \mathrm{mi}$ to the southwest) located in Area 18 was 1,081 ft bgs (USGS and DOE, 2003). Past investigations of muckpiles at the NTS have indicated that contamination has not migrated vertically into the native material underlying the muckpile, but has migrated laterally due to erosion. The CSM for the CAU 309 muckpiles has been constructed based on the assumption that the conditions present at CAU 309 are sufficiently similar to those at the previously investigated muckpiles to assume that COPCs will have a similar fate. Therefore, lateral migration is expected to dominate over vertical migration.

Horizontal and vertical migration of contamination is expected to decrease with distance from the release points. Surface migration may occur as a result of storm events when precipitation rates exceed infiltration (stormwater run-off). These events are infrequent but can produce high precipitation rates for short periods of time. Surface migration is a biasing factor considered in the selection of sampling points. The steep terrain of CAU 309 would tend to drive the overland transport of water, rather than vertical migration, from rain events. 
Migration of contamination for any potential release scenarios would be expected to be down slope from the point of initial deposition. The muckpiles and fallout plume are contained within one watershed and drain southwest into the P-Tunnel drainage channel. The boreholes that vented on top of Rainier Mesa may have contaminants that drained to the north into the P-Tunnel canyon. Potential contamination is not expected outside of this watershed.

\section{A.3.2.2 Potential Contaminants}

The COPCs for CAU 309 are generally defined as the list of constituents reported from laboratory analyses. The list of COPCs is intended to encompass all of the contaminants that could potentially be present at each CAS. These COPCs were identified during the planning process through the review of site history, process knowledge, personal interviews, past investigation efforts (where available), and inferred activities associated with the CASs. Common contaminants detected at other similar or other NTS sites were also included in the COPC list to reduce the uncertainty about potential contamination at the CASs because complete information regarding activities performed at the CAU 309 sites is not available.

Organic COPCs are analytes listed in Table A.3-3 and Table A.3-4 for which the EPA Region 9 has established PRGs (EPA, 2002d) or for which toxicity and/or carcinogenicity data are listed in the EPA IRIS database (EPA, 2002e). The radionuclides, PCBs, and metals compounds are listed in Table A.3-5.

During the review of site history documentation, process knowledge information, personnel interviews, past investigation efforts of other muckpiles, and inferred activities associated with the CASs, some of the COPCs were identified as targeted analytes at specific CASs. Targeted analytes are those COPCs for which evidence in the available site and process information suggests that they may be reasonably suspected to be present at a given CAS. The targeted analytes are required to meet a more stringent completeness criteria than other COPCs thus providing greater protection against a decision error (see Section A.3.2). Targeted analytes for each CAU 309 CAS are identified in Table A.3-6.

Slopes on and around the muckpiles present a climbing hazard to samplers, and limit the accessibility to mechanical sampling equipment (e.g., drilling, backhoe). Therefore, "expected COCs" for the 
Table A.3-3

Analytes Reported from VOC Analysis

\begin{tabular}{|c|c|c|}
\hline $\begin{array}{l}\text { 1,1,1-Trichloroethane } \\
\text { 1,1,1,2-Tetrachloroethane } \\
\text { 1,1,2,2-Tetrachloroethane } \\
\text { 1,1,2-Trichloroethane } \\
\text { 1,1-Dichloroethane } \\
\text { 1,1-Dichloroethene } \\
\text { cis-1,2-Dichloroethene } \\
\text { trans-1,2-Dichloroethene } \\
\text { 1,2-Dichloroethane } \\
\text { 1,2-Dichloropropane } \\
\text { 1,2,3-Trichloropropane } \\
\text { 1,2,4-Trimethylbenzene } \\
\text { 1,2-Dibromo-3-chloropropane } \\
\text { 1,2-Dibromoethane } \\
\text { 1,3,5-Trimethylbenzene } \\
\text { cis-1,3-Dichloropropene } \\
\text { trans-1,3-Dichloropropene } \\
\text { 2-Butanone } \\
\text { 2-Chlorotoluene }\end{array}$ & $\begin{array}{l}\text { 4-Methyl-2-pentanone } \\
\text { Acetone } \\
\text { Benzene } \\
\text { Bromobenzene } \\
\text { Bromochloromethane } \\
\text { Bromodichloromethane } \\
\text { Bromoform } \\
\text { Bromomethane } \\
\text { Carbon disulfide } \\
\text { Carbon tetrachloride } \\
\text { Chlorobenzene } \\
\text { Chloroethane } \\
\text { Chloroform }\end{array}$ & $\begin{array}{l}\text { Chloromethane } \\
\text { Dibromochloromethane } \\
\text { Dibromomethane } \\
\text { Dichlorodifluoromethane } \\
\text { Ethylbenzene } \\
\text { lodomethane } \\
\text { Isopropylbenzene } \\
\text { Methyl tertbutyl ether } \\
\text { Methylene chloride } \\
\text { N-Butylbenzene } \\
\text { N-Propylbenzene } \\
\text { sec-Butylbenzene } \\
\text { Styrene } \\
\text { tert-Butylbenzene } \\
\text { Tetrachloroethene } \\
\text { Toluene } \\
\text { Trichloroethene } \\
\text { Trichlorofluoromethane } \\
\text { Trichlorotrifluoroethane } \\
\text { Vinyl acetate } \\
\text { Vinyl chloride } \\
\text { Xylene }\end{array}$ \\
\hline
\end{tabular}

Table A.3-4

Analytes Reported from SVOC Analysis

\begin{tabular}{|l|l|l}
\hline 1,2,4-Trichlorobenzene (a) & Acenaphthylene & Di-n-butyl Phthalate \\
1,2-Dichlorobenzene (a) & Aniline & Di-n-octyl Phthalate \\
1,3-Dichlorobenzene (a) & Anthracene & Fluoranthene \\
1,4-Dichlorobenzene (a) & Benzo(a)anthracene & Fluorene \\
2,4,5-Trichlorophenol & Benzo(a)pyrene & Hexachlorobenzene \\
2,4,6-Trichlorophenol & Benzo(b)fluoranthene & Hexachlorocyclopentadiene \\
2,4-Dichlorophenol & Benzo(g,h,i)perylene & Hexachloroethane \\
2,4-Dimethylphenol & Benzo(k)fluoranthene & Hydroquinone \\
2,4-Dinitrophenol & Benzoic Acid & Indeno(1,2,3-cd)pyrene \\
2,4-Dinitrotoluene & Benzyl Alcohol & Isophorone \\
2,6-Dinitrotoluene & Bis(2-chloroethoxy) methane & Naphthalene (a) \\
2-Chloronaphthalene & Bis(2-chloroethyl)ether & Nitrobenzene \\
2-Chlorophenol & Bis(2-chloroisopropyl)ether & N-Nitroso-di-n-propylamine \\
2-Methylphenol & Bis(2-ethylhexyl) phthalate & N-Nitrosodimethylamine \\
2-Nitroaniline & Butyl benzyl phthalate & N-Nitrosodiphenylamine \\
3,3-Dichlorobenzidine & Carbazole & Pentachlorophenol \\
4-Bromophenyl phenyl ether & Chrysene & Phenanthrene \\
4-Chloroaniline & Dibenzo(a,h)anthracene & Phenol \\
4-Methylphenol & Dibenzofuran & Pyrene \\
4-Nitrophenol & Diethyl Phthalate & Pyridine \\
Acenaphthene & Dimethyl Phthalate & .
\end{tabular}

(a) May be reported with VOCs 
Table A.3-5

Analytes Reported from Radionuclides, PCB, and Metals Analyses

\begin{tabular}{||l|ll|ll||}
\hline \multicolumn{1}{|c|}{ Radionuclides } & \multicolumn{2}{|c|}{ PCB } & \multicolumn{1}{c|}{ Metals } \\
\hline \hline Gamma-emitting radionuclides & Aroclor-1016 & Aroclor-1248 & Arsenic & Lead \\
Strontium-90 & Aroclor-1221 & Aroclor-1254 & Barium & Mercury \\
Uranium- 234, 235, 238 & Aroclor-1232 & Aroclor-1260 & Beryllium & Selenium \\
Plutonium- 238, 239/240 & Aroclor-1242 & & Cadmium & Silver \\
Tritium & & & Chromium \\
\hline
\end{tabular}

Table A.3-6

Targeted Analytes for CAU 309

\begin{tabular}{||c|c|c||}
\hline CAS & $\begin{array}{c}\text { Chemical } \\
\text { Targeted Analyte(s) }\end{array}$ & \multicolumn{1}{c|}{$\begin{array}{c}\text { Radiological } \\
\text { Targeted Analyte(s) }\end{array}$} \\
\hline \hline $\begin{array}{c}12-06-09 \\
12-08-02\end{array}$ & Arsenic, Lead, TPH (DRO) & Sr-90, Cs-137, Co-60, Pu-238, Pu239 \\
\hline $12-28-01$ & None & $\begin{array}{l}\text { Sb-125, Sr-90, Eu-152, Eu-154, Eu-155, Cs-137, } \\
\text { Co-60, Am-241, Pu-238, Pu239, Pu-240 }\end{array}$ \\
\hline
\end{tabular}

muckpiles were established based on data from previously investigated NTS muckpiles. The "expected COCs" are the same as the targeted analytes listed in Table A.3-6 for CASs 12-06-09 and 12-08-02, except for the addition of Sr-90 to the targeted analyte list.

\section{A.3.2.3 Contaminant Characteristics}

Contaminant characteristics include, but are not limited to: solubility, density, and adsorption potential. In general, contaminants with low solubility, high affinity for media, and high density can be expected to be found relatively close to release points. Contaminants with small particle size, high solubility, low density, and/or low affinity for media are found further from release points or in low areas where evaporation of ponding will concentrate dissolved constituents.

The following organic and inorganic constituents could be present at CAU 309. Arsenic compounds tend to adsorb to soils and leaching usually results in translocation over only relatively short distances in soil. However, arsenic is generally relatively soluble so leaching may be more significant if the environmental media has limited adsorptive capacity. Lead compounds are more adsorptive and less soluble than arsenic compounds; therefore, are less mobile. The solubility and mobility of TPH as a group of organic compounds is dependent upon the type of product released. Diesel oil is only slightly soluble and tends to form a viscous layer around soil particles. 
The plutonium and americium radionuclides are very immobile constituents that are highly adsorptive and very insoluble. Cesium-137 is moderately adsorptive and relatively insoluble. Strontium-90 is only slightly adsorptive and very soluble. If vertical translocation is a significant migration pathway, Cs-137 should be found at greater depths than the other radionuclides. However, previous investigations at NTS sites have shown that contaminants have not migrated significant vertical distances from the original spill locations.

\section{A.3.2.4 Site Characteristics}

Site characteristics are defined by the interaction of physical, topographical, and meteorological attributes and properties. Physical properties include permeability, porosity, hydraulic conductivity, degree of saturation, sorting, chemical composition, and organic content. Topographical and meteorological properties and attributes include slope stability, precipitation frequency and amounts, precipitation run-off pathways, drainage channels and ephemeral streams, and evapotranspiration potential.

The migration of organic constituents (e.g., petroleum hydrocarbons) can be controlled to some extent by their affinity for organic material present in soil. However, this mechanism is considered insignificant because of the lack of organic carbon in the desert soil, and the muck at CAU 309. Other site characteristics at CAU 309 include steep, unstable terrain susceptible to erosion during rain events. Surface migration is a biasing factor considered in the selection of sampling points.

\section{A.3.2.5 Migration Pathways and Transport Mechanisms}

An important element of the CSM in developing a sampling strategy is the expected fate and transport of contaminants (how contaminants migrate through media and where they can be expected in the environment). Fate and transport of contaminants are presented in the CSM as the migration pathways and transport mechanism that could potentially move the contaminants throughout the various media. Fate and transport are influenced by physical and chemical characteristics of the contaminants and media described in Section A.3.2.3 and Section A.3.2.4.

Infiltration and percolation of precipitation can serve as a driving force for downward migration of contaminants. However, due to high potential evapotranspiration (annual potential 
evapotranspiration at the Area 3 Radiological Waste Management Site has been estimated at 62.6 in. [Shott et al., 1997]) and limited precipitation for this region (6 to 12 in. per year [USGS, 1965]), percolation of infiltrated precipitation at the NTS does not provide a significant mechanism for vertical migration of contaminants to groundwater.

Pathways for contaminant migration at CAU 309 may be present in the form of small gullies and washes that channel the overland flow of run-off from the muckpiles or fallout plume that may increase lateral transport prior to infiltration. Rain may wash contaminants from the muckpiles or fallout plume down into the gullies and washes or the surrounding soil. Drainage from CAU 309 is ultimately into Yucca Flat, which is located southeast of the site. The pathways for contaminant migration will be considered in the development of sampling schemes and sampling contingencies discussed in Step 7, Optimize the Design for Obtaining Data, and the CAIP.

The degree of contaminant migration at this site is unknown but is expected to be limited based on the affinity of the COPCs for soil particles, and the low precipitation and high evapotranspiration rates typical of the NTS environment. Run-off from the muckpiles or fallout plume down one of several washes could cause lateral migration of contaminants from the muckpiles over the ground surface. Contaminants may also have been transported by infiltration and percolation of precipitation through soil, which would serve as the primary driving force for downward migration. The migration of organic constituents (e.g., petroleum hydrocarbons, chlorinated solvents) would be limited to some extent by their affinity for organic material present in soil. However, this mechanism is considered insignificant because of the lack of organic carbon in the desert soil, and the muck in Area 12. Migration of certain inorganic constituents (e.g., metals in waste oil) is controlled by geochemical processes such as adsorption, ion exchange, and precipitation of solids from solution.

Because of the low volatility of the critical contaminants in the muckpiles and fallout plume, an airborne release subsequent to the initial contaminant release is not considered a significant release pathway. The main process of migration through the air would be through windblown dust.

The resuspension of particles is directly affected by particle size, weathering, and migration. The three mechanisms that result in movement of particles deposited onto surfaces are surface creep (particles rolling across the surface), saltation (bouncing particles that become airborne for short distances $[\sim 10 \mathrm{~m}]$ ), and true suspension (particles that were once deposited on the ground become 
airborne and travel upward for great distances). True resuspension affects only particles that are less than $50 \mu \mathrm{m}$ in size. However, smaller particles can attach to larger soil particles and larger particles can be broken up so that long-term behavior cannot, in general, be predicted from the initial particle size of the deposited material. Various resuspension studies have been conducted on plutonium contaminated soils at the NTS and other locations. These studies have identified that for fresh deposition ( $<1$ year) the initial resuspension factors to be used are $10^{-4}$ to $10^{-6} \mathrm{~m}^{-1}$. However, these studies also have shown that as the deposition ages the resuspension factor drops exponentially and within 30 days of initial deposition the resuspension factor has dropped by 2 to 3 orders of magnitude even on asphalt surfaces. A conservative determination of the appropriate resuspension factor based on age of deposition is given in Radiological Dose Assessment: A Textbook on Environmental Dose Analysis (NRC, 1983).

For all transport mechanisms, it would be expected that contaminant levels generally decrease with distance from the point of release. If present, contamination from the muckpiles and fallout plume is generally expected to be contiguous to the release site, with possible contaminated spots down gradient from the muckpiles in drainages. As previously discussed, data from previous NTS muckpile investigations indicates little to no migration of contaminants into the native material underlying the muckpile.

\section{A.3.2.6 Exposure Scenarios}

The future land-use scenario for CAU 309 includes defense and nondefense research, development, and testing activities (see Table A.3-7).

The Nuclear Test Zone referenced in the table is defined as "reserved for dynamic experiments, hydrodynamic tests, and underground nuclear weapons and weapons effects tests" (DOE/NV, 1998). The potential for exposure to contamination at the CAU 309 CASs is limited to industrial and construction workers as well as military personnel conducting training (DOE/NV, 1998).

Human receptors may be exposed to COPCs through oral ingestion, inhalation, dermal contact (absorption) of soil or debris due to inadvertent disturbance of these materials or irradiation by radioactive materials. 
Table A.3-7

Future Land-Use Scenarios for CAU 309

\begin{tabular}{|c|l||}
\hline Land Use Zone & \multicolumn{1}{c||}{ Zone Description } \\
\hline \hline $\begin{array}{c}\text { Nuclear and High } \\
\text { Explosives Test Zone }\end{array}$ & $\begin{array}{l}\text { This area is designated within the Nuclear Test Zone for additional underground nuclear } \\
\text { weapons tests and outdoor high explosives tests. This zone includes compatible defense } \\
\text { and nondefense research, development, and testing activities (DOE/NV, 1998). }\end{array}$ \\
\hline
\end{tabular}




\section{A.4.0 Step 2 - Identify the Decision}

Step 2 of the DQO process identifies the decision statements and defines alternative actions that may be taken, depending on the answer of the decision statements.

\section{A.4.1 Decision Statements}

The fallout plume and muckpiles will be differentiated in the following sections due to differences associated with the investigation strategies.

The Decision I statement is: "Is any COPC present in environmental media within the CAS at a concentration exceeding its corresponding action level?" Any contaminant associated with a CAS activity that is present at concentrations exceeding its corresponding action levels defined in Section A.7.3 will be defined as a COC. The presence of a contaminant within a CAS will be defined by the analytical detection of a COPC. If a COC is detected, then Decision II must be resolved.

The Decision II statement is: "If a COC is present, is sufficient information available to evaluate potential corrective action alternatives?" Sufficient information is defined to include:

- Identification of the volume of media containing any COC bounded by analytical sample results in lateral and vertical directions.

- Collection of the information needed to characterize IDW for disposal.

If sufficient information is not available to evaluate potential corrective action alternatives then site conditions will be re-evaluated and additional samples will be collected (as long as the scope of the investigation is not exceeded and any CSM assumption has not been shown to be incorrect).

\section{A.4.1.1 Decision Statements for CAS 12-28-01, I-, J-, and K-Tunnel Debris}

Because the investigation of the fallout plume follows a more typical CAI, Decisions I and II given above are precise as presented and no further development is needed. 


\section{A.4.1.2 Decision Statements for CASs 12-06-09, 12-08-02, Muckpiles}

Because the investigation of the CAU 309 muckpiles follows the model developed for the CAU 551 muckpile CAI, further development of the Decision I statement is required.

Based on a recent slope stability study (SNJV, 2004b) of the slopes on and around the two muckpiles, safety hazards exist to the field personnel who would be collecting samples on the muckpiles under sampling programs (e.g., rotosonic drilling) used during previous NTS muckpile investigations. The slope stability study indicated the muckpiles are not stable enough to support a drill rig due to the limited amount of level ground, the steep slopes, and the stability of those slopes. This prevents the collection of sufficient representative sample populations to answer Decision I directly. Therefore, this investigation will adopt an approach to the Decision I statement that conservatively infers the partial resolution of Decision I through the use of historical NTS muckpile data.

This investigation will assume COCs identified at similar sites are present at the CAU 309 muckpiles. To contend with the two types of analytical data inputs (i.e., historical and newly acquired data), the Decision I statement has been further broken out into three supporting decision statements. The Decision I statements, their relationships to one another in the decision process, and the role of historical and new sample data for CAU 309 muckpiles are depicted in Figure A.4-1.

Decision Ia addresses historical muckpile data only. During the Decision Ia process, the COCs that are identified by a review of historical muckpile data as exceeding current PALs will become the expected COCs for the CAU 309 CASs associated with the muckpiles and are termed "exp-COCs." To establish guidelines for the CSM, expected concentration ranges for these exp-COCs need to be set. These concentration ranges for each exp-COC will be set at twice the highest detected concentration that was determined from the CAIs conducted at CAUs 475, 476, 477, 482, and 504. The exp-COCs are the same as the critical COPCs for the purpose of this investigation, but are differentiated given the context in which they are discussed.

Decision Ib addresses the identification of COCs in new samples collected at the CAU 309 muckpiles.

Decision Ic addresses the fit of the newly generated data into the CSM constructed for CAU 309, including the presence of exp-COCs. The convention for differentiating between the exp-COCs and 


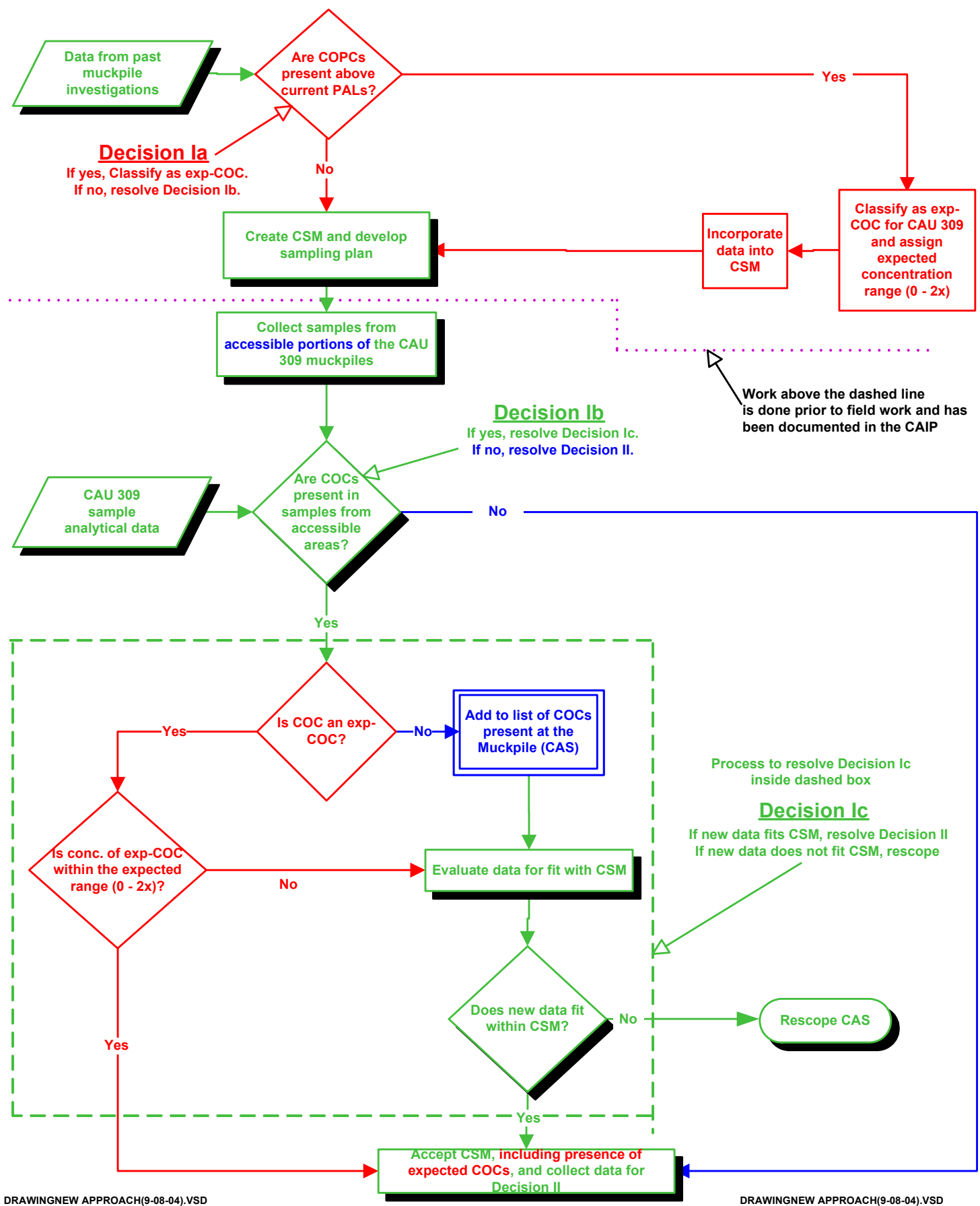

Key
green \& shadow boxes = typical DQO process

red \& no shadow boxes $=$ similar sites evaluation of data from blue $\&$ double line boxes $=$ other site-specific variation

Figure A.4-1

CAU 309 Decision Flow Diagram 
the newly identified COCs found from Decision I sampling at CAU 309 muckpiles is to term the latter COCs as "newly identified COCs." The acronym "COC" will be used either generically or in reference to the sum of exp-COCs and newly identified COCs.

The Decision Ia statement is:

- Are COPCs present in muck samples collected during previous muckpile investigations at levels above current PALs?

The two Decision I statements addressing newly acquired muckpile data are:

- Decision Ib statement is: Are COCs present in the samples that can be collected at CAU 309 muckpiles?

- Decision Ic statement is: Does the data acquired at CAU 309 muckpiles support the CSM, including the outputs of Decisions Ia and Ib?

Decision Ia, which only addresses historical data, can be answered by examining data from the previous muckpile investigations at the NTS. Using data from these investigations assumes that the CAU 309 CSM for muckpiles is consistent with the CSMs for the previously investigated muckpiles in several key areas including source of potential contamination, affected media, location of contamination/release points, and transport mechanisms. Based on the comparative evaluation of the CAU 309 muckpiles to the previously investigated muckpile in these key areas as presented in Appendix B, it was determined there is sufficient similarity in the CSMs to accept this assumption. Specific areas where the CSMs for muckpiles differed and the potential impact on the CAU 309 investigation are also addressed in Appendix B.

Because of the additional release scenario of containment failure present in the CAU 309 CSM it is important to note that additional surface/near-surface samples will be collected to account for the potential presence of contamination due to the J- and K-Tunnel ventings.

To answer Decision Ia (which COPCs might become exp-COCs for CAU 309 muckpiles), historical data from previous muckpile investigations were used to determine which COPCs were detected in previous muckpile investigations at concentrations above the current PALs (see Appendix B and Table A.4-1). All COCs identified in previous muckpile investigations are listed as target analyses in Table A.3-1. 
Table A.4-1

Expected COCs for CAU 309 Muckpile Investigation

\begin{tabular}{|c|l|c|c|c|c||}
\hline COC & \multicolumn{1}{|c|}{$\begin{array}{c}\text { Summary of Detects for } \\
\text { Previous Muckpile } \\
\text { Investigation }\end{array}$} & $\begin{array}{c}\text { Highest } \\
\text { Concentration } \\
\text { Detected }\end{array}$ & $\begin{array}{c}\text { Two Times } \\
\text { Highest } \\
\text { Concentration }\end{array}$ & PAL & Units \\
\hline \hline Arsenic & 1 detection above PAL at CAU 477 & 38.8 & 77.6 & 23 & $\mathrm{mg} / \mathrm{kg}$ \\
\hline Lead & 2 detections above PAL at CAU 477 & 59,700 & 119,400 & 750 & $\mathrm{mg} / \mathrm{kg}$ \\
\hline TPH-DRO & $\begin{array}{l}\text { Multiple detections above PAL at } \\
\text { CAUs 475, 476, 477 }\end{array}$ & 10,000 & 20,000 & 100 & $\mathrm{mg} / \mathrm{kg}$ \\
\hline Cesium-137 & $\begin{array}{l}\text { Multiple detections above PAL at } \\
\text { CAUs 476, 477, 482, 504 }\end{array}$ & 3,050 & 6,100 & 7.3 & $\mathrm{pCi} / \mathrm{g}$ \\
\hline Cobalt -60 & $\begin{array}{l}\text { 2 detections above PAL at CAUs 476, } \\
504\end{array}$ & 5.3 & 10.6 & 1.61 & $\mathrm{pCi} / \mathrm{g}$ \\
\hline Plutonium-238 & 1 detection above PAL at CAU 504 & 20.2 & 40.4 & 7.78 & $\mathrm{pCi} / \mathrm{g}$ \\
\hline Plutonium-239 & $\begin{array}{l}6 \text { detections above PAL at CAUs 476, } \\
482,504\end{array}$ & 122 & 244 & 7.62 & $\mathrm{pCi} / \mathrm{g}$ \\
\hline
\end{tabular}

To answer Decision Ib (Are COCs present in CAU 309 muckpiles from areas that can be sampled?), samples will be collected from accessible portions of the CAU 309 muckpiles that are most likely to contain the highest concentrations of contaminants, and evaluated against the PALs identified in Step 3.

To answer Decision Ic (Does the new data fit within the CSM?), the CAU 309 muckpile sample COC data will be evaluated against muckpile CSM parameters for both COC status and concentrations. Only within Decision Ic would a rescoping of the CAI for the muckpile CAS be considered. If actual concentrations in samples collected from CAU 309 muckpiles are found to exceed the exp-COC range (greater than $2+$ the highest previously detected concentration, see Table A.4-1), the CSM will be reevaluated.

To determine the concentration of COCs for purposes of selecting, designing, and implementing potential corrective actions, the following rules will be applied. For exp-COCs detected at concentrations above the highest detected concentration in muck samples from previous NTS muckpile investigations, the highest concentration detected in the applicable CAU 309 muckpile will be assigned, or else the highest previous detected concentration will be assigned. For newly identified COCs, the highest concentration detected in the applicable CAU 309 muckpile sample will be assigned. 
The potential recommended corrective actions for the CAU 309 muckpiles are likely to be limited to closure in place. Therefore, the conservative approach to the investigation and designation of exp-COCs and concentrations is not anticipated to lead to an overly restrictive burden on potential corrective actions.

\section{A.4.2 Alternative Actions to the Decision}

In this section the actions that may be taken to solve the problem are identified depending on the possible outcomes of the investigation. An alternative decision statement has been developed for each decision identified in the previous section.

\section{A.4.2.1 Alternative Actions to Decision I for CAS 12-28-01 (Fallout Plume)}

If no COPCs associated with a release from the CAS is detected then further assessment of the CAS is not required.

If COPCs are detected above PALs, is sufficient information available to evaluate potential corrective action alternatives?

\section{A.4.2.2 Alternative Actions to Decision I for CASs 12-06-09 and 12-08-02 (Muckpiles)}

The alternative for Decision Ia is: If no COPCs are present in samples of muck collected during previous NTS muckpile investigations at concentrations above current PALs, no exp-COCs will be identified for this CAU. COPCs present in samples of muck collected during previous NTS muckpile investigations at concentrations above current PALs will be identified as exp-COCs for CAU 309.

The alternatives for Decision Ib are: If the new data does not identify any additional COCs, resolve Decision II (Is sufficient information available to evaluate potential corrective action alternatives for the exp-COCs?). If the new data identifies COCs, resolve Decision Ic for the exp-COCs and the newly identified COCs.

The alternatives for Decision Ic are: If the new data from a CAU 309 muckpile does not fit within the CSM, rescope the CAS. If the new data does fit within the CSM, is sufficient information available to evaluate potential corrective action alternatives? 


\section{A.4.2.3 Alternative Actions to Decision II for CAU 309 CASs}

If sufficient information is available to evaluate potential corrective action alternatives then further assessment of the CAS is not required.

"If the extent of migration for a $\mathrm{COC}$ is defined in lateral directions, further assessment of the CAS is not required. If the extent of a $\mathrm{COC}$ is not defined, reevaluate site conditions and collect additional samples."

Regardless of the outcome for the analysis of Decision I samples, Decision II samples will be taken for the muckpiles at (1) areas below the foot of the muckpiles, (2) at the confluence of drainages (targeting settling basins), and (3) at the point prior to which the drainages intersects the P-Tunnel wash by the main access road. 


\section{A.5.0 Step 3 - Identify the Inputs to the Decisions}

This step identifies the information needed, determines sources for information, and identifies sampling and analysis methods that will allow reliable comparisons with action levels.

\section{A.5.1 Information Needs for Decision I}

To resolve Decision I for CAS 12-28-01 (determine if a COC is present), samples need to be collected and analyzed following these two criteria: (1) samples must be collected in areas most likely to contain a COC; and (2) the analytical suite selected must be sufficient to identify any COCs present in the samples. Biasing factors to support Criterion \#1 are listed in Section A.5.3.1.

To resolve decision Ia for CASs 12-06-09 and 12-08-02 historical data derived from previous NTS muckpile investigations was used. The input can be obtained prior to field sampling and is presented in this document. The use of historical data is carried out under the implicit assumption that previous muckpile data was generated using a properly implemented DQO process, thus the data generated from these investigations provides an accurate representation of the conditions at the applicable CAU.

In order to determine if COCs other than exp-COCs are present at a muckpile CAS, decision $1 \mathrm{~b}$ sample data must be collected and analyzed following these two criteria: (1) samples must be collected in accessible areas most likely to contain a COC, and (2) the analytical suite selected must be sufficient to detect any COCs present in the samples.

\section{A.5.2 Information Needs for Decision II}

To resolve Decision II (determine if sufficient information is available to evaluate potential corrective action alternatives at each CAS), samples need to be collected and analyzed to meet the following criteria:

- Samples must be collected in areas contiguous to the contamination but where contaminant concentrations are below action levels.

- Samples of the waste or environmental media must provide sufficient information to characterize the IDW for disposal. 
- The analytical suites selected must be sufficient to detect COCs at concentrations equal to or less than their corresponding action levels

In order to determine the extent of a COC for Decision II, samples will be collected from locations to bound the lateral extent. Due to the hazards present on the muckpiles, determination of the vertical boundary is not feasible; drill rigs could not be set up and operated around the muckpiles. Information for vertical extent of COCs will be obtained from previous muckpile investigations. Decision II sampling analytical suites may be limited to those COCs that exceed PALs in prior samples (both CAU 309 and other muckpiles). The data required to satisfy the information needs for Decision II for each COC is a step-out sample concentration that is below the corresponding PAL. Step-out locations will be selected based on the CSM, biasing factors, and previous analytical results.

When analytical results or other biasing factors suggest that the COC concentrations at the step-out location(s) may still exceed the PAL, an additional step-out distance may be used to define the lateral extent of contamination. In that case, sampling may consist only of sampling from deeper intervals at or near the original location to determine the vertical extent of contamination. In most cases, vertical sampling beyond the limit of hand sampling techniques (approximately 2 to $5 \mathrm{ft}$ bgs) will not be possible based on the practical constraints imposed by the topography of the site.

Sampling locations may be moved due to access problems, underground utilities, or safety issues; however, the modified locations must meet the decision requirements and criteria necessary to fulfill the information needs.

Where vertical sampling is not possible, vertical contaminants may be estimated using decreasing trends or contaminant migration data from similar investigations.

\section{A.5.3 Sources of Information}

Information to satisfy Decision I and Decision II will be other muckpile investigations and generated by collecting environmental samples using grab sampling, hand auguring, or other appropriate sampling methods. These samples will be submitted to analytical laboratories meeting the quality criteria stipulated in the Industrial Sites QAPP (NNSA/NV, 2002a). Only validated data from analytical laboratories will be used to make DQO decisions. On-site gamma spectrometry and 
radiological survey results may be used to aid in selecting sample locations. Sample collection and handling activities will follow standard procedures.

\section{A.5.3.1 Sample Locations}

Decision I samples must be collected at locations most likely to contain a COC, if present. These locations will be selected based on field-screening techniques, biasing factors, the CSM, and existing information. Analytical suites for Decision I samples will include all COPCs identified in Table A.3-3.

Field-screening techniques may be used to select appropriate sampling locations by providing semiquantitative data that can be used to comparatively select samples to be submitted for laboratory analyses from several screening locations. Field screening may also be used for health and safety monitoring and to assist in making certain health and safety decisions. The following field-screening methods may be used to select analytical samples at CAU 309:

- TPH - A gas chromatograph, or equivalent equipment or method, may be used at all CAS because TPH is a common concern at the NTS and has not been ruled out based upon process knowledge. TPH field screening will be conducted at the discretion of the site supervisor based on biasing factors and results of previous samples.

- Surface area radiological surveys - A plastic scintillator will be used over approximately 100 percent of the CAS boundaries, as permitted by terrain and field conditions to detect hot spots of radiological contamination. Results of surveys may be used in conjunction with laboratory soil sample analytical results to correlate field screening readings to $\mathrm{pCi} / \mathrm{g}$ equivalents for the purpose of selecting additional sample locations.

- Alpha and Beta/Gamma Radiation - An NT Technology Electra, or equivalent instrument or method.

- Gamma Radiation - Gamma spectrometry, or an equivalent instrument or method, may be used. Results of the gamma spectrometry may be used to estimate the concentration of $\mathrm{Pu}-238, \mathrm{Pu}-239 / 240$, and $\mathrm{Sr}-90$, based on known ratios of these isotopes to gamma-emitting isotopes. 
Biasing factors may also be used to select samples to be submitted for laboratory analyses based on existing site information and site conditions discovered during the investigation. The following factors will be considered in selecting locations for analytical samples at CAU 309:

- Aerial photograph review and evaluation

- Walk-over radiological surveys

- Visual indicators such as discoloration, textural discontinuities, disturbance of native soils, or any other indication of potential contamination

- Known or suspected sources and locations of release

- Process knowledge on source and location of releases (muckpile and fallout deposition)

- Geologic and/or hydrologic conditions

- Field-screening results (radiological and chemical)

- Historical survey data

- Physical and chemical characteristics of contaminants

- Areas of erosion

- Areas of sediment collection in the wash

- Previous sample or screening results

- Presence of debris, waste, or equipment

Decision II sample step-out locations will be selected based on the CSM, biasing factors, and existing data. Analytical suites will include those parameters that exceeded action levels (i.e., COCs) in prior samples. Biasing factors to support Decision II sample locations include Decision I biasing factors plus available analytical results.

\section{A.5.3.2 Analytical Methods}

Analytical methods are available to provide the data needed to resolve the decision statements. The analytical methods and laboratory requirements (e.g., detection limits, precision, and accuracy) are 
CAU 309 CAIP

Appendix A

Revision: 0

Date: December 2004

Page A-40 of A-63

provided in Table 3-5 and Table 3-6 of the CAIP along with specific analyses required for the disposal of IDW. 


\section{A.6.0 Step 4 - Define the Boundaries of the Study}

The purpose of this step is to define the population of interest, define the spatial boundaries, determine practical constraints on data collection, and define the scale of decision making.

\section{A.6.1 Populations of Interest}

The population of interest to resolve Decision I ("Is any COPC present in environmental media within the CAS at a concentration exceeding its corresponding action level?") is any single location within the site that is contaminated with any contaminant above an action level. The populations of interest to resolve Decision II ("If a COC is present, is sufficient information available to evaluate potential corrective action alternatives?”) are:

- Each one of a set of locations bounding contamination in lateral and vertical directions.

- IDW or environmental media that must be characterized for disposal

- Potential remediation waste

The populations of interest for the CAU 309 muckpiles Decision Ia are the highest detected concentrations of COCs in sample analytical data for samples of muck collected during previous NTS muckpile investigations. The use of historical data is carried out under the implicit assumption that previous muckpile data was generated using a properly implemented DQO process; therefore, the data generated from these investigations provides an accurate representation of the conditions at the applicable CAU.

Decision I populations of interest for CAS 12-28-01 and Decision Ib populations of interest for CASs 12-06-09 and 12-08-02 represent locations within the CASs that contain COCs, if present. Decision II populations of interest for all CASs are areas within the CASs where COC concentrations are less than PALs and are contiguous to areas of COC contamination. These populations of interest represent locations within the CAS that, when sampled, will provide sufficient data to resolve the primary problem statement (Section A.4.1). 
The populations of interest for the CAS 12-28-01 Decision I samples, and CASs 12-06-09 and 12-08-02 Decision Ib samples, are:

- Soil with elevated radiological readings based on surface radiological surveys.

- The material in accessible areas of the muckpiles.

The populations of interest for the Decision Ic are:

- All COCs identified in Decisions I and Ib.

The populations of interest for the Decision II samples are:

- The native material in lateral areas around areas with elevated radiological readings, or contiguous to the muckpiles (contamination, if present, is expected to be contiguous to the release site, with possible contaminated spots down gradient from the muckpiles in drainages).

\section{A.6.2 Spatial Boundaries}

Spatial boundaries are the maximum lateral and vertical extent of expected contamination at each CAS, as shown in Table A.6-1 and Figure A.2-5. The vertical spatial boundary at CAS 12-28-01 has been established at $2 \mathrm{ft}$ bgs. Analysis of plutonium distribution due to aerial deposition in a desert pavement desert-mound soil system in Area 11 of the NTS has identified the following:

- For desert pavement environs 95 percent of the radiological activity is contained in the surface layer of the soil ( 0 to 2.5 centimeters $[\mathrm{cm}])$ with the remaining 5 percent of the activity distributed in the lower horizons to a depth of $10 \mathrm{~cm}$ (NAEG, 1977).

- For desert-mound environs 60 percent of the radiological activity is contained in the surface layer of the soil ( 0 to $2.5 \mathrm{~cm})$ with 30 percent contributions in the $2.5-$ to $5.0-\mathrm{cm}$ interval, and 7 percent contributions in the 5.0 - to $7.5-\mathrm{cm}$ interval. This suggests a sizable mound buildup subsequent to the detonation event (NAEG, 1977).

Contamination found beyond the boundaries described in Table A.6-1 may indicate a flaw in the CSM and may require re-evaluation of the CSM before the investigation could continue. The CASs are not considered geographically independent so intrusive activities may extend into the boundaries of neighboring CASs due to the nature of the fallout plume. 
Table A.6-1

Spatial Boundaries of CAU 309 CASs

\begin{tabular}{|c|l||}
\hline Corrective Action Site & \multicolumn{1}{c|}{ Spatial Boundaries } \\
\hline \hline $12-06-09$ & $\begin{array}{l}\text { The footprint of each muckpile and associated drainage plus a } \\
200-f t \text { lateral buffer; } 5 \mathrm{ft} \text { bgs vertically. }\end{array}$ \\
\hline $12-08-02$ & $\begin{array}{l}\text { The footprint of the fallout plume plus a } 500-\mathrm{ft} \text { lateral buffer; } \\
2 \mathrm{ft} \text { bgs vertically. }\end{array}$ \\
\hline $12-28-01$ & \\
\hline
\end{tabular}

\section{A.6.3 Practical Constraints}

The primary practical constraints to be encountered at the muckpiles are the inability to collect samples by mechanical means from the muckpiles due to unstable conditions and safety considerations, and the safety hazards that hand-sampling personnel will encounter due to the steepness of the slopes (e.g., unstable soil, steep slopes, and lack of staging areas for drill rigs). Additional practical constraints for all CASs include steep slopes, the presence of overhead and underground utilities. Utility constraints are subject to change as additional information is collected prior to the commencement of investigation activities, and will be appropriately documented. Locations where intrusive activities are planned will be surveyed for utilities prior to field activities in accordance with the site-specific health and safety plan.

The combination of steep slopes and the presence of radiological conditions on the muckpiles and in the surrounding slopes establish added potential constraints for field personnel to set up hot lines and travel across the rugged terrain while dressed out in PPE. Decisions on accessibility to potential samples locations made in the field will be documented.

Prior to samples being taken, the proposed locations will be examined by the Site Supervisor and Site Safety Officer for accessibility and to ensure that safe movement in the area is possible. Sampling will not be conducted in areas that expose workers to entrapment or engulfing hazards from unstable soil and/or excessive slopes. Also, any hazardous conditions that would endanger the individuals surveying or sampling shall be taken into consideration.

Nevada Test Site-controlled activities (e.g., military exercises) may affect the ability to investigate the CASs. 


\section{A.6.4 Define the Scale of Decision Making}

The scale of decision making in Decision I is defined as the CAS. Any COC detected at any location within the CAS will cause the determination that the CAS is contaminated and needs further evaluation. The scale of decision making for Decision II is defined as a contiguous area contaminated with any COC originating from the CAS. Resolution of Decision II requires this contiguous area to be bounded laterally and vertically. 


\section{A.7.0 Step 5-Develop a Decision Rule}

This step develops a decision rule ("If..., then...") statement that defines the conditions under which possible alternative actions will be chosen. In this step, we specify the statistical parameters that characterizes the population of interest, specify the action levels, confirm that detection limits are capable of detecting action levels, and present decision rules.

\section{A.7.1 Population Parameter}

Each sample result representing each population of interest defined in Step 4 will be compared to the action levels to determine the appropriate resolution to Decision I and Decision II. For the Decision I population of interest, a single analytical sample result above action levels would cause a determination that a COC is present within the CAS. The population parameter for all Decision I and Decision II data is the observed concentration of each COPC within the target population. For the CAU 309 muckpiles, this observed concentration will be the maximum value from previous muckpile investigations or the new COPC data values generated from sampling in accessible areas of the CAU 309 muckpiles.

\section{A.7.2 Decision Rule}

The decision rule applicable to both Decision I and Decision II is:

- If contamination is inconsistent with the CSM or extends beyond the spatial boundaries identified in Section A.6.2, then work will be suspended and the investigation strategy will be reconsidered. If contamination is consistent with the CSM and is within spatial boundaries, then the decision will be to continue sampling to define the extent.

The decision rule for Decision I is:

- If the population parameter (the observed concentration of each analyte) of any COPC in the Decision I population of interest (defined in Step 4) exceeds the corresponding action level, then that analyte is identified as a COC, and Decision II samples will be collected. If all COPC concentrations in samples collected from the CAU 309 muckpiles are less than the corresponding PALs, the decision will be that only those COPCs considered exp-COCs will be assumed to be present at the CAU 309 muckpiles. If all COPC concentrations in samples collected from the fallout plume are less than the corresponding PALs, then no further action is required. 
The decision rules for Decision II are:

- If the population parameter (the observed concentration of any COC) in the Decision II population of interest (defined in Step 4) exceeds the corresponding action level, then additional samples will be collected to complete the Decision II evaluation. If all observed COC concentrations are less than the corresponding action levels, then the decision will be that the extent of contamination has been defined in the corresponding lateral and/or vertical direction.

If valid analytical results are available for the waste characterization samples then the decision will be that sufficient information exists to characterize the IDW for disposal, determine potential remediation waste types, and to evaluate the feasibility of remediation alternatives.

\section{A.7.3 Preliminary Action Levels}

The PALs presented in this section are to be used for site-screening purposes. They are not necessarily intended to be used as cleanup action levels or FALs. However, they are useful in screening out analytes that are not present in sufficient concentrations to warrant further evaluation; therefore, streamline the consideration of remedial alternatives. The process that will be used to move from PALs to FALs is to:

- Establish FALs that are equal to the PALs.

- Establish FALs based on risk to human health and the environment.

If FALs are used that are not equal to the PALs, the derivation of the FALs will be presented in an appendix to the investigation report. The FALs (along with the basis for their selection) will be proposed in the investigation report where they will be compared to laboratory results in the evaluation of potential corrective actions.

\section{A.7.3.1 Chemical PALs}

Except as noted herein, the chemical PALs are defined as the EPA Region 9 risk-based PRGs for chemical constituents in industrial soils (EPA, 2002c). Background concentrations for RCRA metals will be used instead of PRGs when natural background concentrations exceed the PRG, as is often the case with arsenic on the NTS. Background is considered the mean plus two standard deviations of the mean for sediment samples collected by the Nevada Bureau of Mines and Geology throughout the Nevada Test and Training Range (formerly the Nellis Air Force Range) (NBMG, 1998; Moore, 
1999). For detected chemical COPCs without established PRGs that have toxicity and carcinogenicity data listed in the EPA IRIS database (EPA, 2002d), the protocol used by the EPA Region 9 in establishing PRGs (or similar) will be used to establish PALs. If used, this process will be documented in the investigation report. The specific chemical PALs for CAU 309 are listed in Table 3-5 of the CAIP.

\section{A.7.3.2 Total Petroleum Hydrocarbon PALs}

The PAL for TPH is 100 ppm as listed in the NAC 445A.2272 (NAC, 2003).

\section{A.7.3.3 Radionuclide PALs}

The PALs for radiological contaminants are based on the NCRP Report No. 129 recommended screening limits for construction, commercial, industrial land-use scenarios (NCRP, 1999) scaled from 25 to $15 \mathrm{mrem} / \mathrm{yr}$ dose constraint and the generic guidelines for residual concentration of radionuclides in DOE Order 5400.5 (DOE, 1993). These PALs are based on the Construction, Commercial, Industrial land-use scenario provided in the guidance and are appropriate for the NTS based on future land use scenarios as presented in Section A.3.2. The specific radiological PALs for CAU 309 are listed in Table 3-5 of the CAIP.

Solid media such as concrete and/or structures may pose a potential radiological exposure risk to site workers if contaminated. The radiological PAL for solid media will be defined as the unrestricted-release criteria defined in the NV/YMP RadCon Manual (DOE/NV, 2000b).

\section{A.7.4 Measurement and Analysis Sensitivity}

The measurement and analysis methods listed in Section A.5.3.2 and in the Industrial Sites QAPP (NNSA/NV, 2002a) are capable of measuring analyte concentrations at or below the corresponding action levels for each COPC, unless specified otherwise in the CAIP. See Table 6.2-8 of the CAIP for additional details. 


\section{A.8.0 Step 6 - Tolerable Limits on Decision Errors}

The purpose of this step is to specify performance criteria for the decision rule. Setting tolerable limits on decision errors is neither obvious nor easy. It requires the planning team to weigh the relative effects of threat to human health and the environment, expenditure of resources, and consequences of an incorrect decision. Section 7.1 of the EPA QA/G-4HW guidance (EPA, 2000a) states that if judgemental sampling approaches are used, quantitative statements about data quality will be limited to measurement error. Measurement error is influenced by imperfections in the measurement and analysis system. Random and systematic measurement errors are introduced in the measurement process during physical sample collection, sample handling, sample preparation, sample analysis, and data reduction. If measurement errors are not controlled they may lead to errors in making the DQO decisions.

The steepness of the slopes on and around the CAU 309 muckpiles creates hazardous conditions for sampling personnel and prohibits the use of mechanized sampling equipment on the muckpiles. This limits the areas of the muckpiles from which samples can be collected. Decision I samples will be collected from accessible locations based on biasing factors such as walk-over surveys, drainage patterns, etc. The approach for making DQO decisions is based on the results of individual samples (both historic from similar sites and newly acquired samples); therefore, statistical analysis of CAU 309 muckpile samples is not appropriate. The sampling strategy for CAS 12-28-01 (fallout plume) includes collecting samples from hotspots biased from the surface radiological walk-over survey; therefore, statistical analysis of these samples is not appropriate.

This section provides an assessment of the possible outcomes of DQO decisions and the impact of those outcomes if the decisions are in error.

The baseline condition (i.e., null hypothesis) and alternative condition for Decision I are:

- Baseline condition - A COC is present.

- Alternative condition - A COC is not present. 
The baseline condition (i.e., null hypothesis) and alternative condition for Decision II are as follows:

- Baseline condition - The extent of a COC has not been defined.

- Alternative condition - The extent of a COC has been defined.

Decisions and/or criteria have false rejection (false negative) or false acceptance (false positive) errors associated with their determination. The impact of these decision errors and the methods that will be used to control these errors are discussed in the following subsections. In general terms, confidence in DQO decisions based on judgmental sampling results will be established qualitatively by:

- The development of and concurrence of conceptual site models (based on process knowledge) by stakeholder participants during the DQO process;

- Testing the validity of conceptual site models based on investigation results; and

- Evaluating the quality of the data based on DQI parameters.

\section{A.8.1 False Negative Decision Error}

The false negative decision error would mean deciding that a COC is not present when it actually is (Decision I), or deciding that the extent of a COC has been defined when it has not (Decision II). In both cases the potential consequence is an increased risk to human health and environment.

For the muckpiles, a false negative decision error is more improbable due to the assumption of a worst-case scenario (e.g., highest concentrations of COCs detected in previous muckpile investigations). However, some uncertainty does exist. The assumptions may not be correct (e.g., levels of exp-COCs could be higher, or non-expected COCs could be present). The CAI for CAU 309 muckpiles will protect against this type of error by collecting Decision I samples from the CAU 309 muckpiles to reduce the error inherent in using data from similar sites to characterize CAU 309 muckpiles. For CAS 12-28-01, a false negative decision error is made less probable by selecting soil sampling locations based on the surface radiological survey. 
The false negative decision error (where consequences are more severe) is controlled by meeting these criteria:

1. Having a high degree of confidence that historical data evaluations (Decision Ia for muckpile investigations) combined with data generated from accessible portions of the CAU 309 muckpiles will identify COCs, if present, anywhere within the CASs. For Decision II, having a high degree of confidence that the sample locations selected will identify the extent of COCs.

2. Having a high degree of confidence that analyses conducted on the newly obtained CAU 309 data will be sufficient to detect any COCs present in the samples.

3. Having a high degree of confidence that the dataset is of sufficient quality and completeness.

To satisfy the first criterion, Decision I samples must be collected in areas most likely to be contaminated by COCs. Decision II samples must be collected in areas that represent the lateral and vertical extent of contamination (above action levels). The following characteristics must be considered to control decision errors for the first criterion:

- Source and location of release

- Chemical nature and fate properties

- Physical transport pathways and properties

- Hydrologic drivers

These characteristics were considered during the development of the CSMs and selection of sampling locations. The field-screening methods and biasing factors listed in Section A.5.3.1 will be used to further ensure that appropriate sampling locations are selected to meet these criteria. Radiological survey instruments and field-screening equipment will be calibrated and checked in accordance with the manufacturer's instructions and approved procedures. The investigation report will present an assessment on the DQI of representativeness that samples were collected from those locations that best represent the populations of interest as defined in Section A.6.1.

To satisfy the second criterion, Decision I samples will be analyzed for the chemical and radiological parameters listed in Section 3.2 of the CAIP. Decision II samples will be analyzed for those chemical and radiological parameters that identified unbounded COCs. The DQI of sensitivity will be assessed for all analytical results to ensure that all sample analyses had measurement sensitivities (detection limits) that were less than or equal to the corresponding PALs. If this criterion is not achieved, the 
affected data will be assessed (for usability and potential impacts on meeting site characterization objectives) in the investigation report.

To satisfy the third criterion, the entire dataset, as well as individual sample results, will be assessed against the DQIs of precision, accuracy, comparability, and completeness as defined in the Industrial Sites QAPP (NNSA/NV, 2002a) and in Section 6.2.2 of the CAIP. The DQIs of precision and accuracy will be used to assess overall analytical method performance as well as to assess the need to potentially "flag" (qualify) individual analyte results when corresponding QC sample results are not within the established control limits for precision and accuracy. Data qualified as estimated for reasons of precision or accuracy may be considered to meet the analyte performance criteria based on an assessment of the data. The DQI of completeness will be assessed to ensure that all data needs identified in the DQO have been met. The DQI of comparability will be assessed to ensure that all analytical methods used are equivalent to standard EPA methods so that results will be comparable to regulatory action levels that have been established using those procedures. Site-specific DQIs are discussed in more detail in Section 6.2.2 of the CAIP. Strict adherence to established procedures and QA/QC protocol protects against false negatives. To provide information for the assessment of the DQIs of precision and accuracy, the following quality control samples will be collected as required by the IS QAPP (NNSA/NV, 2002a):

- Field duplicates (minimum of 1 per CAS matrix for environmental samples)

- Laboratory QC samples (minimum of 1 per matrix per 20 environmental samples)

- Matrix spike/matrix spike duplicate (1 per 20 environmental samples or 1 per CAS per matrix, if less than 20 collected, as required by the analytical methods)

\section{A.8.2 False Positive Decision Error}

The false positive (beta) decision error would mean deciding that a COC is present when it is not, or a COC is unbounded when it is not, resulting in increased costs for unnecessary sampling and analysis.

The false positive decision error is controlled by implementing the controls that protect against false negative decision errors. False positive results are typically attributed to laboratory and/or sampling/handling errors that could cause cross contamination. To control against cross contamination, decontamination of sampling equipment will be conducted according to established 
and approved procedures and only clean sample containers will be used. To determine if a false positive analytical result may have occurred, the following quality control samples will be collected as required by the IS QAPP (NNSA/NV, 2002a):

- Trip blanks (1 per sample cooler containing VOC environmental samples)

- Equipment blanks (1 per sampling event for each type of decontamination procedure)

- Field blanks (minimum of 1 per CAS - additional if field conditions change)

For the muckpile investigations, the false positive decision error is further elevated for Decision I by assuming COCs found to be at or above PALs in previous NTS muckpile investigations are present in the CAU 309 muckpiles. This approach, through its conservative orientation, necessitates elevation of a false positive error in order that human and environmental health become more protected. The approach ultimately results in a higher potential for corrective action. However, because the expected corrective action is use restriction, the potential for increased costs due to the conservative assumption is limited (i.e., cost for placing a use restriction is the same regardless of the number of COCs). 


\section{A.9.0 Step 7 - Optimize the Design for Obtaining Data}

This section provides the general approach for obtaining the information necessary to resolve Decision I and Decision II. A judgemental (nonprobabilistic) sampling scheme will be implemented to select sample locations and evaluate analytical results. Judgmental sampling allows the methodical selection of sample locations that target the populations of interest (defined in Step 4) rather than nonselective random locations. Random sample locations are used to generate average contaminant concentrations that estimate the true average ("characteristic") contaminant concentration of the site to some specified degree of confidence.

Since individual sample results, rather than an average concentration, will be used to compare to action levels, statistical methods to generate site characteristics will not be necessary. Section 0.4.4 of the EPA Data Quality Objectives, for Hazardous Waste Site Investigations (2000a) guidance states that the use of statistical methods may not be warranted by program guidelines or site-specific sampling objectives. The need for statistical methods is dependent upon the decisions being made. Section 7.1 of the EPA QA/G-4HW guidance states that a nonprobabilistic (judgmental) sampling design is developed when there is sufficient information on the contamination sources and history to develop a valid CSM and to select specific sampling locations. This design is used to confirm the existence of contamination at specific locations and provide information (such as extent of contamination) about specific areas of the site.

All sample locations will be selected to satisfy the DQI of representativeness in that samples collected from selected locations will best represent the populations of interest as defined in Section A.6.1. To meet this criterion, a biased sampling strategy will be used for Decision I to target areas with the highest potential for contamination, if it is present anywhere in the CAS. Sample locations will be determined based on process knowledge, previously acquired data, or the field screening and biasing factors listed in Section A.5.3.1. If biasing factors are present in soils below locations where Decision I samples were removed, additional Decision I soil samples will be collected at depth intervals selected by the Site Supervisor based on biasing factors to a depth where the biasing factors are no longer present. The Site Supervisor has the discretion to modify the sample locations, but only if the modified locations meet the decision needs and criteria stipulated in this DQO. 
To meet the DQI of representativeness for step-out (Decision II) samples (that Decision II sample locations represent the population of interest as defined in Section A.6.1), sampling locations at each CAS will be selected based on the outer boundary sample locations where COCs were detected, the CSM, and other field screening and biasing factors listed in Section A.5.3.1. In general, Decision II sample locations will be arranged in a triangular pattern around the Decision I location at distances based on site conditions, process knowledge, and biasing factors. At CAU 309, this may be adjusted to concentrate Decision II samples down slope where migration is more likely. If COCs extend beyond the initial step-outs, Decision II samples will be collected from incremental step-outs. Initial step-outs will be at least as deep as the vertical extent of contamination defined at the Decision I location and the depth of the incremental step-outs will be based on the deepest contamination observed at all locations. A clean sample (i.e., COCs less than FALs) collected from each step-out direction (lateral or vertical) will define extent of contamination in that direction. The number, location, and spacing of step-outs may be modified by the Site Supervisor, as warranted by site conditions.

\section{General Investigation Strategy}

The initial activities to be conducted will be a visual inspection of the site and a surface radiation survey of accessible areas of the fallout plume. The visual inspection and radiation survey will provide biasing factors for locating soil samples and will be used to identify any potential conditions that may affect sampling and sample locations.

\section{Radiological Survey Methodologies, Instruments, and Sampling}

Land radiological surveys will be conducted to determine the presence of surficial gamma and high-energy beta-emitting radiological contaminants. A radiological survey will be performed at CAU 309 by either walk-over methods and/or aerial survey methods, and cover as much of an area as terrain and field conditions permit. A plastic scintillator will be used as the instrument for the walk-over survey. Additional equipment and software to be used in the radiological data collection and processing include a Trimble ${ }^{\mathrm{TM}}$ GPS receiver, laptop computer used to log and process the data and Surfer ${ }^{\mathrm{TM}}$ software to plot the data. DOE Order 5400.5 (DOE, 1993) defines residual concentrations of radioactive material in soil as those concentrations in excess of background concentrations averaged over an area of 100 square meters $\left(\mathrm{m}^{2}\right)$; therefore, a 10 - by 10 -meter area of 
the highest contamination will be selected based on the results of the radiological walk-over survey. The 10- by 10-m area will then be divided into four quadrants. A surface sample (0- to 6-in bgs) will be collected from the approximate center of each quadrant. Deeper bounding samples (1- to 3-ft bgs) will be collected at several locations to confirm contaminants are not migrating vertically. Selected samples will be sent to an off-site laboratory for analysis. The general aerial extent of the survey is shown in Figure A.9-1 and includes the general area of the north-south oriented elongated circles and the area between them. This area is shows the general extent of the fallout plume and may be adjusted if field conditions warrant. Due to the practical constraints discussed in Section A.6.3, a walk-over survey will not cover areas of steep terrain such as the mesa face but will cover the area on top of the mesa around the boreholes, if accessible.

The following sections discuss additional CAS-specific investigation activities. As the sampling strategy for each CAS is developed, specific biasing factors will be described. In the absence of biasing factors, samples will be collected from the default sampling locations described for each CAS.

\section{A.9.1 CAS 12-28-01, I-, J-, and K-Tunnel Debris}

A biased sampling strategy will be used for Decision I to target the area with the highest potential for contamination (i.e., radiological hotspots). The sample location will be determined based on the biasing factors listed in Section A.5.3.1. Samples will be collected at:

- Areas of elevated radiological readings

- From under a minimum of five pieces of debris (rust may flake off and contribute to point-source contamination)

- The mesa top by the boreholes, if accessible 


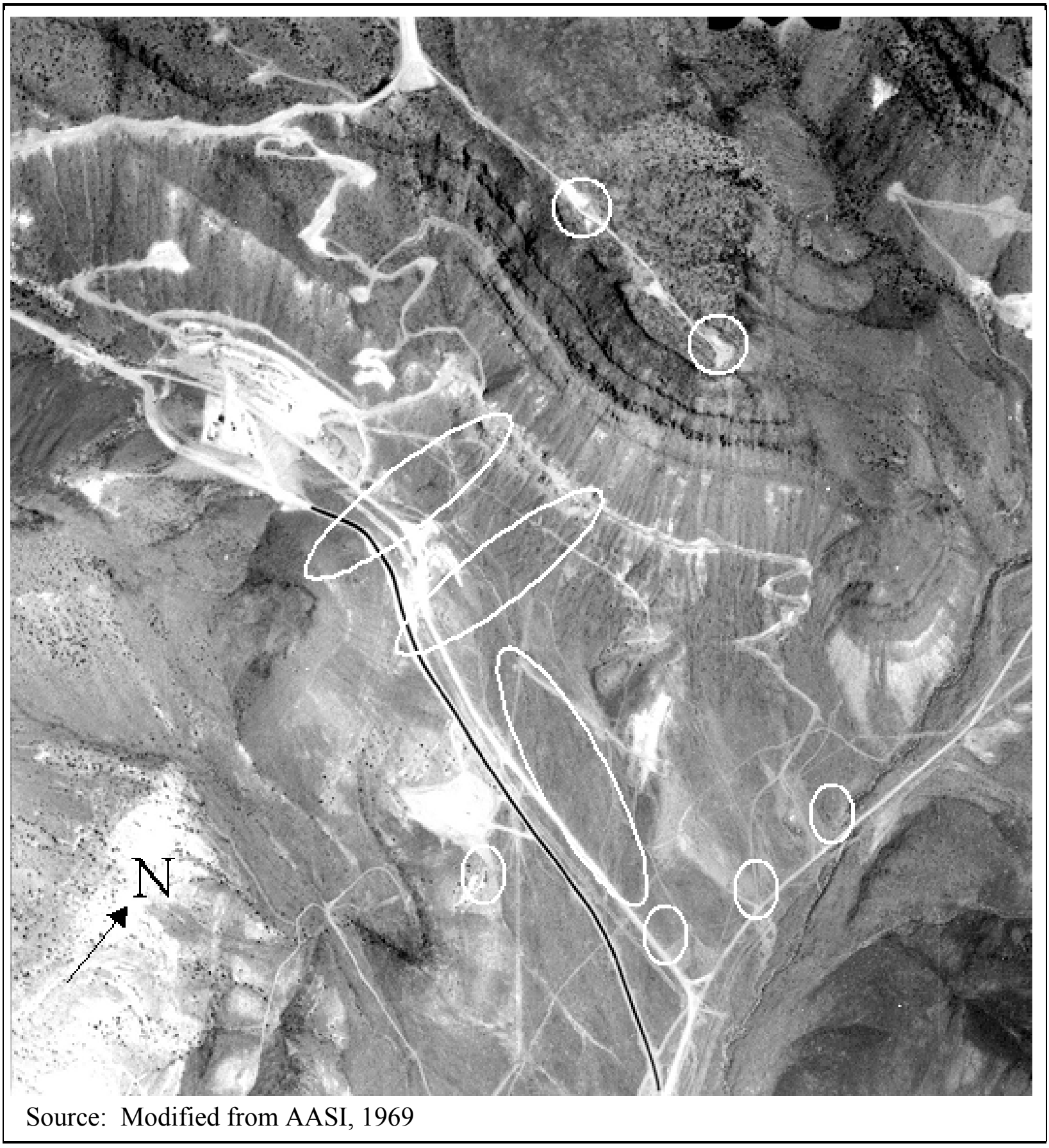

Figure A.9-1

\section{Estimated Sampling Areas for Fallout Plume}


As discussed in Section A.6.2, the majority of contamination from aerial dispersion in desert mound environments is expected to be found in the top 2 in. (approximately the top $5.0 \mathrm{~cm}$ ) of soil.

Therefore, initial Decision I surface samples for the fallout plume will be limited to 0 to 2 in. bgs. If biasing factors are present in soil below the location where the Decision I sample was removed, subsurface Decision I soil samples will be collected by hand augering. Decision I subsurface soil samples will be collected at depth intervals selected by the Site Supervisor based on biasing factors to a depth where the biasing factors are no longer present. The CAU 309 general sampling areas believed to be accessible within safety guidelines are shown in Figure A.9-1. The circled sampling areas shown in the figure were chosen based on biasing factors including fallout debris paths, walkover surveys, previous sample results, and drainage areas in and exiting the CAS boundary.

To meet the DQI of representativeness step-out (Decision II) sample locations will be arranged around the Decision I location at distances based on site conditions, process knowledge, and biasing factors. If COCs extend beyond the initial step-outs, Decision II samples will be collected at the maximum depth where COCs were encountered and from two additional depth intervals. If the FSRs are not greater than field-screening levels (FSLs), one of these samples (typically the uppermost) will be submitted to the laboratory for analysis. A minimum of one clean sample (i.e., FSLs less than FSRs) will be collected from each lateral and vertical direction and submitted for laboratory analysis to define the extent of COC contamination. The lateral and vertical extent of COCs will be established based on validated laboratory analytical results. The number, location, and spacing of step-outs may be modified by the Site Supervisor as warranted by site conditions. This sampling approach is designed to bound the COCs both vertically and horizontally.

\section{A.9.2 CAS 12-06-09, Muckpile, and CAS 12-08-02, CWD}

The CAU 309 general sampling areas believed to be accessible within safety guidelines are shown in Figure A.9-2. Decision I sample locations are depicted with small black dots and Decision II sample locations are depicted in large white elongated circles. Final sampling areas will be made in the field based on newly identified biasing factors (visual inspection and radiological surveys). The visual inspection will focus on identifying evidence of contamination in the muckpiles, including any visible soil staining, debris that may contribute to soil contamination, and areas of erosion and drainage. The visual inspection will be conducted by walking on and around accessible areas. Areas of elevated 


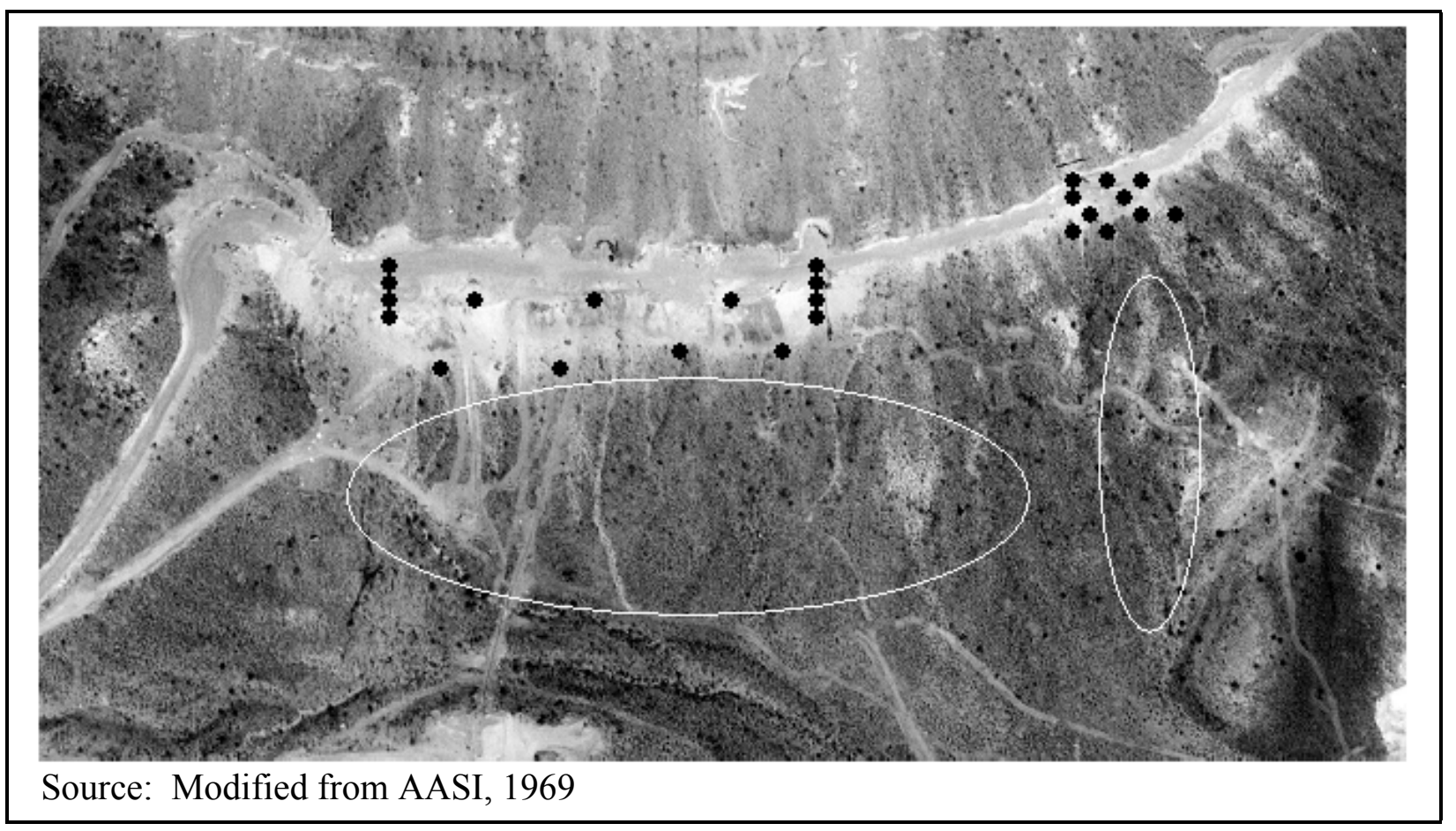

Figure A.9-2

Estimated Sampling Areas for Muckpiles

radioactivity identified during the radiological survey will be recorded and sampled as appropriate. The information generated during these initial activities will be used to provide additional biasing factors for the placement of field screening and confirmatory soil samples.

In general, samples submitted for off-site analysis will be those that best meet the DQI for representativeness and those that define the nature (Decision I) and extent (Decision II) of COCs.

Approximately 10 to 15 soil samples will be collected for Decision I in accessible areas of each muckpile for CAS 12-06-09 and CAS 12-08-02. One surface sample ( 0 to $0.5 \mathrm{ft} \mathrm{bgs)} \mathrm{will} \mathrm{be}$ collected at each location. Additionally, one sample will be collected at depth at each location, where possible. The depth of the second sample may be limited by the hand sampling techniques. It is anticipated the sample will be collected between 1 to $4 \mathrm{ft}$ bgs. If lead bricks are present on top of the muckpiles, removal will be attempted down to the surface of the muckpile. If bricks are removed, a confirmatory soil sample will be collected beneath this location. The corrugated metal tank in front of I-Tunnel and the outhouse in front of the K-Tunnel re-entry will be investigated for contents and sampled if present. Additional samples may be collected from locations in front of J- and K-Tunnel 
portals to account for potentially higher levels of contamination associated with the failure of the containment systems.

Approximately 15 to 20 additional samples for initial Decision II sampling will be taken from (1) areas below the foot of the muckpiles, (2) at the confluence of the drainages from the muckpiles, and (3) at the point at which the main wash intersects the P-Tunnel access road. These locations are estimated in Figure A.9-1.

Step-out (extended) sampling may commence either up-slope or down-slope based on results. All data collected from initial sampling results and the biasing factors listed in Section A.5.3.1 will be used to select extended Decision II sample locations.

Due to the nature of buried features possibly present beneath the muckpiles (e.g., structures, buried debris, and utilities), sample locations may be relocated based upon the information obtained during the site visit. However, the new locations selected will meet the decision needs and criteria stipulated in Section A.5.1.

Surface soil samples will be collected by hand. Handheld augers or other hand sampling techniques (e.g., shovel and scoop) will be used, as appropriate, to collect subsurface samples. Samples for IDW and waste characterization purposes may also be collected. 


\section{A.10.0 References}

AEC, see U.S. Atomic Energy Commission.

ASTM, see American Society for Testing and Materials.

Alderson, S.L., Stoller-Navarro Joint Venture. 2004. Memorandum to B.S. Bailey (SNJV) entitled, "Preliminary Assessments Radiological Survey 2004," 17 February. Las Vegas, NV.

American Aerial Surveys, Inc. 1964. Aerial photograph N-48_A_U-OP showing the I-, J-, and K-Tunnels area, including the muckpile and CWD, 19 March. Mercury, NV: Archives and Records Center.

American Aerial Surveys, Inc. 1969. Aerial photograph N-59_001 U-OP showing the I-, J-, and K-Tunnels muckpile and CWD, 21 June. Mercury, NV: Archives and Records Center.

DOE, see U.S. Department of Energy.

DOE/NV, see U.S. Department of Energy, Nevada Operations Office.

DTRA, see Defense Threat Reduction Agency.

Defense Threat Reduction Agency. 2002. Corrective Action Decision Document for Corrective Action Unit 504: U16a Muckpile, Nevada Test Site. Mercury, NV.

Defense Threat Reduction Agency. 2003. Corrective Action Decision Document for Corrective Action Unit 482: U15a/e Muckpiles and Ponds, Nevada Test Site. Mercury, NV.

Desert Research Institute. 1989. Nevada Test Site Radionuclide Inventory and Distribution Program: Report \#5. Areas 5, 11, 12, 15, 17, 18, 19, 25, 26, and 30, DOE/NV/10384-26, June. Prepared for U.S. Department of Energy, Nevada Operations Office. Las Vegas, NV.

Desert Research Institute. 1996. ER-12-1 Completion Report, December. Prepared by C.E. Russell, D. Gillespie, J.C. Cole, S.L. Drellack, L.B. Prothro, P.H. Thompson, R.L. McCall, G.A. Pawloski, and R. Carlson. Las Vegas, NV.

EPA, see U.S. Environmental Protection Agency.

McLane, M., Stoller-Navarro Joint Venture. 2004b. Record of meeting with R. McCall (SNJV) regarding CAU 475 Muckpiles, 14 September. Las Vegas, NV. 
Moore, J., Science Applications International Corporation. 1999. Memorandum to M. Todd (SAIC) entitled, "Background Concentrations for NTS and TTR Soil Samples," 3 February. Las Vegas, NV.

NAC, see Nevada Administrative Code.

NAEG, see Nevada Applied Ecology Group

NBMG, see Nevada Bureau of Mines and Geology.

NCRP, see National Council on Radiation Protection and Measurements.

NNSA/NV, see U.S. Department of Energy, National Nuclear Security Administration Nevada Operations Office.

NNSA/NSO, see U.S. Department of Energy, National Nuclear Security Administration Nevada Site Office.

National Council on Radiation Protection and Measurements. 1999. Recommended Screening Limits for Contaminated Surface Soil and Review of Factors Relevant to Site-Specific Studies, NCRP Report No. 129. Washington, DC.

Nevada Administrative Code. 2003. NAC 445A, "Water Controls.” Carson City, NV.

Nevada Applied Ecology Group. 1977. Environmental Plutonium on the Nevada Test Site and Environs, NVO-170. Las Vegas, NV.

Nevada Bureau of Mines and Geology. 1998. Mineral and Energy Resource Assessment of the Nellis Air Force Range, Open-File Report 98-1. Reno, NV.

Penwell, C., Reynolds Electrical \& Engineering Co., Inc. 1971. Memorandum to A.E. Bicker (REECo) entitled, "Current Tunnel Surveys, Radiological Conditions and Reentry Requirements," 30 September. Las Vegas, NV.

REECo - see Reynolds Electrical and Engineering Co., Inc.

Reynolds Electrical and Engineering Co., Inc. 1991. Nevada Test Site Inventory of Inactive and Abandoned Facilities and Waste Sites, Volumes 1-4, DOE/NV/10630-18. Prepared for U.S. Department of Energy, Nevada Operations Office. Las Vegas, NV.

Ristvet, B., DTRIAC. 2004. Record of Telecon with C. Sloop (SNJV) regarding CAU 309, 9 February. Las Vegas, NV.

SNJV, see Stoller-Navarro Joint Venture. 
Shott, G.J., V. Yucel, M.J. Sully, L.E. Barker, S.E. Rawlinson, and B.A. Moore. 1997. Performance Assessment/Composite Analysis for the Area 3 Radioactive Waste Management Site at the Nevada Test Site, Nye County, Nevada, Rev. 2.0. Las Vegas, NV.

Stoller-Navarro Joint Venture. 2003a. Site Sketch from the CAU 309, CAS 12-06-09 Project Files. Las Vegas, NV.

Stoller-Navarro Joint Venture. 2003b. Site Sketch from the CAU 309, CAS 12-08-02 Project Files. Las Vegas, NV.

Stoller-Navarro Joint Venture. 2004a. Slope Stability Analyses E-Tunnel, G-Tunnel and I, J, K-Tunnel Muckpiles by Stoller-Navarro Joint Venture. July 1, 2004. Grand Junction, CO.

USGS, see U.S. Geological Survey.

USGS and DOE, see U.S. Geological Survey and U.S. Department of Energy.

U.S. Atomic Energy Commission. 1966. Summary Information on Releases of Radioactive Effluent to the Atmosphere from Underground Nuclear Detonations, 1961 - 1964, October. Washington, DC.

U.S. Department of Energy. 1988. "Environmental Survey Preliminary Report: Nevada Test Site, Mercury, Nevada," April. Washington, DC.

U.S. Department of Energy. 1993. DOE Order 5400.5, Change 2, "Radiation Protection of the Public and the Environment." Washington, DC.

U.S. Department of Energy. 1997. The Procedures Manual of the Environmental Measurements Laboratory, HASL-300, 28th Ed., Vol. I. New York, NY.

U.S. Department of Energy, Nevada Operations Office. 1999. An Aerial Radiological Survey of the Nevada Test Site, Bechtel Nevada, Remote Sensing Laboratory. DOE/NV/11718--324. Las Vegas, NV.

U.S. Department of Energy, National Nuclear Security Administration Nevada Operations Office. 2002a. Industrial Sites Quality Assurance Project Plan, Nevada Test Site, Nevada, DOE/NV--372-Rev. 3. Las Vegas, NV.

U.S. Department of Energy, National Nuclear Security Administration Nevada Operations Office. 2002b. Underground Test Area Project Waste Management Plan, DOE/NV--343-Rev. 2. Las Vegas, NV.

U.S. Department of Energy, National Nuclear Security Administration Nevada Site Office. 2004. Corrective Action Investigation Plan for Corrective Action Unit 551: Area 12 Muckpiles, Nevada Test Site, Nevada, DOE/NV--976-Rev. 0. Las Vegas, NV. 
U.S. Department of Energy, Nevada Operations Office. 1996. Final Environmental Impact Statement for the Nevada Test Site and Off-Site Locations in the State of Nevada, DOE/EIS 0243. Las Vegas, NV.

U.S. Department of Energy, Nevada Operations Office. 1998. Nevada Test Site Resource Management Plan, DOE/NV--518. Las Vegas, NV.

U.S. Department of Energy, Nevada Operations Office. 2000a. Nevada Test Site Contaminated Land Areas Report, Volume 1, DOE/NV11718--481-Vol. Las Vegas, NV.

U.S. Department of Energy, Nevada Operations Office. 2000b. NV/YMP Radiological Control Manual, Rev. 4, DOE/NV/11718-079, UC-702. Prepared by A.L. Gile of Bechtel Nevada. Las Vegas, NV.

U.S. Department of Energy, Nevada Operations Office. 2000c. United States Nuclear Tests, July 1945 through September 1992, DOE/NV--209-Rev. 15. Las Vegas, NV.

U.S. Environmental Protection Agency. 2000a. Data Quality Objectives Process for Hazardous Waste Site Investigations, EPA QA/G-4HW. Washington, DC.

U.S. Environmental Protection Agency. 2000b. Guidance for the Data Quality Objectives Process, EPA QA/G-4. Washington, DC.

U.S. Environmental Protection Agency. 2002a. Guidance for Quality Assurance Project Plans, EPA QA/G-5, EPA/240/R-02/009. Washington, DC.

U.S. Environmental Protection Agency. 2002c. Region 9 Preliminary Remediation Goals (PRGs). Prepared by S.J. Smucker. San Francisco, CA.

U.S. Environmental Protection Agency. 2002d. Integrated Risk Information System (IRIS) Database. As accessed at http://www.epa.gov/iris/index.html on 16 October 2002.

U.S. Geological Survey. 1965. Perched Ground Water in Zeolitized-Bedded Tuff, Rainier Mesa and Vicinity, Nevada Test Site, Nevada, USGS Report TEI-862. Prepared by W. Thordarson.

U.S. Geological Survey and U.S. Department of Energy. 2003. "USGS/DOE Nevada Well WW-8 WWW Site Page.” As accessed at http://nevada.usgs.gov/doe_nv/area18/ww8.asp on 17 November.

U.S. Nuclear Regulatory Commission. 1983. Radiological Dose Assessment: A Textbook on Environmental Dose Analysis, NUREG/CR-3332, ORNL-5968. Edited by J.E. Till and H.R. Meyer. Washington, DC. 
Appendix B

Documentation to Support the Assumption that the CAU 309 Muckpiles are Similar to Previously Investigated NTS Muckpiles 


\section{B.1.0 Documentation to Support the Assumption that the CAU 309 Muckpiles are Similar to Previously Investigated NTS Muckpiles}

For CASs 12-06-09 and 12-08-02, muckpiles, it is impractical to resolve the Decision I and II statements based solely on collecting and analyzing samples gathered at CAU 309. Slopes on and around the muckpiles present a falling hazard to samplers and surveyors, and limit accessibility to mechanical sampling equipment. Sampling only in safely accessible areas may not provide sufficient data to answer Decision I (i.e., is contamination present). Thus, a conservative assumption that all contamination detected at any previously sampled muckpile is also present within the CAU 309 muckpile.

A strategy has been developed to help characterize the contents of the CAU 309 muckpiles by use of data from previous NTS muckpile investigations at CAUs 475, 476, 477, 482, and 504. This strategy is based on the assumption that similarities exist in the operational histories and environmental settings of previously investigated NTS muckpiles and the CAU 309 muckpiles. Given these similarities, the data and information obtained during the previous NTS muckpile investigations can be used to help characterize the CAU 309 muckpiles.

\section{B.1.1 Purpose}

Consistent with standard environmental investigations, the CAU 309 investigation is based on identifying COPCs and their expected fates at the site to be investigated. The purpose of this appendix is to:

- Support the general assumption that findings at previously investigated NTS muckpiles can be applied to the investigation of the CAU 309 muckpiles

- Support the specific assumptions that sample analytical data from muck samples collected at previously investigated NTS muckpiles can be used to make determinations about which COCs can be expected at CAU 309 and the fate of those COCs in the environment. The three general qualitative metrics to support these assumptions are:

1. Similarity of the physical settings and the impact of these settings on the fates of COPCs at the subject muckpiles based on site-specific conditions such as geology and topography. 
2. Similarity of the historical waste-generating operations (i.e., tunnel operations), including related nuclear testing time lines for the subject muckpiles.

3. Usability of historical muckpile investigation analytical data.

The discussion presented in this appendix focuses on the impact that similarities or differences in these three areas have on the acceptability of the assumptions and thus the investigation strategy. The information presented on the general environmental factors and fates of COPCs at NTS muckpiles is based on information on soil chemistry, site-specific geology, site-specific topography, and data from previously investigated NTS muckpiles. Information on historical tunnel operations was obtained by reviewing available documentation including tunnel logbooks and conducting interviews with personnel who worked at the NTS tunnels. Data from previously investigated NTS muckpiles was obtained from the CADDs for these sites.

\section{B.1.2 Objective}

The objective for this appendix is to present data and information to support the assumptions on which the CAU 309 investigation strategy is based. Achievement of this objective will produce the ability to make qualitative statements about the level of confidence that the investigation strategy provides in generating defensible data that can support closure recommendations for the CAU 309 muckpiles.

\section{B.1.3 Similarity of Physical Settings}

Physical settings may affect the nature and location of muckpile contaminants through translocation of the contaminants and the transformation of contaminants by physical and chemical processes. Significant differences in the geologic (chemical) properties of the muck could affect the mobility and/or degradation (transformation) of contaminants. Significant differences in the topography and climate at the different muckpiles could also affect the potential for migration and transformation of contaminants.

\section{B.1.3.1 Geology}

The CAU 309 muckpiles are located on Rainier Mesa as are the muckpiles associated with U12 N-, Pand T-Tunnels. The tunnels of CAU 309 are on or near the boundary of friable tuff beds and 
zeolitized tuff beds. The U12 N-, P-, and T-Tunnels lie either in a welded tuff sandwiched between zeolitized tuff beds, or in the zeolitized tuff beds (Russell, 1987).

In keeping with common convention, the U12N-, P-, and T-Tunnels will be referred to as the N-, P-, and T-Tunnels.

Tunnels U15a and e are constructed on the southeastern flank of the Belted Range in granitic rocks of the Cretaceous period (DTRA, 2002). These intrusive rocks consist of the gray, zoned, equigranular to porphyritic Climax stock, chiefly quartz monzonite and granodiorite (Winograd and Thordarson, 1975; USGS, 1999). Muck removed from these tunnels would consist of granitic mineral fragments, also of various size fractions. Tunnel U16a was constructed on the eastern slope of Shoshone Mesa in bedded and nonbedded tuffs (DTRA, 2001).

In keeping with common convention, the U15a and e-, and 16a-Tunnels will be referred to as the $15 \mathrm{a}$ and e-, and 16a-Tunnels.

The muckpiles for I-, J-, K-, N-, P-, T- and 16a-Tunnels were created from material made up of volcanic ash tuffs, whereas the muckpiles for 15a and e-Tunnels were created from granitic material.

Some beds of the tuffs are zeolitized; zeolites are a large group of complex aluminosilicates, having a high cation exchange capacity (Sparks, 1986). Muck derived from granitic material can contain micas, which may also have a measurable amount of cation exchange capacity. Cation exchange capacity can also originate from edges and corners of mineral grains, especially more noncrystalline, glassy minerals as would be found in volcanic tuffs. High cation exchange capacity, in general, impedes the movement of cationic contaminants.

Common to all geological material in the muckpiles are the distribution of particle sizes within the muck from drilling and blasting operations. The processes of drilling and blasting broke the geological material into smaller pieces, ranging from clay-size mineral grains up to boulders. In general, the more rock is pulverized into smaller particles, the greater the potential to retard the migration of contaminants through the material. Differences in the tunnel development and mucking operations (blasting versus drilling) may have affected the particle size distribution of the muck. 
Because volcanic material is less crystalline (more structurally disordered) than granitic material, in general the muck created from tuffs can be expected to have broken into smaller particles, with the less crystalline material not maintaining its integrity as well as crystalline minerals. The geological material of the muckpiles at the 15a and e-Tunnels can be expected to have greater structural integrity than volcanic ash tuff, and can be expected to not be as susceptible to being pulverized as the tuff. Thus, the muck material from 15a and e-Tunnels can be expected to be larger grained.

\section{B.1.3.2 Topography and Climate}

The amount of precipitation falling annually on all areas under consideration is from 6 to 12 in. per year (USGS, 1965).

The CAU 309 muckpiles are at lower elevations and the surrounding topography is similar to previously investigated muckpiles (i.e., steep canyon or mesa slopes above the muckpile and less steep slopes below the muckpile). Generally, lower elevation muckpiles will receive less precipitation and have less of an altitude loss to nearby flats. In general, higher elevation muckpiles will receive greater amounts of precipitation, experience a greater incidence of freeze and thaw cycles, and have greater differences in altitude changes from nearby flat lands. The evapotranspiration rates for these areas exceed precipitation rates. Therefore, the CAU 309 muckpiles generally possess a lessor potential for possible translocation of contaminants via erosion.

\section{B.1.3.3 Summary of Physical Setting Considerations}

All of the muckpiles in consideration are located in the same general area and, with slight variations, are subject to the same general arid environment. They are not expected to have significant amounts of moisture moving through them due to the high evapotranspiration rates of the area. All of the muckpile material is expected to exhibit a slight to moderate capacity to sorb cationic contaminants. The muckpiles were all created from pulverized rock material, with all but the 15a and e-Tunnel muckpiles (granite derived) having come from the tunneling of volcanic tuffs. All have particle size distributions ranging from boulder to clay sizes. The most significant physical setting considerations for the CAU 309 muckpiles are the narrower muckpiles inhibiting the ability to use mechanized sampling techniques and the lower elevation leading to a generally lessor potential for translocation of CAU 309 muckpile contaminants by erosion. 
The potential for translocation of contaminants from CAU 309 was taken into account in the design of the CAU 309 sample plan. The accessible areas in the washes located down gradient of the CAU 309 muckpiles will be included in the radiological walk-over survey. Also, the collection of Decision II (extent of contamination) type samples will be conducted as part of the initial field investigation. Decision II samples will be collected from three areas during the initial field investigation: (1) the areas below the foot of the muckpiles, (2) at the confluence of the drainages from the muckpiles, and (3) at the point at which the drainage leaves the site (e.g., main wash intersects the access road). At each of these locations, multiple samples will be collected. Additional Decision II sampling will proceed, as necessary, based on the results of the initial Decision II samples. Specific sample locations will be selected in the field based on the presence of biasing factors. Biasing factors pertinent to Decision II sampling include the presence of sediment traps, where contaminants are more likely to have settled.

\section{B.1.4 Similarity of Waste-Generating Operations}

Information on historical tunnel operations was obtained by reviewing available documentation including tunnel logbooks and conducting interviews with personnel who worked at the NTS tunnels.

The CAU 309 muckpiles, as well as other NTS muckpiles, were created by waste-generating activities related to preparation for nuclear testing, the testing itself, and tunnel re-entry and recovery following testing. Information on historical operations that contributed to potential COPCs in the muckpiles was gained through interviews with former tunnel workers familiar with historical muckpile operations, and a review of historical documentation (e.g., logbooks) and literature that provides some discussion on tunnel/muckpile operations recorded as they occurred.

Factors affecting the similarity of operations at the muckpiles that will be discussed in the following sections are:

- Muckpile nuclear testing time lines for the applicable tunnels

- Standard tunnel operations for the early days of underground testing

- Significant changes in tunnel operations and policies that may have affected muckpile waste 


\section{B.1.4.1 Nuclear Testing Time Lines}

A time line for nuclear tests conducted at the I-, J-, K-, N-, P-, T-, 15a- and e-, and 16a-Tunnels is presented in Figure B.1-1 (DOE/NV, 2000). Included in the time line are approximate periods of changes in practices and policies discussed in Section B.1.4.3.

The CAU 309 muckpiles were associated with the 2 nuclear tests conducted 1962 in J-and K-Tunnels. These early operations would be most comparable to the nine tests conducted at Tunnels 15a and e and Tunnel 16a from 1962 to 1971. Eight of these tests were conducted in tunnel drifts; one test, Hard Hat, was conducted in a shaft at 15a-Tunnel. The material removed from the shaft was likely deposited in the 15a-Tunnel muckpile.

In addition to the time frame in which the tests were conducted, similarities or differences in the type or purpose of the experiments conducted in the tunnels may have impacted the nature of potential contamination in the muckpiles. Each of the experiments conducted in the tunnels associated with the previously investigated NTS Muckpiles (i.e., N-, P-, T-, 15a and e-, and 16a-Tunnels) were conducted as weapons effects experiments or as part of the Vela Uniform program (DOE/NV, 2000) and thus can be expected to have produced a fission reaction consuming much of the plutonium. Both the Platte (K-Tunnel) and the Des Moines (J-Tunnel) were weapons related tests (DOE/NV, 2000) and can also have been expected to have produced a fission reaction leading to similar radiological contaminants.

\section{B.1.4.2 Standard Early Tunnel Operations}

During the early days of tunnel operations, tunneling was typified by the "drill and blast" (followed by material-mucking) mining techniques. Most of the tunneling generated uncontaminated muck material. The contaminated muck material primarily came from re-entry mining following a nuclear test, and has been estimated to comprise less than one percent by volume of each muckpile (Fiore, 1991).

\section{B.1.4.3 Significant Changes in Tunnel Operations and Policies}

Changes in operations at the tunnels may have affected the nature of the wastes deposited in the muckpiles. Through interviews with former tunnel workers, five significant changes were identified 


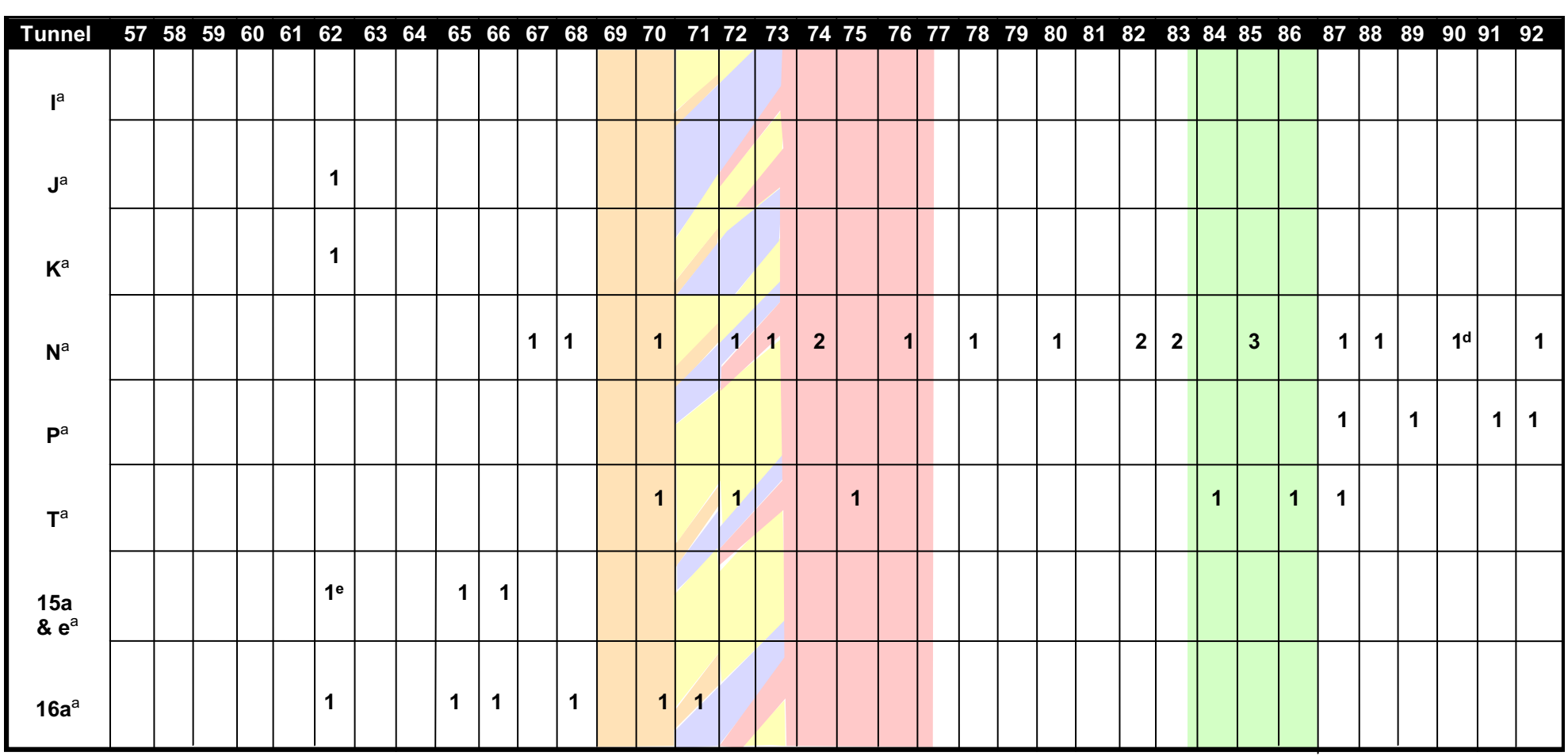

Numbers $=$ No. tests per year per tunnel

Or shaft within a tunnel
Source: a DOE/NV, 2000; b Metcalf, 2004; c Griffin, 2004;

Two separate devices were tested simultaneously

in separate drifts, the volume of material removed from both drifts

before and after the tests, and deposited in the N-Tunnel Muckpile,

was likely twice that removed from a single test in one drift alone;

material removed from the shaft was likely deposited in the

15a-Tunnel Muckpile
Transition from slushing \& washing contamination to painting contamination in place $(\sim 1969-1972)^{b}$

Start to use mechanical miners in addition to blasting $(\sim 1971-1973)^{b}$

Change over in tunnel wall \& support system from sets and lagging to use of rock bolts, mesh and epoxy $(\sim 1971-1973)^{\mathrm{b}}$

Start of storage of contaminated muck into drifts $(\sim 1971-1977)^{b}$

Discontinued decontamination of equipment and the drainage

of oil on and near muckpiles (1983-1987)

\section{Figure B.1-1}

Time Lines for Testing in Tunnels I, J, K, N, P, T, 15a and e, and 16a 
in tunnel operations that may have impacted the muckpiles. The approximate periods of time for these changes, as estimated by interviewees, are given in Figure B.1-1. These changes are:

- A change from "washing" or "slushing" to painting contaminated material onto fixed surfaces.

- Use of machines for tunneling.

- A move from the use of sets and lagging to the use of rock bolts, mesh, and epoxy.

- The placing of contaminated muck into drifts instead of on muckpiles.

- A discontinuation of the decontamination of equipment and of equipment maintenance on or near the muckpiles.

In the late 1950s and early 1960s, several references to the practice of "slushing" and "washing" appear in logbooks. No discrimination between washing fixed surfaces and loose material appears to have been made at the time, as both walls and unpaved roads were slushed/washed. Towards the late 1960s, the practice of slushing and washing appears to have become less commonplace, with the practice of painting alpha contamination on fixed surfaces beginning around 1971 or 1972 in the G-Tunnel (Metcalf, 2004). The approximate period of change from slushing and washing contaminated fixed surfaces to painting is represented in Figure B.1-1 by orange for the period of 1969 through 1971. It would be expected that once painting became common place less contamination was available for disposal in the muckpiles.

In the early 1970s, the use of machines to assist in the tunneling process began (Rowsell, 2004). These machines are believed to be of the "Alpine" mining type (Metcalf, 2004). In the 1980s, a boring machine was used in the E- and N-Tunnels (Griffin, 2004). Drill and blast techniques were still used up to the moratorium on underground testing in 1992 (Metcalf, 2004). Thus, while tunneling machines would have affected material going into the N-, P-, and T-Tunnel muckpiles, the use of blasting techniques would have affected all tunnel muckpiles; the impact on possible COPCs being placed into the muckpiles is unclear. The approximate period of implementation of tunneling machines is represented in Figure B.1-1 by yellow for the period of late 1970 through 1973.

In the early 1970s, a change also occurred in the tunnel wall and ceiling support systems, moving from mostly a "sets and lagging" approach (i.e., use of timber supports) to a "rock bolts, mesh, and 
epoxy" approach (Metcalf, 2004). Although wire mesh had been used to support the roof in at least one side drift (04) in the B-Tunnel in 1958 (Holmes \& Narver, 1959), extensive use of meshing apparently occurred a decade or so later. The use of wire mesh may have affected the inclusion of COPCs into the muckpiles through providing greater stability to tunnel walls. With greater stability of tunnel walls, the ratio of potentially contaminated muck and materials to noncontaminated muck and materials might have been significantly altered until the change in muck dumping practices changed. This would have impacted N-, P-, and T-Tunnel muckpiles the greatest. The approximate period of change in tunnel wall and ceiling support systems is represented in Figure B.1-1 by blue for the period of 1971 through 1973.

Up until the mid-1970s, contaminated muck removed during mining and re-entry operations at NTS was placed in the muckpiles (Deshler, 2003; Rowsell, 2004; Seals, 2004), and bulldozed (Metcalf, 2004). Clean muck was then placed atop the contaminated muck (Metcalf, 2004), reportedly at a minimum of $10 \mathrm{ft}$ deep (DOE, 1988). In the mid-1970s, muck that was determined to be radioactively contaminated was stored in unused underground drifts (DOE, 1988; Griffin, 2004), with some drifts being created exclusively for that purpose (Metcalf, 2004). Only uncontaminated debris was then disposed of in the muckpiles (Deshler, 2003). This change in policy would have impacted the N-, P-, and T-Tunnel muckpiles the greatest (i.e., less potential for contaminated material being added to the muckpiles). This is reflected in the data presented in Table B.1-1 which indicates no radionuclide COPCs were detected in the muck above MRLs. Lesser effects, primarily on the latter material placed on the muckpiles serving 15a and e- and 16a-Tunnel muckpiles would have occurred, with no impact occurring on the CAU 309 muckpiles. The approximate period of implementation of a change in muck dumping policies is represented in Figure B.1-1 by red for the period of mid-1973 through 1977.

Decontamination of equipment on a muckpile would occur if a decontamination station was set up at a tunnel portal, and sometimes a limited washdown would occur (Metcalf, 2004). Locomotives were sometimes left on a muckpile and the oil drained in place (Griffin, 2004). By the mid-1980s, both practices appear to have been discontinued. This change in practices would have resulted in less of a potential for COPCs being placed in the N-, P-, and T-Tunnel muckpiles, with the greatest impact occurring on the P-Tunnel muckpiles. The approximate period during which equipment was not 
decontaminated and oil was not drained on and near the muckpiles is represented in Figure B.1-1 by green for the period of late 1983 through 1987.

The two significant changes relevant to the use of historical NTS muckpile investigation data for the CAU 309 investigation that would have affected COPCs in the muckpiles the greatest are: (1) the change towards placing contaminated muck into drifts instead of the muckpiles, and (2) a discontinuation of equipment decontamination and maintenance on or near the muckpiles.

\section{B.1.4.4 Summary of Waste-Generating Operations Considerations}

In general, the CAU 309 muckpiles were associated with early nuclear testing operations that would be most comparable with the tests conducted at Tunnels 15a and e and at Tunnel 16a from 1962 to 1971. Most of the nuclear tests conducted in the previously investigated NTS muckpiles were conducted in the later period (21 tests conducted in N-tunnel). Data from samples of muck generated in these later periods may not be as comparable. However, all operations conducted at the sites generating the muckpiles supported the same nuclear testing program and used similar procedures and materials. The biggest impact on the comparability of data from the previously investigated NTS muckpiles is that early testing activities (pre-1969), including those at the CAU 309 muckpiles, may have had less stringent control of hazardous and radioactive wastes. Therefore, muck resulting from the earlier testing may be more contaminated (e.g., higher concentrations and/or additional contaminants).

The investigation strategy for the CAU 309 muckpiles has been designed to address the following potential differences in the nature of contamination.

- Historical data from all the previously investigated NTS muckpiles has been reviewed and the highest previously detected results for contaminants have been used to determine the assumed level of contamination in the CAU 309 muckpiles for all six constituents which were detected at concentrations above current PALs. This is a conservative assumption. There is no direct evidence at this time that these contaminants are present in the CAU 309 muckpiles.

- Samples will be collected from the CAU 309 muckpiles and analyzed for all COPCs. Although these samples may not be fully representative of conditions at the CAU 309 muckpiles (because some areas are inaccessible to sampling), it lowers the potential of a false negative decision error by adding additional data points for all COPCs. It also lowers the potential for misidentifying the highest concentration of each COC. 
- Initial Decision II samples will be collected regardless of what is identified in the samples collected from the CAU 309 muckpiles. This further lowers the potential of a false negative decision error by providing still more data points for all COPCs.

- Tunnel containment failures may have contributed to higher levels of contamination on the muckpiles. This is accounted for in the sampling plan by analyzing additional samples from the muckpiles. Venting, controlled releases, and/or accidental releases also occurred at N-, $\mathrm{T}-$, 15a and e-, and 16a-Tunnels.

\section{B.1.5 Data From Comparable Muckpiles}

Data from previously investigated NTS muckpiles was obtained from the CADDs for these sites.

Historical data derived from Defense Threat Reduction Agency (DTRA) investigations of muckpiles at N-, P-, T-, 15a and e-, and 16a-Tunnels is presented in Table B.1-1 and Table B.1-2. This data has been broken into "Muck data," and "Native Soil data" (beneath muckpiles) to discern the existence and potential movement of contamination from the muckpiles into the surrounding environment.

In general, although COPCs below PALs have been identified in native soil beneath previously investigated muckpiles, significant vertical transport of contaminants has not been found at these sites. Significant transport of contaminants by leachate in the muckpiles at CAU 309 is not expected given the similarities in operations and environmental factors and fates.

The muck data was reviewed to determine which constituents detected in muck at previously investigated NTS muckpiles were detected at concentrations equal to or greater than current PALs (Decision Ia for the muckpiles). It was determined that the data included six constituents which met this criteria: lead, arsenic, TPH-DRO, Pu-238, Pu-239, and Cs-137. It was determined that all six constituents would be considered COCs for the CAU 309 muckpiles. This is a conservative assumption given that some of these six constituents were detected in only several samples (Table A.4-1) or were detected at only one previous muckpile (Table A.4-1) at concentrations above the PAL. However, since the assumption that even one COC is present in the CAU 309 muckpiles will lead to consideration of corrective actions, it was determined that considering all six constituents as COCs will likely not lead to an additional burden when considering potential corrective actions. 
Table B.1-1

Analytical Detects above MRLs in Muck Samples Collected at Previously Investigated NTS Muckpiles

(Page 1 of 3 )

\begin{tabular}{|c|c|c|c|c|c|c|c|c|c|c|c|}
\hline \multirow{2}{*}{ Analyte } & \multicolumn{2}{|c|}{ CAU 475 P-Tunnel } & \multicolumn{2}{|c|}{ CAU 476 T-Tunnel } & \multicolumn{2}{|c|}{ CAU 477 N-Tunnel } & \multicolumn{2}{|c|}{$\begin{array}{c}\text { CAU } 482 \\
\text { 15a- and e-Tunnels }\end{array}$} & \multicolumn{2}{|c|}{ CAU 504 16a-Tunnel } & \multirow{2}{*}{ PAL } \\
\hline & $\begin{array}{l}\text { No. of } \\
\text { Detects }\end{array}$ & Range & $\begin{array}{l}\text { No. of } \\
\text { Detects }\end{array}$ & Range & $\begin{array}{l}\text { No. of } \\
\text { Detects }\end{array}$ & Range & $\begin{array}{l}\text { No. of } \\
\text { Detects }\end{array}$ & Range & $\begin{array}{c}\text { No. of } \\
\text { Detects }\end{array}$ & Range & \\
\hline \multicolumn{12}{|c|}{ Volatile Organic Compounds, $\mu \mathrm{g} / \mathrm{kg}$} \\
\hline 1,2,4-Trimethylbenzene & -- & -- & 1 & 1 & 1 & 180 & -- & -- & -- & -- & 170,000 \\
\hline 1,3,5-Trimethylbenzene & -- & -- & -- & -- & 1 & 59 & -- & -- & -- & -- & 70,000 \\
\hline 1,1-Dichloroethene & -- & -- & 2 & $1.1-1.3$ & -- & -- & -- & -- & -- & -- & 410,000 \\
\hline 1,2-Dibromo-3-chloropropane & -- & -- & -- & -- & -- & -- & -- & -- & -- & -- & 2,000 \\
\hline 2-Butanone & 1 & 240 & -- & -- & 13 & $2.2-11$ & 1 & 11 & -- & -- & $27,000,000$ \\
\hline 4-Methyl-2-pentanone & 2 & $16-270$ & 1 & 2.7 & -- & -- & -- & -- & -- & -- & $2,800,000$ \\
\hline Acetone & 8 & $9.3-2,300$ & 9 & $9.4-25$ & 22 & $9.3-180$ & 11 & $8.4-48$ & 2 & $23-29$ & $6,000,000$ \\
\hline Bromodichloromethane & -- & -- & -- & -- & -- & -- & -- & -- & -- & -- & 1,800 \\
\hline Bromoform & -- & -- & -- & -- & -- & -- & -- & -- & -- & -- & 220,000 \\
\hline n-Butylbenzene & -- & -- & 1 & 0.88 & 1 & 20 & -- & -- & -- & -- & 240,000 \\
\hline sec-Butylbenzene & -- & -- & -- & -- & 1 & 15 & -- & -- & -- & -- & 220,000 \\
\hline tert-Butylbenzene & -- & -- & -- & -- & -- & -- & -- & -- & -- & -- & 390,000 \\
\hline Carbon disulfide & -- & -- & -- & -- & -- & -- & -- & -- & -- & -- & 720,000 \\
\hline Carbon tetrachloride & -- & -- & -- & -- & 1 & 2 & -- & -- & -- & -- & 550 \\
\hline Chlorobenzene & -- & -- & -- & -- & -- & -- & -- & -- & -- & -- & 530,000 \\
\hline Chloroform & -- & -- & -- & -- & 1 & 1.8 & -- & -- & -- & -- & 12,000 \\
\hline Chloromethane & -- & -- & -- & -- & 1 & 5.1 & -- & -- & -- & -- & 2,600 \\
\hline Ethylbenzene & -- & -- & -- & -- & 5 & $0.82-6.4$ & -- & -- & -- & -- & 20,000 \\
\hline Isopropyl benzene & -- & -- & -- & -- & 1 & 7.2 & -- & -- & -- & -- & $2,000,000$ \\
\hline Methylene chloride & 4 & $14-18$ & -- & -- & -- & -- & 7 & $2.6-44$ & 8 & $9.7-45$ & 21,000 \\
\hline n-Propyl benzene & -- & -- & -- & -- & 1 & 15 & -- & -- & -- & -- & 240,000 \\
\hline
\end{tabular}


Table B.1-1

Analytical Detects above MRLs in Muck Samples Collected at Previously Investigated NTS Muckpiles

(Page 2 of 3 )

\begin{tabular}{|c|c|c|c|c|c|c|c|c|c|c|c|}
\hline \multirow{2}{*}{ Analyte } & \multicolumn{2}{|c|}{ CAU 475 P-Tunnel } & \multicolumn{2}{|c|}{ CAU 476 T-Tunnel } & \multicolumn{2}{|c|}{ CAU 477 N-Tunnel } & \multicolumn{2}{|c|}{$\begin{array}{c}\text { CAU } 482 \\
\text { 15a- and e-Tunnels }\end{array}$} & \multicolumn{2}{|c|}{ CAU 504 16a-Tunnel } & \multirow{2}{*}{ PAL } \\
\hline & $\begin{array}{l}\text { No. of } \\
\text { Detects }\end{array}$ & Range & $\begin{array}{l}\text { No. of } \\
\text { Detects }\end{array}$ & Range & $\begin{array}{l}\text { No. of } \\
\text { Detects }\end{array}$ & Range & $\begin{array}{l}\text { No. of } \\
\text { Detects }\end{array}$ & Range & $\begin{array}{c}\text { No. of } \\
\text { Detects }\end{array}$ & Range & \\
\hline Tetrachloroethene & $\overline{1}$ & 9.2 & $\overline{---}$ & $\overline{---}$ & $\overline{---}$ & -- & -- & $\overline{---}$ & -- & $\overline{---}$ & 3,400 \\
\hline Toluene & -- & -- & 1 & 0.9 & 2 & $1.2-1.7$ & 1 & 3.6 & -- & -- & 520,000 \\
\hline Trichloroethene & -- & -- & 2 & $0.49-0.76$ & 1 & 1.2 & -- & -- & -- & -- & 110 \\
\hline Trichlorofluoromethane & -- & -- & -- & -- & -- & -- & -- & -- & -- & -- & $2,000,000$ \\
\hline Trichlorotrifluoroethane & -- & -- & 2 & $1-1.1$ & -- & -- & -- & -- & -- & -- & $5,600,000$ \\
\hline Xylenes & -- & -- & -- & -- & 9 & $0.94-35$ & -- & -- & -- & -- & 420,000 \\
\hline \multicolumn{12}{|c|}{ Semivolatile Organic Compounds, $\mu$ g/kg } \\
\hline 1,2,4-Trichlorobenzene & -- & -- & 1 & 1.2 & -- & -- & -- & -- & -- & -- & $3,000,000$ \\
\hline 1,2-Dichlorobenzene & -- & -- & -- & -- & -- & -- & -- & -- & -- & -- & 370,000 \\
\hline Benzo(a)anthracene & -- & -- & -- & -- & -- & -- & -- & -- & 1 & 39 & 2,100 \\
\hline Benzo(a)pyrene & -- & -- & -- & -- & -- & -- & -- & -- & -- & -- & 210 \\
\hline Benzo(b)fluoranthene & -- & -- & -- & -- & -- & -- & -- & -- & 1 & 41 & 2,100 \\
\hline Benzo(g,h,I)perylene & -- & -- & -- & -- & -- & -- & -- & -- & -- & -- & $N / A^{\#}$ \\
\hline Benzo(k)fluoranthene & -- & -- & -- & -- & -- & -- & -- & -- & -- & -- & 21,000 \\
\hline Benzoic acid & -- & -- & -- & -- & -- & -- & -- & -- & -- & -- & $100,000,000$ \\
\hline Bis(2-ethylhexyl) phthalate & -- & -- & 1 & 350 & 3 & $69-850$ & 2 & $200-310$ & 1 & 120 & 120,000 \\
\hline Chrysene & -- & -- & -- & -- & -- & -- & -- & -- & -- & -- & 210,000 \\
\hline Dimethyl phthalate & -- & -- & -- & -- & 4 & $96-2500$ & -- & -- & -- & -- & $100,000,000$ \\
\hline Di-n-butyl phthalate & -- & -- & 1 & 26000 & -- & -- & -- & -- & -- & -- & $62,000,000$ \\
\hline Fluoranthene & -- & -- & -- & -- & -- & -- & -- & -- & -- & -- & $22,000,000$ \\
\hline Indeno(1,2,3-cd)pyrene & -- & -- & -- & -- & -- & -- & -- & -- & -- & -- & 2,100 \\
\hline Naphthalene & -- & -- & 1 & 1.6 & 3 & $3.1-7000$ & -- & -- & -- & -- & 190,000 \\
\hline
\end{tabular}


Table B.1-1

Analytical Detects above MRLs in Muck Samples Collected at Previously Investigated NTS Muckpiles

(Page 3 of 3 )

\begin{tabular}{|c|c|c|c|c|c|c|c|c|c|c|c|}
\hline \multirow{2}{*}{ Analyte } & \multicolumn{2}{|c|}{ CAU 475 P-Tunnel } & \multicolumn{2}{|c|}{ CAU 476 T-Tunnel } & \multicolumn{2}{|c|}{ CAU 477 N-Tunnel } & \multicolumn{2}{|c|}{$\begin{array}{c}\text { CAU } 482 \\
\text { 15a- and e-Tunnels }\end{array}$} & \multicolumn{2}{|c|}{ CAU 504 16a-Tunnel } & \multirow{2}{*}{ PAL } \\
\hline & $\begin{array}{l}\text { No. of } \\
\text { Detects }\end{array}$ & Range & $\begin{array}{l}\text { No. of } \\
\text { Detects }\end{array}$ & Range & $\begin{array}{l}\text { No. of } \\
\text { Detects }\end{array}$ & Range & $\begin{array}{l}\text { No. of } \\
\text { Detects }\end{array}$ & Range & $\begin{array}{l}\text { No. of } \\
\text { Detects }\end{array}$ & Range & \\
\hline Phenol & -- & --- & $-\overline{-}$ & -- & -- & -- & $\overline{---}$ & -- & 1 & $\overline{55}$ & $\overline{100,000,000}$ \\
\hline Pyrene & -- & -- & -- & -- & 1 & 4300 & -- & -- & -- & -- & $29,000,000$ \\
\hline \multicolumn{12}{|c|}{ Total Petroleum Hydrocarbons (DRO/GRO), mg/kg } \\
\hline DRO & 14 & $2-10000$ & 11 & $22-1200$ & 36 & $3.1-3300$ & 17 & $4-510$ & 5 & $1.7-82$ & 100 \\
\hline GRO & -- & -- & $\begin{array}{l}- \\
-\end{array}$ & - & 1 & 0.68 & -- & -- & - & - & 100 \\
\hline \multicolumn{12}{|c|}{ Metals, mg/kg } \\
\hline Arsenic & 16 & $1.2-4.4$ & 33 & $1.6-13$ & 51 & $2.2-38.8$ & 22 & $1.7-15$ & 28 & $2.3-8.4$ & 23 \\
\hline Barium & 21 & $27-2100$ & 33 & $19-4500$ & 50 & $38.3-5300$ & 25 & $46-230$ & 28 & $34-4300$ & 67,000 \\
\hline Beryllium & 20 & $0.61-1.9$ & -- & -- & -- & -- & -- & -- & -- & -- & 1,900 \\
\hline Cadmium & 1 & 11 & 16 & $0.04-0.4$ & 5 & $0.07-0.46$ & 3 & $0.11-2.9$ & 2 & $0.29-0.42$ & 450 \\
\hline Chromium & 14 & $1.2-11$ & 29 & $0.42-12$ & 48 & $0.68-13.3$ & 25 & $1.6-30$ & 27 & $0.47-12$ & 450 \\
\hline Lead & 21 & $2.3-26$ & 33 & $3-210$ & 51 & $5.7-59700$ & 25 & $2-57$ & 28 & $4.2-32$ & 750 \\
\hline Mercury & -- & -- & 1 & 0.079 & 22 & $0.04-0.29$ & 13 & $0.0026-0.047$ & 17 & $0.023-0.12$ & 310 \\
\hline Selenium & -- & -- & 6 & $0.61-4.1$ & 3 & $0.45-1.1$ & 15 & $0.41-1.1$ & 11 & $0.22-1.3$ & 5,100 \\
\hline Silver & -- & -- & 4 & $0.31-2.4$ & 6 & $0.18-1.1$ & 4 & $0.6-1.5$ & 1 & 1.4 & 5,100 \\
\hline \multicolumn{12}{|c|}{ Radionuclides, $\mathrm{pCi} / \mathrm{g}$} \\
\hline Americium-241 & -- & -- & - & -- & -- & -- & -- & -- & 1 & 1.48 & 7.62 \\
\hline Cesium-137 & -- & -- & 8 & $0.58-382$ & 8 & $0.4-1340$ & 22 & $0.282-3050$ & 24 & $0.5-1770$ & 7.30 \\
\hline Cobalt-60 & -- & -- & 1 & 1.76 & 1 & 0.73 & 1 & 0.123 & 3 & $0.77-5.3$ & 1.61 \\
\hline Plutonium-238 & -- & -- & 3 & $\begin{array}{c}0.179-0.9 \\
1\end{array}$ & 2 & $0.048-0.272$ & 2 & $0.089-1.28$ & 14 & $0.098-20.2$ & 7.78 \\
\hline Plutonium-239/240 & -- & -- & 3 & $0.54-2.87$ & 2 & $0.454-0.55$ & 7 & $0.038-7.7$ & 20 & $0.0168-122$ & 7.62 \\
\hline Strontium-90 & $\overline{--}$ & -- & 3 & $2.27-13$ & -- & -- & 11 & $0.38-66$ & 16 & $1.11-117$ & 503 \\
\hline
\end{tabular}


Table B.1-2

Analytical Detects above MRLs in Native Soil Samples Collected at Previously Investigated NTS Muckpiles

(Page 1 of 4 )

\begin{tabular}{|c|c|c|c|c|c|c|c|c|c|c|c|}
\hline \multirow{2}{*}{ Analyte } & \multicolumn{2}{|c|}{ CAU 475 P-Tunnel } & \multicolumn{2}{|c|}{ CAU 476 T-Tunnel } & \multicolumn{2}{|c|}{ CAU 477 N-Tunnel } & \multicolumn{2}{|c|}{$\begin{array}{c}\text { CAU } 482 \\
\text { 15a- and e-Tunnels }\end{array}$} & \multicolumn{2}{|c|}{ CAU 504 16a-Tunnel } & \multirow{2}{*}{ PAL } \\
\hline & $\begin{array}{l}\text { No. of } \\
\text { Detects }\end{array}$ & Range & $\begin{array}{l}\text { No. of } \\
\text { Detects }\end{array}$ & Range & $\begin{array}{l}\text { No. of } \\
\text { Detects }\end{array}$ & Range & $\begin{array}{l}\text { No. of } \\
\text { Detects }\end{array}$ & Range & $\begin{array}{l}\text { No. of } \\
\text { Detects }\end{array}$ & Range & \\
\hline \multicolumn{12}{|c|}{ Volatile Organic Compounds, $\mu \mathrm{g} / \mathrm{kg}$} \\
\hline 1,2,4-Trimethylbenzene & -- & -- & -- & -- & -- & -- & -- & -- & -- & -- & 170,000 \\
\hline 1,3,5-Trimethylbenzene & -- & -- & -- & -- & -- & -- & -- & -- & -- & -- & 70,000 \\
\hline 1,1-Dichloroethene & -- & -- & 3 & $1.1-1.3$ & -- & -- & -- & -- & -- & -- & 410,000 \\
\hline 1,2-Dibromo-3-chloropropane & -- & -- & -- & -- & 1 & 2.1 & -- & -- & -- & -- & 2,000 \\
\hline 2-Butanone & -- & -- & -- & -- & 6 & $2-5.9$ & -- & -- & -- & -- & $27,000,000$ \\
\hline 4-Methyl-2-pentanone & -- & -- & 1 & 2 & -- & -- & -- & -- & -- & -- & $2,800,000$ \\
\hline Acetone & 8 & $8.5-21$ & 5 & $8.6-19$ & 13 & $9.2-32$ & 2 & 10 & -- & -- & $6,000,000$ \\
\hline Bromodichloromethane & -- & -- & -- & -- & -- & -- & -- & -- & -- & -- & 1,800 \\
\hline Bromoform & -- & -- & -- & -- & -- & -- & -- & -- & -- & -- & 220,000 \\
\hline n-Butylbenzene & -- & -- & -- & -- & -- & -- & -- & -- & -- & -- & 240,000 \\
\hline sec-Butylbenzene & -- & -- & -- & -- & -- & -- & -- & -- & -- & -- & 220,000 \\
\hline tert-Butylbenzene & -- & -- & -- & -- & 1 & 0.83 & -- & -- & -- & -- & 390,000 \\
\hline Carbon disulfide & -- & -- & -- & -- & -- & -- & -- & -- & -- & -- & 720,000 \\
\hline Carbon tetrachloride & -- & -- & -- & -- & -- & -- & -- & -- & -- & -- & 550 \\
\hline Chlorobenzene & -- & -- & -- & -- & 1 & 0.69 & -- & -- & -- & -- & 530,000 \\
\hline Chloroform & -- & -- & -- & -- & -- & -- & -- & -- & -- & -- & 12,000 \\
\hline Chloromethane & -- & -- & -- & -- & -- & -- & -- & -- & -- & -- & 2,600 \\
\hline
\end{tabular}


Table B.1-2

Analytical Detects above MRLs in Native Soil Samples Collected at Previously Investigated NTS Muckpiles

(Page 2 of 4 )

\begin{tabular}{|c|c|c|c|c|c|c|c|c|c|c|c|}
\hline \multirow{2}{*}{ Analyte } & \multicolumn{2}{|c|}{ CAU 475 P-Tunnel } & \multicolumn{2}{|c|}{ CAU 476 T-Tunnel } & \multicolumn{2}{|c|}{ CAU 477 N-Tunnel } & \multicolumn{2}{|c|}{$\begin{array}{c}\text { CAU } 482 \\
\text { 15a- and e-Tunnels }\end{array}$} & \multicolumn{2}{|c|}{ CAU 504 16a-Tunnel } & \multirow{2}{*}{ PAL } \\
\hline & $\begin{array}{l}\text { No. of } \\
\text { Detects }\end{array}$ & Range & $\begin{array}{l}\text { No. of } \\
\text { Detects }\end{array}$ & Range & $\begin{array}{c}\text { No. of } \\
\text { Detects }\end{array}$ & Range & $\begin{array}{l}\text { No. of } \\
\text { Detects }\end{array}$ & Range & $\begin{array}{c}\text { No. of } \\
\text { Detects }\end{array}$ & Range & \\
\hline Ethylbenzene & -- & -- & -- & -- & 1 & 0.82 & -- & -- & -- & -- & 20,000 \\
\hline Isopropyl benzene & -- & -- & -- & -- & -- & -- & -- & -- & -- & -- & $2,000,000$ \\
\hline Methylene chloride & 3 & $13-17$ & -- & -- & -- & -- & 5 & $2.3-7.7$ & 3 & $1.9-71$ & 21,000 \\
\hline n-Propyl benzene & -- & -- & -- & -- & -- & -- & -- & -- & -- & -- & 240,000 \\
\hline Tetrachloroethene & -- & -- & -- & -- & -- & -- & -- & -- & -- & -- & 3,400 \\
\hline Toluene & -- & -- & -- & -- & 1 & 0.78 & -- & -- & 1 & 1.2 & 520,000 \\
\hline Trichloroethene & -- & -- & -- & -- & 1 & 0.83 & -- & -- & -- & -- & 110 \\
\hline Trichlorofluoromethane & -- & -- & -- & -- & -- & -- & -- & -- & -- & -- & $2,000,000$ \\
\hline Trichlorotrifluoroethane & -- & -- & 2 & $0.8-0.96$ & -- & -- & -- & -- & -- & -- & $5,600,000$ \\
\hline Xylenes & -- & -- & -- & -- & 1 & 1.9 & -- & -- & -- & -- & 420,000 \\
\hline \multicolumn{12}{|c|}{ Semivolatile Organic Compounds, $\mu \mathrm{g} / \mathrm{kg}$} \\
\hline 1,2,4-Trichlorobenzene & -- & -- & -- & -- & -- & -- & -- & -- & -- & -- & $3,000,000$ \\
\hline 1,2-Dichlorobenzene & -- & -- & -- & -- & 1 & 1 & -- & -- & -- & -- & 370,000 \\
\hline Benzo(a)anthracene & -- & -- & -- & -- & -- & -- & -- & -- & -- & -- & 2,100 \\
\hline Benzo(a)pyrene & -- & -- & -- & -- & -- & -- & -- & -- & -- & -- & 210 \\
\hline Benzo(b)fluoranthene & -- & -- & -- & -- & -- & -- & -- & -- & -- & -- & 2,100 \\
\hline Benzo(g,h,l)perylene & -- & -- & -- & -- & 3 & $120-140$ & -- & -- & -- & -- & $\mathrm{N} / \mathrm{A}^{\#}$ \\
\hline Benzo(k)fluoranthene & -- & -- & -- & -- & -- & -- & -- & -- & -- & -- & 21,000 \\
\hline
\end{tabular}


Table B.1-2

Analytical Detects above MRLs in Native Soil Samples Collected at Previously Investigated NTS Muckpiles

(Page 3 of 4 )

\begin{tabular}{|c|c|c|c|c|c|c|c|c|c|c|c|}
\hline \multirow{2}{*}{ Analyte } & \multicolumn{2}{|c|}{ CAU 475 P-Tunnel } & \multicolumn{2}{|c|}{ CAU 476 T-Tunnel } & \multicolumn{2}{|c|}{ CAU 477 N-Tunnel } & \multicolumn{2}{|c|}{$\begin{array}{c}\text { CAU } 482 \\
\text { 15a- and e-Tunnels }\end{array}$} & \multicolumn{2}{|c|}{ CAU 504 16a-Tunnel } & \multirow{2}{*}{ PAL } \\
\hline & $\begin{array}{l}\text { No. of } \\
\text { Detects }\end{array}$ & Range & $\begin{array}{l}\text { No. of } \\
\text { Detects }\end{array}$ & Range & $\begin{array}{l}\text { No. of } \\
\text { Detects }\end{array}$ & Range & $\begin{array}{l}\text { No. of } \\
\text { Detects }\end{array}$ & Range & $\begin{array}{l}\text { No. of } \\
\text { Detects }\end{array}$ & Range & \\
\hline Benzoic acid & -- & -- & 1 & 270 & -- & -- & -- & -- & -- & -- & $\begin{array}{c}100,000,00 \\
0\end{array}$ \\
\hline Bis(2-ethylhexyl) phthalate & -- & -- & -- & -- & 2 & $200-220$ & -- & -- & -- & -- & 120,000 \\
\hline Chrysene & -- & -- & -- & -- & -- & -- & -- & -- & -- & -- & 210,000 \\
\hline Dimethyl phthalate & -- & -- & -- & -- & 3 & $94-100$ & -- & -- & -- & -- & $\begin{array}{c}100,000,00 \\
0\end{array}$ \\
\hline Di-n-butyl phthalate & -- & -- & -- & -- & --- & -- & -- & -- & -- & -- & $62,000,000$ \\
\hline Fluoranthene & -- & -- & -- & -- & -- & -- & -- & -- & -- & -- & $22,000,000$ \\
\hline Indeno(1,2,3-cd)pyrene & -- & -- & -- & -- & -- & -- & -- & -- & -- & -- & 2,100 \\
\hline Naphthalene & -- & -- & -- & -- & 2 & $1.2-2.6$ & -- & -- & -- & -- & 190,000 \\
\hline Phenol & -- & -- & -- & -- & -- & -- & -- & -- & -- & -- & $\begin{array}{c}100,000,00 \\
0\end{array}$ \\
\hline Pyrene & -- & -- & -- & -- & -- & -- & -- & -- & -- & -- & $29,000,000$ \\
\hline \multicolumn{12}{|c|}{ Total Petroleum Hydrocarbons (DRO/GRO), mg/kg } \\
\hline DRO & 7 & $2-120$ & 1 & 47 & 23 & $2.6-22$ & 1 & 4.5 & 1 & 59 & 100 \\
\hline GRO & -- & -- & -- & -- & -- & -- & -- & -- & -- & -- & 100 \\
\hline \multicolumn{12}{|c|}{ Metals, mg/kg } \\
\hline Arsenic & 16 & $1.9-6.4$ & 20 & $1.2-7.2$ & 35 & $1.3-6.6$ & 13 & $0.81-12$ & 16 & $1.9-7.2$ & 23 \\
\hline Barium & 17 & $37-750$ & 21 & $30-200$ & 35 & $22.9-1290$ & 16 & $39-120$ & 16 & $30-450$ & 67,000 \\
\hline
\end{tabular}


Table B.1-2

Analytical Detects above MRLs in Native Soil Samples Collected at Previously Investigated NTS Muckpiles

(Page 4 of 4 )

\begin{tabular}{|c|c|c|c|c|c|c|c|c|c|c|c|}
\hline \multirow{2}{*}{ Analyte } & \multicolumn{2}{|c|}{ CAU 475 P-Tunnel } & \multicolumn{2}{|c|}{ CAU 476 T-Tunnel } & \multicolumn{2}{|c|}{ CAU 477 N-Tunnel } & \multicolumn{2}{|c|}{$\begin{array}{c}\text { CAU } 482 \\
\text { 15a- and e-Tunnels }\end{array}$} & \multicolumn{2}{|c|}{ CAU 504 16a-Tunnel } & \multirow{2}{*}{ PAL } \\
\hline & $\begin{array}{l}\text { No. of } \\
\text { Detects }\end{array}$ & Range & $\begin{array}{l}\text { No. of } \\
\text { Detects }\end{array}$ & Range & $\begin{array}{l}\text { No. of } \\
\text { Detects }\end{array}$ & Range & $\begin{array}{l}\text { No. of } \\
\text { Detects }\end{array}$ & Range & $\begin{array}{l}\text { No. of } \\
\text { Detects }\end{array}$ & Range & \\
\hline Beryllium & 11 & $0.57-1.2$ & - & -- & -- & -- & - & - & -- & -- & 1,900 \\
\hline Cadmium & -- & -- & -- & -- & -- & -- & -- & -- & -- & -- & 450 \\
\hline Chromium & 16 & $2.2-12$ & 18 & $0.57-10$ & 31 & $0.29-8.6$ & 16 & $1.7-4.9$ & 15 & $0.98-210$ & 450 \\
\hline Lead & 17 & $3.7-9.7$ & 21 & $2.7-18$ & 35 & $2.3-44.1$ & 16 & $0.67-4.5$ & 16 & $2.4-44$ & 750 \\
\hline Mercury & -- & -- & -- & -- & 26 & $0.04-0.8$ & 6 & $\begin{array}{c}0.0019-0.006 \\
6\end{array}$ & 1 & 0.046 & 310 \\
\hline Selenium & -- & -- & 3 & $0.6-1.5$ & -- & -- & 7 & $0.37-0.99$ & 6 & $0.23-0.5$ & 5,100 \\
\hline Silver & -- & -- & 5 & $0.18-0.8$ & 5 & $0.49-1.3$ & -- & -- & 7 & $0.075-530$ & 5,100 \\
\hline \multicolumn{12}{|c|}{ Radionuclides, pCi/g } \\
\hline Americium-241 & -- & -- & 1 & 0.62 & -- & -- & -- & -- & -- & -- & 7.62 \\
\hline Cesium-137 & 1 & 0.173 & -- & -- & 2 & $0.37-1.54$ & 2 & $0.202-0.246$ & 2 & $0.83-9.9$ & 7.30 \\
\hline Cobalt-60 & -- & -- & -- & -- & -- & -- & -- & -- & -- & -- & 1.61 \\
\hline Plutonium-238 & 2 & $\begin{array}{c}0.184-0.6 \\
6\end{array}$ & -- & -- & -- & -- & -- & -- & 1 & 0.071 & 7.78 \\
\hline Plutonium-239/240 & 2 & $0.54-1.29$ & -- & -- & -- & -- & -- & -- & 1 & 0.439 & 7.62 \\
\hline Strontium-90 & -- & -- & -- & -- & -- & -- & -- & -- & -- & -- & 503 \\
\hline
\end{tabular}

\# = Presently there is not a PRG for this contaminant. If this contaminant is detected, a PAL with a similar protocol to that used by the EPA Region 9 will be used in establishing an action level for those COPCs listed in the EPA IRIS database (EPA, 2002). 


\section{B.1.6 Conclusion}

In general, the operations associated with the CAU 309 muckpiles were most closely associated with the tests conducted at Tunnels 15a and e and at Tunnel 16a. However, all operations conducted at the sites generating the muckpiles supported the same nuclear testing program and used similar procedures and materials. Early testing activities (pre-1969) may have had less stringent control of hazardous and radioactive wastes. However, a larger number of tests (and by extension, more waste contaminants) were conducted in the later period (e.g., 21 tests conducted in N-Tunnel).

All of the muckpiles in consideration are located in the same general area and, with slight variations, are subject to the same general arid environment. The muckpiles were all created from pulverized rock material and have particle size distributions ranging from boulder to clay sizes. The lessor potential for translocation of the CAU 309 muckpile contaminants by erosion is the most significant consideration of the physical setting.

Since the highest concentrations of contaminants that occurred above current PALs in historical NTS muckpile investigations are being used, sufficient operational similarities and environmental factors exist to warrant the use of previous investigative results in identifying COCs for the CAU 309 investigation. Additionally, the slight differences in operational histories and physical settings have been taken into account in the design of the sampling plan for the CAU 309 muckpiles. 


\section{B.2.0 References}

DOE, see U.S. Department of Energy.

DOE/NV, see U.S. Department of Energy, Nevada Operations Office.

DTRA, see Defense Threat Reduction Agency.

Defense Threat Reduction Agency. 2001. Corrective Action Investigation Plan for Corrective Action Unit 504: 16a-Tunnel Muckpile, Nevada Test Site, Rev. 0. Prepared by IT Corporation. Las Vegas, NV.

Defense Threat Reduction Agency. 2002. Corrective Action Investigation Plan for Corrective Action Unit 482: Area 15 U15a/e Muckpiles and Ponds, Nevada Test Site, Rev. 0. Prepared by IT Corporation. Las Vegas, NV.

Deshler, R., Shaw Environmental, Inc. 2003. Record of meeting with T. Enyeart (SAIC) regarding CAUs 551 and 552, 11 August. Las Vegas, NV.

Fiore, J., U.S. Department of Energy, Nevada Operations Office. 1991. Letter to D. Bedsun (DNA) entitled, "Tunnel Operations Report to State of Nevada," May. Las Vegas, NV.

Griffin, W., Bechtel Nevada. 2004. Record of meeting with T. Murarik (SNJV) regarding U12, U15, and U16 Tunnel Sites, 4 March. Las Vegas, NV.

Holmes \& Narver, Inc. 1959. Completion Report, Operation Hardtack, Phase II. Prepared for the U.S. Atomic Energy Commission. Las Vegas, NV.

Metcalf, J., Sandia National Laboratories. 2004. Record of meeting with T. Murarik (SNJV) regarding U12, U15, and U16 Tunnel Sites, 4 March. Las Vegas, NV.

Rowsell, D., Fluid Tech, Inc. 2004. Record of meeting with T. Murarik (SNJV) regarding U12, U15, and U16 Tunnel Sites, 5 March. Las Vegas, NV.

Russell, C. 1987. Hydrologeologic Investigations of Flow in Fractured Tuffs, Rainier Mesa, Nevada Test Site. Thesis submitted to the University of Nevada through the Desert Research Institute, Water Resources Center. Las Vegas, NV.

Seals, J., Fluid Tech, Inc. 2004. Record of meeting with T. Murarik (SNJV) regarding U12, U15, and U16 Tunnel Sites, 5 March. Las Vegas, NV.

Sparks, D. 1986. Soil Physical Chemistry. Boca Raton, FL: CRC Press, Inc. 
USGS, see U.S. Geological Survey.

U.S. Department of Energy. 1988. Environmental Survey Preliminary Report, Nevada Test Site, Mercury, Nevada, DOE/EH/OEV-15-p. Washington, DC: Environment, Safety and Health Office of Environmental Audit.

U.S. Department of Energy, Nevada Operations Office. 2000. United States Nuclear Tests, July 1945 through September 1992, DOE/NV--209-REV 15. Las Vegas, NV.

U.S. Geological Survey. 1965. Perched Ground Water in Zeolitized-Bedded Tuff, Rainier Mesa and Vicinity, Nevada Test Site, Nevada, USGS Report TEI-862. Prepared by W. Thordarson. Las Vegas, NV.

U.S. Geological Survey. 1999. "Digital Geologic Map of the Nevada Test Site and Vicinity, Nye, Lincoln, and Clark Counties, Nevada, and Inyo County, California." Washington, DC.

Winograd, I., and W. Thordarson. 1975. Hydrogeologic and Hydrochemical Framework, South-Central Great Basin, Nevada-California, with Special Reference to the Nevada Test Site, USGS Professional Paper 712-C. Washington, DC: U.S. Geological Survey. 
Appendix C

\section{Project Organization}




\section{C.1.0 Project Organization}

The NNSA/NSO Project Manager is Janet Appenzeller-Wing. Her telephone number is (702) 295-0461.

The identification of the project Health and Safety Officer and the Quality Assurance Officer can be found in the appropriate plan. However, personnel are subject to change, and it is suggested that the appropriate DOE Project Manager be contacted for further information. The Task Manager will be identified in the FFACO Monthly Activity Report prior to the start of activities. 


\section{Appendix D NDEP Responses}


NEVADA ENVIRONMENTAL RESTORATION PROJECT

DOCUMENT REVIEW SHEET

\begin{tabular}{|c|c|c|c|c|c|}
\hline \multicolumn{4}{|c|}{$\begin{array}{l}\text { 1. Document Title/Number: Draft Corrective Action Investigation Plan for Corrective Action Unit 309: I-, J-, and } \\
\text { K-Tunnel Muckpiles, Nevada Test Site, Nevada }\end{array}$} & \multicolumn{2}{|l|}{ 2. Document Date: November 2004} \\
\hline \multicolumn{4}{|c|}{ 3. Revision Number: 0} & \multicolumn{2}{|c|}{ 4. Originator/Organization: Stoller-Navarro } \\
\hline \multicolumn{4}{|c|}{ 5. Responsible DOE/NV ERP Subproject Mgr.: Janet Appenzeller-Wing } & \multicolumn{2}{|c|}{ 6. Date Comments Due: November 24, 2004} \\
\hline \multicolumn{6}{|c|}{ 7. Review Criteria: Full } \\
\hline \multicolumn{4}{|c|}{ 8. Reviewer/Organization/Phone No.: Don Elle, NDEP, 486-2874 } & \multicolumn{2}{|l|}{ 9. Reviewer's Signature: } \\
\hline $\begin{array}{l}\text { 10. Comment } \\
\text { Number/ } \\
\text { Location }\end{array}$ & 11. Type* & 12. Comment & \multicolumn{2}{|l|}{ 13. Comment Response } & 14. Accept \\
\hline $\begin{array}{l}\text { 1) Section } 4.1 \\
\text { Technical } \\
\text { Approach } \\
3^{\text {rd }} \text { Paragraph }\end{array}$ & & $\begin{array}{l}\text { Since this CAIP only addresses } \\
\text { contamination originating from CAU } \\
309 \text {, it may be necessary to distinguish } \\
\text { overlapping contamination originating } \\
\text { from other sources. This approach } \\
\text { does not make technical sense and } \\
\text { should be discussed in more detail if it } \\
\text { is to be seriously pursued. If the } \\
\text { NNSA/NSO is in the process of } \\
\text { cleaning up, then they should clean all } \\
\text { of the contaminants up, unless there is } \\
\text { an extenuating circumstance. If there is } \\
\text { an extenuating circumstance, this must } \\
\text { be clearly described and fully justified. }\end{array}$ & \multicolumn{2}{|c|}{$\begin{array}{l}\text { The purpose of the paragraph in question is to communicate that it is not the intent of NNSA/NSO } \\
\text { to investigate potential contamination during the CAU } 309 \text { corrective action investigation that did } \\
\text { not originate from one or more of the release mechanisms described in the CAU } 309 \text { conceptual } \\
\text { site model (CSM). Admittedly, the source of such contamination may be difficult to identify. This } \\
\text { process is also discussed in Section } 3.1 \text { (last paragraph on page 19) and Section A.3.2 (second } \\
\text { to last paragraph on page A-16). To clarify the intent, the paragraph in question has been } \\
\text { replaced with the following paragraph. } \\
\text { "The scope of CAU } 309 \text { is to determine the nature and extent of contamination associated with } \\
\text { the releases described in the CAU } 309 \text { CSM (i.e., release of contaminants to the environment by } \\
\text { placement on the muckpile, erosion of the muckpile, and/or the containment failure of J-and } \\
\text { K-Tunnels). Generally, contamination identified in the valley below the I-, J-, and K-Tunnel } \\
\text { portals is assumed to be from one of these sources except for contamination associated with the } \\
\text { T-Tunnel Muckpile and Ponds as described in the CADDs for CAU } 476 \text {, Area } 12 \text { T-Tunnel } \\
\text { Muckpile and CAU } 478 \text {, Area } 12 \text { T-Tunnel Ponds. However, if contamination can be identified as } \\
\text { coming from a source outside CAU } 309 \text {, such as fallout from atmospheric testing, the extent of } \\
\text { such contamination may not be investigated as part of CAU } 309 \text {. Such a determination may be } \\
\text { difficult to make; however, identification of contaminants in background locations and/or the } \\
\text { identification of increasing concentrations of contaminants with increasing distance from CAU } 309 \\
\text { may indicate contamination from a release outside the scope of CAU } 309 \text {. If contamination is } \\
\text { discovered that is outside the spatial boundaries of CAU } 309 \text { or is believed to be outside the } \\
\text { scope of the CAU } 309 \text { CSM, the situation will be reviewed and a recommendation will be made as } \\
\text { to how best to proceed (e.g., revise the CSM or create a new CAS). In such cases, NDEP and } \\
\text { NNSA/NSO will be notified and given the opportunity to comment on, or concur with, the } \\
\text { recommendation." }\end{array}$} & \\
\hline
\end{tabular}

a Comment Types: $M=$ Mandatory, $S=$ Suggested

Return Document Review Sheets to DOE/NV Environmental Restoration Division, Attn: QAC, M/S 505. 


\section{Library Distribution List}

$\underline{\text { Copies }}$

U.S. Department of Energy

National Nuclear Security Administration

Nevada Site Office

Technical Library

P.O. Box 98518, M/S 505

Las Vegas, NV 89193-8518

U.S. Department of Energy

Office of Scientific and Technical Information

P.O. Box 62

Oak Ridge, TN 37831-0062

Southern Nevada Public Reading Facility

c/o Nuclear Testing Archive

P.O. Box 98521, M/S 400

Las Vegas, NV 89193-8521

Manager, Northern Nevada FFACO

Public Reading Facility

c/o Nevada State Library \& Archives

100 N. Stewart Street

Carson City, NV 89701-4285
1 (Uncontrolled)

1 (Uncontrolled, electronic copy)

2 (Uncontrolled, electronic copy)

1 (Uncontrolled, electronic copy) 